\title{
From structural ceramics to 2D materials with multi-applications: A review on the development from MAX phases to MXenes
}

\author{
Aiguo ZHOU ${ }^{a, *}$, Yi LIU ${ }^{b, *}$, Shibo $\mathrm{LI}^{c, *}$, Xiaohui $\mathrm{WANG}^{d, *}$, \\ Guobing YING ${ }^{e, *}$, Qixun XIA ${ }^{a}$, Peigen ZHANG ${ }^{f *}$ \\ ${ }^{a}$ School of Materials Science and Engineering, Henan Polytechnic University, Jiaozuo 454003, China \\ ${ }^{b}$ School of Materials Science \& Engineering, Shaanxi University of Science \& Technology, Xi'an 710021, China \\ ${ }^{c}$ Center of Materials Science and Engineering, School of Mechanical and Electronic Control Engineering, \\ Beijing Jiaotong University, Beijing 100044, China \\ ${ }^{d}$ Shenyang National Laboratory for Materials Science, Institute of Metals Research, \\ Chinese Academy of Sciences, Shenyang 110016, China \\ ${ }^{e}$ College of Mechanics and Materials, Hohai University, Nanjing 211100, China \\ ${ }^{f}$ School of Materials Science and Engineering, Southeast University, Nanjing 211189, China
}

Received: July 5, 2021; Revised: September 6, 2021; Accepted: September 7, 2021

(c) The Author(s) 2021.

\begin{abstract}
MAX phases $\left(\mathrm{Ti}_{3} \mathrm{SiC}_{2}, \mathrm{Ti}_{3} \mathrm{AlC}_{2}, \mathrm{~V}_{2} \mathrm{AlC}, \mathrm{Ti}_{4} \mathrm{AlN}\right.$, etc.) are layered ternary carbides/nitrides, which are generally processed and researched as structure ceramics. Selectively removing A layer from MAX phases, MXenes $\left(\mathrm{Ti}_{3} \mathrm{C}_{2}, \mathrm{~V}_{2} \mathrm{C}, \mathrm{Mo}_{2} \mathrm{C}\right.$, etc.) with two-dimensional (2D) structure can be prepared. The MXenes are electrically conductive and hydrophilic, which are promising as functional materials in many areas. This article reviews the milestones and the latest progress in the research of MAX phases and MXenes, from the perspective of ceramic science. Especially, this article focuses on the conversion from MAX phases to MXenes. First, we summarize the microstructure, preparation, properties, and applications of MAX phases. Among the various properties, the crack healing properties of MAX phase are highlighted. Thereafter, the critical issues on MXene research, including the preparation process, microstructure, MXene composites, and application of MXenes, are reviewed. Among the various applications, this review focuses on two selected applications: energy storage and electromagnetic interference shielding. Moreover, new research directions and future trends on MAX phases and MXenes are also discussed.
\end{abstract}

Keywords: MAX phases; MXenes; $\mathrm{Ti}_{3} \mathrm{SiC}_{2} ; \mathrm{Ti}_{3} \mathrm{C}_{2} \mathrm{~T}_{x}$

\footnotetext{
* Corresponding authors.

E-mail: A. Zhou, zhouag@hpu.edu.cn;

Y.Liu, liuyi@sust.edu.cn;

S. Li, shbli1@bjtu.edu.cn;

X. Wang,wang@imr.ac.cn;

G. Ying, yinggb001@hhu.edu.cn;

P. Zhang, zhpeigen@seu.edu.cn
} 


\section{Introduction}

MAX phases are layered carbides and nitrides with the general formula of $\mathrm{M}_{n+1} \mathrm{AX}_{n}(n=1-4)$, where $\mathrm{M}$ is an early transition metal, $\mathrm{A}$ is a group A element, and $\mathrm{X}$ is either carbon and/or nitrogen. The typical MAX phases are $\mathrm{Ti}_{3} \mathrm{SiC}_{2}, \mathrm{Ti}_{3} \mathrm{AlC}_{2}, \mathrm{Ti}_{2} \mathrm{AlC}, \mathrm{V}_{2} \mathrm{AlC}, \mathrm{Ti}_{2} \mathrm{AlN}$, etc. Currently, there are over 90 MAX phases. The possible constitutive elements of MAX phases that have been experimentally synthesized are shown in Fig. 1. In Fig. 1, the pink elements can be $M$, the green elements can be $\mathrm{A}$, and the blue element can be X. Additionally, more constitutive elements of MAX phases are theoretically predicted and more MAX phases are being synthesized.

In the crystal structure of MAX phases, M atoms are near-closed packed with the $\mathrm{X}$ atoms filling the octahedral sites to form $\mathrm{M}_{n+1} \mathrm{X}_{n}$ layers with ceramic properties. The $\mathrm{M}_{n+1} \mathrm{X}_{n}$ layers are separated by A layers with metal properties. Thus, MAX phases combine the properties of ceramics and metals. Like metals, MAX phases are thermally and electrically conductive, easy to be machined with conventional tools, and resistant to thermal shock; like ceramics, they have high strength, excellent high temperature strength, and thermal stability.

As early as the 1960s, several MAX phase members, such as $\mathrm{Ti}_{3} \mathrm{SiC}_{2}, \mathrm{Ti}_{2} \mathrm{AlC}, \mathrm{Ti}_{2} \mathrm{AlN}$, were synthesized and researched [1-3]. However, most of the researches were ignored until 1996. In 1996, Barsoum and El-Raghy [4] at Drexel University made $\mathrm{Ti}_{3} \mathrm{SiC}_{2}$ samples from $\mathrm{TiH}_{2}, \mathrm{SiC}$, and graphite by reactive hot pressing (HPing) at $1600{ }^{\circ} \mathrm{C}$. The fully dense predominantly single-phase samples of $\mathrm{Ti}_{3} \mathrm{SiC}_{2}$ were characterized with remarkable properties. Thereafter, $\mathrm{Ti}_{3} \mathrm{SiC}_{2}$ and other MAX phases attracted the attention from academia and industry. The scientists around the world have extensively researched the microstructures, properties, and applications of these materials.

Although MAX phases combined the merits of metals and ceramics, they are generally considered as a family of structural ceramics with special properties and applications. Compared with typical structural ceramics, such as $\mathrm{SiC}, \mathrm{Si}_{3} \mathrm{~N}_{4}$, MAX phases are machinable and electrically conductive. Therefore, MAX phases can be applied as structural ceramics, requiring complex shape to replace typical structural ceramics. Additionally, MAX phases can be applied as heating elements, nuclear materials, pantograph slide plate for high-speed trains, etc.

The unique properties of MAX phases origin from the layered crystal structure, in which $\mathrm{M}_{n+1} \mathrm{X}_{n}$ layers are separated by $\mathrm{A}$ layers. The atoms in $\mathrm{M}_{n+1} \mathrm{X}_{n}$ layers are bonded by strong $\mathrm{M}-\mathrm{X}$ bonds, which are ionic and/or covalent bonds. The interlayer bonds between $\mathrm{M}_{n+1} \mathrm{X}_{n}$ layers and $\mathrm{A}$ layers are weak $\mathrm{M}-\mathrm{A}$ bonds, which are metallic bonds. Therefore, MAX phases are layer materials. Another well-known layered material is graphite. Thus, MAX phases have similar properties with graphite.

In 2004, graphite was mechanically exfoliated, resulting in a new two-dimensional (2D) material, graphene [5]. As a 2D material, graphene has different properties from its three-dimensional (3D) counterpart, graphite, and can be applied in many fields. Thereafter, graphene becomes a hot research area. Since then, many

\begin{tabular}{|c|c|c|c|c|c|c|c|c|c|c|c|c|c|c|c|c|c|}
\hline $\mathrm{H}$ & II A & & & M & & A & & $X$ & & $\mathrm{~T}$ & & III A & IVA & $\mathrm{VA}$ & VIA & VII A & $\mathrm{Hc}$ \\
\hline $\mathrm{Li}$ & $\mathrm{Be}$ & & & & & & & & & & & B & C & $\mathrm{N}$ & $\mathrm{O}$ & $\mathrm{F}$ & $\mathrm{Ne}$ \\
\hline $\mathrm{Na}$ & $\mathrm{Mg}$ & III B & IV B & VB & VIB & VII $B$ & & VIII & & IB & II $B$ & $\mathrm{Al}$ & $\mathrm{Si}$ & P & $S$ & $\mathrm{Cl}$ & $\mathrm{Ar}$ \\
\hline K & $\mathrm{Ca}$ & $\mathrm{Sc}$ & $\mathrm{Ti}$ & V & $\mathrm{Cr}$ & $\mathrm{Mn}$ & $\mathrm{Fe}$ & Co & $\mathrm{Ni}$ & $\mathrm{Cu}$ & $\mathrm{Zn}$ & $\mathrm{Ga}$ & $\mathrm{Ge}$ & As & $\mathrm{Se}$ & $\mathrm{Br}$ & $\mathrm{Kr}$ \\
\hline $\mathrm{Rb}$ & $\mathrm{Sr}$ & $Y$ & $\mathrm{Zr}$ & $\mathrm{Nb}$ & $M_{0}$ & $\mathrm{Tc}$ & $\mathrm{Ru}$ & $\mathrm{Rh}$ & $\mathrm{Pd}$ & $\mathrm{Ag}$ & $\mathrm{Cd}$ & In & $\mathrm{Sn}$ & $\mathrm{Sb}$ & $\mathrm{Tc}$ & I & $\mathrm{Xc}$ \\
\hline Cs & $\mathrm{Ba}$ & $\mathrm{Lu}$ & HI & $\mathrm{Ta}$ & W & $\operatorname{Re}$ & Os & Ir & $\mathrm{Pt}$ & $\mathrm{Au}$ & $\mathrm{Hg}$ & $\mathrm{Tl}$ & $\mathrm{Pb}$ & $\mathrm{Bi}$ & Po & At & $\mathrm{Rn}$ \\
\hline $\mathrm{Fr}$ & $\mathrm{Ra}$ & $\mathrm{Lr}$ & $\mathrm{Rf}$ & $\mathrm{Db}$ & $\mathrm{Sg}$ & $\mathrm{Bh}$ & $\mathrm{Hs}$ & Mt & Ds & $\mathrm{Rg}$ & $\mathrm{Cn}$ & $\mathrm{Nh}$ & $\mathrm{Fl}$ & $\mathrm{Mc}$ & Ly & Ts & $\mathrm{Og}$ \\
\hline
\end{tabular}

Fig. 1 Constitutive elements of MAX phases and MXenes in the periodic table. The pink, green, and blue colors indicate the M, $\mathrm{A}$, and X elements in synthesized MAX phases, respectively. The pink and green colors with shading background indicate the M and $\mathrm{X}$ elements in prepared MXenes, respectively. The purple color indicates the common functional termination of prepared MXenes. 
other 2D materials have been discovered, such as transition metal-dichalcogenides (TMDs, e.g., $\mathrm{MoS}_{2}$ ), hexagonal boron-nitride ( $\mathrm{h}-\mathrm{BN}$ ), and black phosphorous or phosphorene. Because MAX phases and graphite have similar structure and properties, some researchers of MAX phases tried to exfoliate MAX phases to obtain a new 2D material. However, the interlayer bonds are metallic bonds, which are weaker than the intralayer bonds of MAX phases, but stronger than the interlayer bonds of graphite, van der Waals bond. Therefore, MAX phases cannot be mechanically exfoliated. All the attempts to exfoliate MAX phases failed until $\mathrm{Ti}_{3} \mathrm{AlC}_{2}$, a typical MAX phase, was exfoliated by selectively etching off $\mathrm{Al}$ atoms in $\mathrm{HF}$ solution to form $2 \mathrm{D} \mathrm{Ti}_{3} \mathrm{C}_{2}$ in 2011 [6]. Then, the same group lead by Prof. Barsoum and Prof. Gogotsi at Drexel University exfoliated a series of Al-contained MAX phases to form many 2D materials [7-10]. The 2D materials are made by selectively removing A layers from MAX phases. The rest MX layers have graphene-like 2D structure and were named as MXenes. The surface of MXenes made in HF solutions was terminated with $\mathrm{F} / \mathrm{OH} / \mathrm{O}$ due to high surface energy. MXenes made by other methods can be terminated by more elements $(\mathrm{Cl}, \mathrm{S}, \mathrm{Br}$, etc.) $[11,12]$. Thus, the general formula of MXenes is $\mathrm{M}_{n+1} \mathrm{X}_{n} \mathrm{~T}_{z}$, where $\mathrm{T}$ is the termination of MXenes. The possible constitutive elements of MXenes are shown in Fig. 1. By now, only part of MAX phases can be exfoliated successfully to make MXenes. Thus, in Fig. 1, the pink elements in shading background can be the constitutive elements of MAX phases and MXenes, while the pink elements in solid background only can be the constitutive element of MAX phases. The blue elements $(\mathrm{C}$ and $\mathrm{N})$ can be $\mathrm{X}$ of both MAX phases and MXene. T can be $\mathrm{F}, \mathrm{Cl}, \mathrm{Br}, \mathrm{O}$ (including $\mathrm{OH}$ ), $\mathrm{S}, \mathrm{Se}$, and $\mathrm{Te}$.

As a novel family of 2D materials, MXenes have different property-combination from other 2D materials. Like graphene, MXenes have high electrical conductivity. However, unlike graphene, MXenes are hydrophilic. Thus, MXenes can be dispersed in water to form colloid solutions, which is the characteristic of clay. Therefore, MXenes can be thought as conductive clay. Since the discovery of MXenes, scientists around the world have been attracted to extensively research these novel 2D materials. Many applications of MXenes have been reported. MXenes can be applied as electrodes in metal-ion batteries and supercapacitors, catalysts, adsorbents for chemicals, electromagnetic shielding materials, sensors, etc.

This article reviews the milestones and the latest progress on the research of MAX phases and MXenes. Especially, different from other reviews on MAX phases or MXenes, this article focuses on the conversion from MAX phases to MXenes. Most authors of this article have the research experience on MAX phases before the discovery of MXenes. From the perspective of ceramic science, we tell the stories of MAX phases and MXenes.

\section{Structure and preparation of MAX phases}

\section{1 Discovery of MAX phases}

MAX phases were firstly discovered by Nowontny and his coworkers during the 1960s and in that time, they were named as $\mathrm{H}$-phases, including more than thirty 211 phases $\left(\mathrm{Ti}_{2} \mathrm{AlC}, \mathrm{Ti}_{2} \mathrm{AlN}, \mathrm{V}_{2} \mathrm{AlC}\right.$, etc.) and two 312 phases $\left(\mathrm{Ti}_{3} \mathrm{SiC}_{2}\right.$ and $\left.\mathrm{Ti}_{3} \mathrm{GeC}_{2}\right)$ [1-3]. In the 1980s, another important 312 phase, $\mathrm{Ti}_{3} \mathrm{AlC}_{2}$, was found by Schuster and Nowotny [13] (Schuster was Nowontny's student). However, these MAX phases have not attracted much attention in scientific community, due to their impure and unstable performance, until the middle of the 1990s. In 1996, fully dense predominantly single-phase samples of $\mathrm{Ti}_{3} \mathrm{SiC}_{2}$ were prepared by Barsoum's group and their mechanical and oxidation behaviors were firstly evaluated [4]. Later, several bulk MAX phases $\left(\mathrm{Ti}_{2} \mathrm{AlC}\right.$, $\mathrm{V}_{2} \mathrm{AlC}, \mathrm{Ti}_{2} \mathrm{SnC}, \mathrm{Nb}_{2} \mathrm{AlC}$, etc.) were successfully fabricated by the same group and it was found that they had similar properties with those of $\mathrm{Ti}_{3} \mathrm{SiC}_{2}$ [14]. Especially in 1999, Barsoum et al. [15] further discovered $\mathrm{Ti}_{4} \mathrm{AlN}_{3}$, which gave the first prototype of 413 phase and led to the birth of the formula $\mathrm{M}_{n+1} \mathrm{AX}_{n}$ or MAX for short.

Since then, numerous research groups focused on the synthesizing and characterizing more MAX phases. A large number of new MAX phases, including $\mathrm{Nb}_{4} \mathrm{AlC}_{3}$ [16], $\mathrm{Ta}_{6} \mathrm{AlC}_{5}$ [17], $\mathrm{Ti}_{3} \mathrm{IrC}_{2}$ [18], $\mathrm{Ti}_{2} \mathrm{ZnC}$ [19], and $\mathrm{V}_{2} \mathrm{SnC}$ [20], were successfully fabricated. Phase diagram was used as an indicator to estimate the thermodynamic stabilities of some novel MAX phases [21].

Besides these MAX phases with the formula of $\mathrm{M}_{n+1} \mathrm{AX}_{n}(\mathrm{X}$ is $\mathrm{C} / \mathrm{N})$, many ternary compounds with similar structures were fabricated. They are not MAX phases because (1) the ratio of $\mathrm{M}: \mathrm{X}$ is not $(n+1) / n$, (2) A is not 1 , or (3) $\mathrm{X}$ is $\mathrm{B}$ rather than $\mathrm{C} / \mathrm{N}$. However, they have MAX-phase-like structure and are researched as 
MAX phases. The typical MAX-phase-like compounds are $\mathrm{Ti}_{5} \mathrm{Si}_{2} \mathrm{C}_{3}$ [22], $\mathrm{Ti}_{7} \mathrm{Si}_{2} \mathrm{C}_{5}$ [23], $\mathrm{V}_{12} \mathrm{Al}_{3} \mathrm{C}_{8}$ [24], $\mathrm{Ti}_{3} \mathrm{Au}_{2} \mathrm{C}_{2}$ [18], $\mathrm{Mo}_{2} \mathrm{Ga}_{2} \mathrm{C}$ [25], $\mathrm{Ti}_{2} \mathrm{InB}_{2}$ [26], and $\mathrm{Cr}_{4} \mathrm{AlB}_{4}$ [27]. For the compounds that $\mathrm{X}$ is $\mathrm{B}$ element instead of $\mathrm{C} / \mathrm{N}$ (such as $\mathrm{Ti}_{2} \mathrm{InB}_{2}$ and $\mathrm{Cr}_{4} \mathrm{AlB}_{4}$ ), a new term, MAB phase, was created to name the compounds.

Additionally, the investigation on the MAX phase solid solutions achieved some exciting results. For instance, in 2014, Liu et al. [28] reported the successful synthesis of $\left(\mathrm{Cr}_{2 / 3} \mathrm{Ti}_{1 / 3}\right)_{3} \mathrm{AlC}_{2}$, which is an out-of-plane ordered, quaternary MAX phase, abbreviated as o-MAX. In 2017, Tao et al. [29] fabricated $\left(\mathrm{Mo}_{2 / 3} \mathrm{Sc}_{1 / 3}\right)_{2} \mathrm{AlC}$ phase, which showed an in-plane ordered structure and was labeled as i-MAX. In 2020, Li et al. [30] prepared a serials of $\mathrm{V}_{2}(\mathrm{Sn}, \mathrm{A}) \mathrm{C}(\mathrm{A}=\mathrm{Fe}, \mathrm{Co}, \mathrm{Ni}, \mathrm{Mn})$ solid solutions and $\mathrm{V}_{2}\left(\mathrm{Mn}_{x} \mathrm{Fe}_{y} \mathrm{Co}_{z} \mathrm{Ni}_{n} \mathrm{Sn}_{1-x-y-z-n}\right) \mathrm{C}$ highentropy MAX phase. Based on these pioneering works, six o-MAX phases and more than thirty i-MAX phases have been discovered in past five years, which greatly enrich the MAX phase family [31,32].

\section{2 Crystal structures of MAX phases and MAX-phase-like compounds}

All ternary MAX phases with the formula $\mathrm{M}_{n+1} \mathrm{AX}_{n}$ have the same space group $\left(P 6_{3} / m m c\right)$ [31]. As shown in Figs. 2(a)-2(d), the 211, 312, 413, and 514 MAX phases crystallize in a hexagonal structure and their unit cells consist of edge-sharing $\mathrm{M}_{6} \mathrm{X}$ octahedra interleaved with layers of A elements. Meanwhile, the MX layers are twinned with each other, where A layer acts as mirror plane and thus, giving a rise to "zig-zag" structures along $c$-axis. The difference between these phases lies in the number of $\mathrm{M}$ layers separating the $\mathrm{A}$

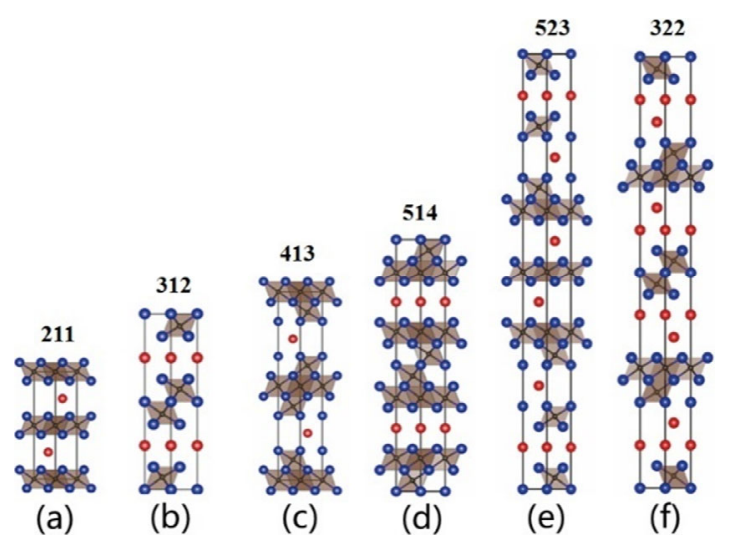

Fig. 2 Illustration of the unit cell projected long (110). Blue, red, and black balls denote the $\mathrm{M}, \mathrm{A}$, and $\mathrm{X}$ atoms, respectively. Reproduced with permission from Ref. [33], (C) Elsevier 2020. layers. Specifically, it is two in the 211 phases, three in the 312 phases, four in the 413 phases, and five in the 514 phases.

There are some compounds that deviate from the formula $\mathrm{M}_{n+1} \mathrm{AX}_{n}$, which can be labeled as $\mathrm{M}_{n+2} \mathrm{~A}_{2} \mathrm{X}_{n}$. Taking $\mathrm{Ti}_{5} \mathrm{Al}_{2} \mathrm{C}_{3}$ for example, its structure can be described as a combination of half unit cell of $\mathrm{Ti}_{2} \mathrm{AlC}$ and half unit cell of $\mathrm{Ti}_{3} \mathrm{AlC}_{2}$ phase (Fig. 2(e)). In the same way, $\mathrm{Ti}_{7} \mathrm{Si}_{2} \mathrm{C}_{5}$ phase can be composed of two half unit cells of $\mathrm{Ti}_{3} \mathrm{SiC}_{2}$ and $\mathrm{Ti}_{4} \mathrm{SiC}_{3}$ phases, with alternating three and four Ti-C layers between the Si layers.

In addition, some other MAX-phase-like compounds, such as $\mathrm{Mo}_{2} \mathrm{Ga}_{2} \mathrm{C}$ [25], $\mathrm{Ti}_{3} \mathrm{Au}_{2} \mathrm{C}_{2}$ [18], $\mathrm{Nb}_{12} \mathrm{Al}_{3} \mathrm{C}_{8}$ [34], $\mathrm{V}_{12} \mathrm{Al}_{3} \mathrm{C}_{8}$ [24], and $\mathrm{Ti}_{2} \mathrm{InB}_{2}$ [26], are not fulfilled with the formula $\mathrm{M}_{n+1} \mathrm{AX}_{n}$ nor $\mathrm{M}_{n+2} \mathrm{~A}_{2} \mathrm{X}_{n}$. For $\mathrm{Mo}_{2} \mathrm{Ga}_{2} \mathrm{C}$, $\mathrm{Mo}_{6} \mathrm{C}$ octahedral layers are interleaved with two $\mathrm{Ga}$ layers and twinned according to the virtual middle plane between the two Ga layers. The structures of $\mathrm{Ti}_{2} \mathrm{Au}_{2} \mathrm{C}$ and $\mathrm{Ti}_{3} \mathrm{Au}_{2} \mathrm{C}_{2}$ are similar with $\mathrm{Mo}_{2} \mathrm{Ga}_{2} \mathrm{C}$, but their twin orientation is dislocated. For $\mathrm{Nb}_{12} \mathrm{Al}_{3} \mathrm{C}_{8}$ and $\mathrm{V}_{12} \mathrm{Al}_{3} \mathrm{C}_{8}$, they are essentially carbon-vacancy-ordered 413 phases and belong to $P 6_{3} / \mathrm{mcm}$ space group. $\mathrm{Ti}_{2} \mathrm{InB}_{2}$ is MAB phase with $\mathrm{X}$ is boron rather than carbon/ nitrogen [26]. The space group of $\mathrm{Ti}_{2} \mathrm{InB}_{2}$ is $P \overline{6} \mathrm{~m} 2$, which is in fact a hexagonal subgroup of $P 6_{3} / m m c$.

If element replacement occurs in the $\mathrm{M}, \mathrm{A}$, or $\mathrm{X}$ site of ternary MAX phases, quaternary MAX phases can be obtained and most of them are disordered solid solutions, which show the similar crystal structure with ternary MAX phases $\left(P 6_{3} / m m c\right)$. It is noteworthy that there exist two kinds of ordered quaternary MAX solid solutions: out-of-plane ordered MAX phases (o-MAX) and in-plane ordered MAX phases (i-MAX). Specifically, o-MAX phases have a general formula of $\left(\mathrm{M}^{\prime}, \mathrm{M}^{\prime \prime}\right)_{n+1} \mathrm{AlC}_{n}$, where $\mathrm{M}^{\prime}$ and $\mathrm{M}^{\prime \prime}$ denote early transition metals and $n$ is either 2 or 3 . For 312 o-MAX phases (Fig. 3(a)), the outer $\mathrm{M}^{\prime}$ atoms occupy two $4 \mathrm{f}$ Wyckoff sites and the inner $\mathrm{M}^{\prime \prime}$ atoms occupy one $2 \mathrm{a}$ Wyckoff site. For $\mathrm{P6}_{3} / \mathrm{mmc}$ group, $2 \mathrm{a}$ Wyckoff sites are the sites of $(0,0$, $0)$ and $(0,0,1 / 2) ; 4 \mathrm{f}$ Wyckoff sites are the sites of $(1 / 3$, $2 / 3, z),(2 / 3,1 / 3, z+1 / 2),(2 / 3,1 / 3,-z),(1 / 3,2 / 3$, $-z+1 / 2$ ). Differently, for 413 o-MAX phases (Fig. 3(b)), the outer $\mathrm{M}^{\prime}$ and the inner $\mathrm{M}^{\prime \prime}$ atoms occupy two $4 \mathrm{e}$ and two $4 \mathrm{f}$ Wyckoff sites, respectively. 4e Wyckoff sites are the sites of $(0,0, z),(0,0, z+1 / 2),(0,0,-z),(0$, $0,-z+1 / 2)$. It should be noted that some of the $M^{\prime}$ and M" atoms exchange their positions, thus resulting in an imperfect ordered structure. For instance, in $\left(\mathrm{Mo}_{0.5} \mathrm{Ti}_{0.5}\right)_{4} \mathrm{AlC}_{3}$ lattice, the outer $\mathrm{M}^{\prime}$ layers were 
(a)

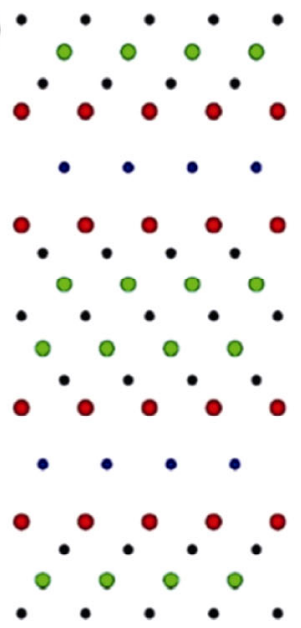

- -Transition metal ( $\left.\mathrm{M}^{\prime}\right)$ (b)

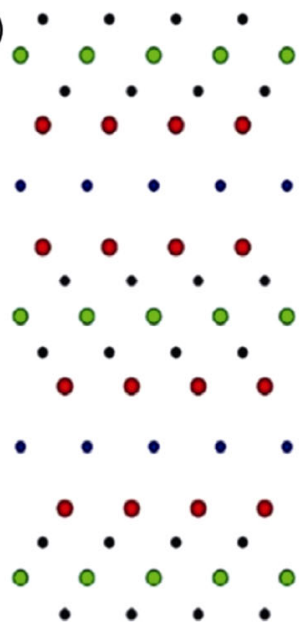

(c)

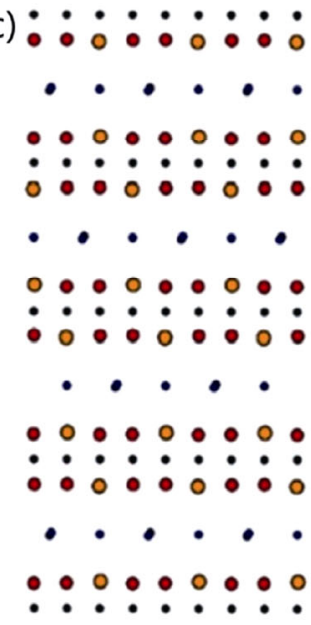

(d)

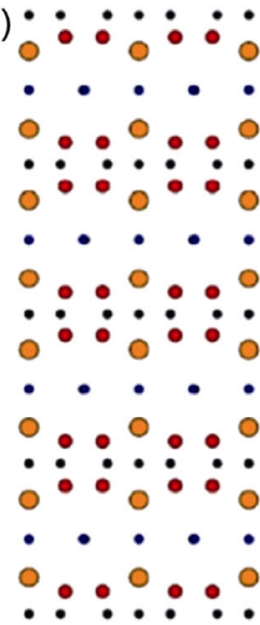

o o-Transition metal (M")

- - Carbon

Fig. 3 Schematics of various ordered MAX phases. (a) 413 o-MAX, (b) 312 o-MAX, (c) C2/c space group i-MAX, and (d) Cmcm space group i-MAX. Reproduced with permission from Ref. [31], (C) Elsevier Inc. 2019.

composed of $77 \%$ Mo and $23 \% \mathrm{Ti}$, whereas the inner M" layers were $86 \%$ Mo and $14 \%$ Ti. To date, although theoretical calculations predict the existence of many o-MAX, only six such phases have been successfully synthesized in the laboratory. Obviously, the crystal structure of these o-MAX phases is hexagonal $\left(\mathrm{Pb}_{3} / \mathrm{mmc}\right)$, which is the same as that of ternary MAX phases.

i-MAX phases are another kind of ordered quaternary MAX solid solutions and their chemical formula can be described as $\left(\mathrm{M}_{2 / 3}^{\prime}, \mathrm{M}_{1 / 3}^{\prime \prime}\right)_{2} \mathrm{AlC}$, where the $\mathrm{M}^{\prime}: \mathrm{M}^{\prime \prime}$ ratio is always 2 . These phases are no longer hexagonal with symmetry of $P 6_{3} / m m c$. Instead, they crystalize in the $\mathrm{C} 2 / \mathrm{c}$ monoclinic or the $\mathrm{Cmcm}$ or thorhombic structure (Figs. 3(c) and 3(d)). In $C 2 / c$ monoclinic i-MAX phases, such as $\left(\mathrm{Mo}_{2 / 3} \mathrm{Sc}_{1 / 3}\right)_{2} \mathrm{AlC}$, Mo atoms are arranged in a hexagonal arrangement and $\mathrm{Sc}$ atoms positioned at the centers of hexagons. Both $\mathrm{Mn}$ and Sc atoms occupy the 8f Wyckoff site, while the $\mathrm{Al}$ atoms partially occupy the $4 \mathrm{e}$ and $8 \mathrm{f}$ sites and the $\mathrm{C}$ atoms partially occupy the $4 \mathrm{~d}$ and $8 \mathrm{f}$ sites. For $C 2 / c$ group, $4 \mathrm{e}$ Wyckoff sites are the sites of $(0,0,0),(1 / 2,1 / 2,0),(0, y, 1 / 4)$, and $(0,-y, 3 / 4)$; $8 \mathrm{f}$ sites are the sites of $(0,0,0),(1 / 2,1 / 2,0),(x, y, z)$, $(-x, y,-z+1 / 2),(-x,-y,-z)$, and $(x,-y, z+1 / 2)$. In $C m c m$ or thorhombic o-MAX phases, taking $\left(\mathrm{Cr}_{2 / 3} \mathrm{Y}_{1 / 3}\right)_{2} \mathrm{AlC}$ for example, the $\mathrm{Cr}$ atoms occupy the $16 \mathrm{~h}$ sites and the $\mathrm{Y}$ atoms occupy the $8 \mathrm{f}$ sites, whereas $\mathrm{Al}$ atoms occupy the $8 \mathrm{~g}$ and $4 \mathrm{c}$ sites, and $\mathrm{C}$ atoms occupy the $4 \mathrm{~b}$ and $8 \mathrm{e}$ Wyckoff sites. For $\mathrm{Cmcm}$ group, $4 \mathrm{~b}$ sites are the sites of $(0,0,0),(1 / 2,1 / 2,0),(0,1 / 2,0),(0,1 / 2,1 / 2) ; 4 \mathrm{c}$ sites are the sites of $(0,0,0),(1 / 2,1 / 2,0),(0, y, 1 / 4),(0,-y$, $3 / 4)$; $8 \mathrm{e}$ sites are the sites of $(0,0,0),(1 / 2,1 / 2,0),(x, 0$, $0),(-x, 0,1 / 2),(-x, 0,0),(x, 0,1 / 2) ; 8 \mathrm{f}$ sites are the sites of $(0,0,0),(1 / 2,1 / 2,0),(0, y, z),(0,-y, z+1 / 2),(0, y$, $-z+1 / 2),(0,-y,-z) ; 8 \mathrm{~g}$ sites are the sites of $(0,0,0)$, $(1 / 2,1 / 2,0),(x, y, 1 / 4),(-x,-y, 3 / 4),(-x, y, 1 / 4),(x,-y$, $3 / 4) ; 16 \mathrm{~h}$ sites are the sites of $(0,0,0),(1 / 2,1 / 2,0),(x$, $y, z),(-x,-y, z+1 / 2),(-x, y,-z+1 / 2),(x,-y,-z),(-x,-y$, $-z),(x, y,-z+1 / 2),(x,-y, z+1 / 2),(-x, y, z)$. A summary on crystal structures of typical MAX phases and MAX-phase-like compounds discovered up to date is given in Table 1.

\section{3 Preparation of MAX phases}

\subsubsection{Preparation of MAX phase bulks}

The synthesis of MAX phase bulks or MAX composite bulks should be conducted at high temperatures under vacuum or inert atmosphere. It is involved complicated reactions of related elements and compounds and usually results in unwanted secondary phases. Hence, preparing MAX phase bulks with high-purity attracts worldwide attention over last two decades, and several methods, such as hot isostatic pressing (HIP) [4,14,38], HPing $[16,17,28,39]$, pressureless sintering (PLS) $[26,29,40,41]$, self-propagation high-temperature synthesis (SHS) [42-44], spark plasma sintering (SPS) [45-48], and microwave sintering (MWS) [49,50], have been extensively investigated. Although most MAX phase bulks can be prepared by HIP and HP, only small samples with simple shape can be obtained. Meanwhile, the high temperature and long holding time also result in low efficiency and high cost. Compared with HP and 
Table 1 Crystal structures of some typical MAX phases and MAX-phase-like compounds [28,30,35-37]

\begin{tabular}{|c|c|c|c|}
\hline \multicolumn{2}{|c|}{ Compound type } & Chemical formula & Space group \\
\hline \multirow{3}{*}{ Ternary MAX phases } & \multirow{3}{*}{$\mathrm{M}_{n+1} \mathrm{AX}_{n}$} & $\mathrm{Ti}_{2} \mathrm{AlC}, \mathrm{V}_{2} \mathrm{AlC}, \mathrm{Cr}_{2} \mathrm{AlC}, \mathrm{Nb}_{2} \mathrm{AlC}$ & \multirow{3}{*}{$\mathrm{Pb}_{3} / m m c$} \\
\hline & & $\mathrm{Ti}_{3} \mathrm{SiC}_{2}, \mathrm{Ti}_{3} \mathrm{AlC}_{2}, \mathrm{Ti}_{3} \mathrm{GeC}_{2}, \mathrm{Ti}_{3} \mathrm{SnC}_{2}, \mathrm{Hf}_{3} \mathrm{SnC}_{2}$ & \\
\hline & & $\mathrm{V}_{4} \mathrm{AlC}_{3}, \mathrm{Ti}_{4} \mathrm{SiC}_{3}, \mathrm{Ta}_{4} \mathrm{AlC}_{3}, \mathrm{Ti}_{4} \mathrm{GeC}_{3}$ & \\
\hline \multirow{6}{*}{$\begin{array}{l}\text { MAX-phase-like } \\
\text { compound }\end{array}$} & \multirow{3}{*}{$\mathrm{M}_{n+2} \mathrm{~A}_{2} \mathrm{X}_{n}$} & $\mathrm{Ti}_{5} \mathrm{Si}_{2} \mathrm{C}_{3}, \mathrm{Ti}_{5} \mathrm{Ge}_{2} \mathrm{C}_{3}, \mathrm{Ti}_{5} \mathrm{Al}_{2} \mathrm{C}_{3}$ & \multirow{3}{*}{$\mathrm{Pb}_{3} / m m c$} \\
\hline & & $\mathrm{Ti}_{7} \mathrm{Si}_{2} \mathrm{C}_{5}, \mathrm{Ti}_{7} \mathrm{Ge}_{2} \mathrm{C}_{5}$ & \\
\hline & & $\mathrm{Nb}_{3} \mathrm{As}_{2} \mathrm{C}, \mathrm{V}_{3} \mathrm{As}_{2} \mathrm{C}, \mathrm{Nb}_{3} \mathrm{P}_{2} \mathrm{C}, \mathrm{Ta}_{3} \mathrm{P}_{2} \mathrm{C}$ & \\
\hline & \multirow{3}{*}{$\begin{array}{l}\mathrm{M}_{m} \mathrm{~A}_{n} \mathrm{X}_{p} \\
m \neq n+p\end{array}$} & $\mathrm{Ti}_{2} \mathrm{InB}_{2}$ & $P \overline{6} m 2$ \\
\hline & & $\mathrm{Ti}_{2} \mathrm{Au}_{2} \mathrm{C}, \mathrm{Ti}_{3} \mathrm{Au}_{2} \mathrm{C}_{2}$ & $P \overline{3} m 1$ \\
\hline & & $\mathrm{Mo}_{2} \mathrm{Ga}_{2} \mathrm{C}, \mathrm{V}_{12} \mathrm{Al}_{3} \mathrm{C}_{8}, \mathrm{Nb}_{12} \mathrm{Al}_{3} \mathrm{C}_{8}$ & $\mathrm{P}_{3} / \mathrm{mcm}$ \\
\hline \multirow{6}{*}{$\begin{array}{l}\text { Quaternary } \\
\text { MAX phases }\end{array}$} & \multirow{3}{*}{ Disordered MAX phases } & $\left(\mathrm{V}_{1-x} \mathrm{Ti}_{x}\right)_{2} \mathrm{AlC},\left(\mathrm{Zr}_{1-x} \mathrm{Ti}_{x}\right)_{2} \mathrm{AlC}$ & \multirow{3}{*}{$P 6_{3} / m m c$} \\
\hline & & $\mathrm{Zr}_{2}\left(\mathrm{Al}_{1-x} \mathrm{Sn}_{x}\right) \mathrm{C}, \mathrm{Cr}_{2}\left(\mathrm{Al}_{x} \mathrm{Ge}_{1-x}\right) \mathrm{C}, \mathrm{Ti}_{3} \mathrm{Si}_{x} \mathrm{Ge}_{1-x} \mathrm{C}_{2}$ & \\
\hline & & $\mathrm{Ti}_{2} \mathrm{Al}\left(\mathrm{C}_{x}, \mathrm{~N}_{1-x}\right)_{y}, \mathrm{Ti}_{3} \mathrm{Al}\left(\mathrm{C}_{0.5} \mathrm{~N}_{0.5}\right)_{2}$ & \\
\hline & \multirow{2}{*}{ i-MAX phases $\left(\mathrm{M}^{\prime}, \mathrm{M}^{\prime \prime}\right)_{n+1} \mathrm{AC}_{n}$} & $\left(\mathrm{Mo}_{2 / 3} \mathrm{Sc}_{1 / 3}\right)_{2} \mathrm{AlC},\left(\mathrm{V}_{2 / 3} \mathrm{Zr}_{1 / 3}\right)_{2} \mathrm{AlC},\left(\mathrm{Mo}_{2 / 3} \mathrm{Y}_{1 / 3}\right)_{2} \mathrm{AlC}$ & $C 2 / c$ \\
\hline & & $\left(\mathrm{Cr}_{2 / 3} \mathrm{Y}_{1 / 3}\right)_{2} \mathrm{AlC},\left(\mathrm{Mo}_{2 / 3} \mathrm{Y}_{1 / 3}\right)_{2} \mathrm{GaC},\left(\mathrm{Mo}_{2 / 3} \mathrm{Sc}_{1 / 3}\right)_{2} \mathrm{GaC}$ & $\mathrm{Cmcm}$ \\
\hline & o-MAX phases $\left(\mathrm{M}_{2 / 3}^{\prime}, \mathrm{M}_{1 / 3}^{\prime \prime}\right)_{2} \mathrm{AC}$ & $\begin{aligned} &\left(\mathrm{Cr}_{2 / 3} \mathrm{Ti}_{1 / 3}\right)_{3} \mathrm{AlC}_{2},\left(\mathrm{Mo}_{2} \mathrm{Sc}\right) \mathrm{AlC}_{2},\left(\mathrm{Mo}_{2} \mathrm{Ti}\right) \mathrm{AlC}_{2},\left(\mathrm{Cr}_{2 / 3} \mathrm{~V}_{1 / 3}\right)_{3} \mathrm{AlC}_{2} \\
&\left(\mathrm{Cr}_{2} \mathrm{~V}_{2}\right) \mathrm{AlC}_{3}\left(\mathrm{Mo}_{2} \mathrm{Ti}_{2}\right) \mathrm{AlC}_{3}\end{aligned}$ & $P 6_{3} / m m c$ \\
\hline \multirow{2}{*}{\multicolumn{2}{|c|}{ High-entropy MAX phases }} & $\mathrm{V}_{2} \mathrm{AC}(\mathrm{A}=\mathrm{Sn}, \mathrm{Fe}, \mathrm{Co}, \mathrm{Ni}, \mathrm{Mn})$ & \multirow{2}{*}{$P 6_{3} / m m c$} \\
\hline & & $\mathrm{M}_{2} \mathrm{AlC}(\mathrm{M}=\mathrm{Ti}, \mathrm{Zr}, \mathrm{Hf}, \mathrm{Nb}, \mathrm{Ta})$ & \\
\hline
\end{tabular}

HIP, SPS possesses rapid heating and cooling rates, relative low synthesis temperature, and short holding time (several minutes). SHS is another rapid synthesis method by which the reactions can be accomplished in several or dozens of seconds. The samples made by SHS are generally porous. To make dense bulk samples, a pseudo-hot isostatic pressing (PHIP) process was combined with the SHS process. The SHS-PHIP method was used to make dense $\mathrm{Ti}_{2} \mathrm{AlC}[51,52]$ and $\mathrm{Ti}_{3} \mathrm{SiC}_{2}$ [53] with high performance. However, both SPS and SHS are not suitable for complex shape or batch preparation. From this point of view, PLS is much more economical and scalable but usually needs high temperature, and the obtained MAX phase bulks show low density and purity. Moreover, MWS can be recognized as special PLS method with rapid heating rate. As mentioned above, each preparation method for MAX phase bulks has advantages and disadvantages. The strategy should be adopted depends on the specific applications and actual conditions. The key point of preparation for MAX phase bulks should be focused on composition and proportion of raw materials as well as processing parameters.

\subsubsection{Preparation of MAX phase films and coatings}

Physical vapor deposition (PVD) and chemical vapor deposition (CVD) are usually adopted to prepare MAX phase films or coatings. The PVD for MAX phase synthesis is far from thermodynamic equilibrium and thus can reduce the temperature substantially. Sputtering technique is the primary PVD method that generally performs at $800-1000{ }^{\circ} \mathrm{C}$. Palmquist et al. [54] first demonstrated the feasibility of $\mathrm{Ti}_{3} \mathrm{SiC}_{2}$ film using sputtering technique from elemental sources and $\mathrm{Ti}_{3} \mathrm{SiC}_{2}$ target. Reactive sputtering is suitable for the preparation of MAX phase nitrides. Joelsson et al. [55] synthesized $\mathrm{Ti}_{2} \mathrm{AlN}$ using reactive sputtering in an $\mathrm{Ar} / \mathrm{N}_{2}$ mixture from a 2Ti:Al target. To further decrease deposition temperature, Rosén et al. [56] investigated $\mathrm{Ti}_{2} \mathrm{AlC}$ synthesis using a pulsed cathodic-arc setup from elemental $\mathrm{Ti}, \mathrm{Al}$, and $\mathrm{C}$ cathodes at a substrate which allowed a deposition temperature of $900{ }^{\circ} \mathrm{C}$. Furthermore, pulsed laser deposition (PLD) was developed and the first attempt on $\mathrm{Ti}_{3} \mathrm{SiC}_{2}$ synthesis was conducted by Phani et al. [57], who deposited Ti-Si-C films over the temperature range of $25-600{ }^{\circ} \mathrm{C}$. Differently, the synthesis of MAX phases through CVD technique is relatively few although the first research paper was published in 1972. Of these limited works, CVD was conducted focusing on the preparation of $\mathrm{Ti}_{3} \mathrm{SiC}_{2}$ film and high temperatures $\left(1000-1300{ }^{\circ} \mathrm{C}\right)$ were required $[58,59]$. Compared with CVD, PVD can not only reduce the synthesis temperature, but also help to find new MAX phases, especially low-temperature metastable 
phases. Meanwhile, the compositions and defects can be easily regulated by PVD and therefore, beneficial to the fundamental research on MAX phases. A detailed and systematic introduction on MAX phase films processing via PVD and CVD can be seen in Ref. [60].

\subsubsection{Preparation of MAX phase powders}

The production of MAX phase powders provides precursors not only for MAX phase bulks but also for MXenes. Molten salt assisted synthesis is a kind of liquid phase synthesis, in which molten inorganic salt is employed as the reaction medium and MAX phase powders can be easily obtained by this method. For instance, Xiao et al. [61] synthesized $\mathrm{Cr}_{2} \mathrm{AlC}$ using $\mathrm{Cr}$, $\mathrm{Al}$, and $\mathrm{C}$ as starting materials and $\mathrm{KCl}$ as molten salt. After holding for $60 \mathrm{~min}$ at $1250{ }^{\circ} \mathrm{C}$ under argon atmosphere, high purity $\mathrm{Cr}_{2} \mathrm{AlC}$ powders were obtained. Wang et al. [62] prepared $\mathrm{V}_{2} \mathrm{AlC}$ using $\mathrm{V}, \mathrm{Al}$, and $\mathrm{C}$ as elemental powders and $\mathrm{NaCl}$ as molten salt. They found that the formation of $\mathrm{V}_{2} \mathrm{AlC}$ starts at $1050{ }^{\circ} \mathrm{C}$, which is far less than that of the conventional solid phase synthesis. Liu et al. [63] synthesized homogenous $\mathrm{Ti}_{3} \mathrm{AlC}_{2}$ powders with particle size of $\sim 100 \mathrm{~nm}$ using $3 \mathrm{Ti} / \mathrm{Al} / 2 \mathrm{C}$ as starting elemental powders in $\mathrm{NaCl}-\mathrm{KCl}$ molten salt at $900{ }^{\circ} \mathrm{C}$ for $10 \mathrm{~h}$. Recently, Dash et al. [64] reported a modified method which named as molten salt shielded synthesis/sintering $\left(\mathrm{MS}^{3}\right)$. They use $\mathrm{KBr}$ to achieve gas-tight encapsulation around a specimen before placing it in a $\mathrm{KBr}$ salt bed for further heating. By this method, the synthesis can be conducted in air and several highly pure MAX phases, such as $\mathrm{Ti}_{3} \mathrm{SiC}_{2}$, $\mathrm{Ti}_{3} \mathrm{AlC}_{2}, \mathrm{Ti}_{2} \mathrm{AlN}, \mathrm{Ti}_{2} \mathrm{AlC}$, and $\mathrm{Cr}_{2} \mathrm{AlC}$, have been successfully prepared at relative low temperatures. In addition to the ternary MAX phases as mentioned above, $\mathrm{V}_{2}\left(\mathrm{~A}_{x} \mathrm{Sn}_{1-x}\right) \mathrm{C}(\mathrm{A}=\mathrm{Fe}, \mathrm{Co}, \mathrm{Ni}, \mathrm{Mn})$ solid solutions were synthesized by Huang's group using V, Sn, Fe, $\mathrm{Co}, \mathrm{Ni}, \mathrm{Mn}$, and $\mathrm{C}$ as starting materials and $\mathrm{NaCl} / \mathrm{KCl}$ as molten salt [30]. This work indicates that molten salt assisted synthesis can offer a simple method not only for the preparation of ternary MAX phases but also for MAX phase solid solutions.

The advantages of molten salt assisted synthesis lie in its low synthesis temperature and small grain size in obtained products. For some strongly bonded MAX phases, small particle size is favorable for subsequent selective etching. Therefore, from the perspective of preparing MXenes, molten salt assisted synthesis provides a good low-cost method to prepare the MAX phase precursors. Although some MAX phases have been synthesized by this method up to now, more MAX phases need to be synthesized. The future work should focus on the optimization of molten salt system and processing parameters to control the composition and morphology of obtained MAX phases.

\section{4 Summary on the structure and preparation of MAX phases}

In summary, we only emphasized here on the lattice structure of MAX phases and overlooked the microstructure which is actually related to the preparation methods. Although over 155 MAX phases have been discovered until now, most of them have the same space group $\left(\mathrm{Pb}_{3} / \mathrm{mmc}\right)$. It is worth noting that i-MAX phases exhibit different lattice structures, which gives us inspiration to explore new MAX phases by the formation of solid solutions. However, the synthesis of high purity MAX phase solid solutions such as i-MAX, o-MAX, and high-entropy MAX, remains challenging. Furthermore, considering the preparation of MXenes, MAX phase solid solutions on M-site or X-site should be paid more attention and much effort should be done in the future.

\section{Crack healing properties and potential applications of MAX phases}

MAX phases are called "remarkable" ceramics because they combine the properties of metals and ceramics [4]. Like ceramics, they are elastically stiff, light-weight, resistant to corrosion and oxidization, and retain strength and stiffness at high-temperature strength. Like metals, MAX phases are thermally and electrically conductive, readily machinable, relatively soft, resistant to thermal shock, and damage-tolerant. Elastically, the MAX phases are in general quite stiff and elastically isotropic. They are generally applied as high-temperature structure ceramics. The mechanical properties of MAX phases at room temperature and high temperatures, such as bending strength, toughness, elastic modulus, are extensively researched and reported. This part mainly focused on crack healing properties of MAX phases.

High-temperature structure ceramics are always brittle and sensitive to the presence of surface cracks caused by machining, loading, thermal shock, or fatigue. The presence of such cracks causes the loss in performance or even a sudden catastrophic failure of ceramic components during service, especially in thermal cycle 
conditions. If ceramics have self-healing ability to repair cracks in situ and thus restore their initial performance, the advantages will be obvious in improving structural integrity and functional reliability.

Great research efforts have been devoted to crack healing ceramics. Early crack healing studies mainly focused on oxide ceramics, such as $\mathrm{Al}_{2} \mathrm{O}_{3}, \mathrm{ZnO}, \mathrm{MgO}$, and $\mathrm{UO}_{2}$ [65-68]. The main crack healing mechanism for these oxide ceramics is grain growth by atomic diffusion to make cracks disappear. Since then, other crack healing mechanisms including oxidation reaction [69-76], phase transformation $\left(m \mathrm{ZrO}_{2} \rightarrow t \mathrm{ZrO}_{2}\right)$ [77,78], and precipitation [79] in binary ceramics and their composites have been successfully developed. Each crack-healing mechanism is effective in certain types of ceramics under certain conditions. However, the above oxide, carbide, and nitride binary ceramics require high temperatures $\left(>1200{ }^{\circ} \mathrm{C}\right)$ and long healing periods to repair micro-sized crack.

Recently, MAX phases have demonstrated attractive crack healing ability to repair millimeter-sized cracks in air at relatively lower temperatures of $800-1200{ }^{\circ} \mathrm{C}$ for short periods of $1-4 \mathrm{~h}$ via the main oxidation-induced crack healing mechanism [80-87]. Most interestingly, two MAX phases $\left(\mathrm{Cr}_{2} \mathrm{AlC}\right.$ and $\left.\mathrm{Ti}_{2} \mathrm{SnC}\right)$ even repair cracks in low oxygen partial pressures or vacuum atmosphere through reaction or precipitation mechanisms $[88,89]$. MAX phases with such crack healing properties and other properties are attractive as high-temperature ceramic components [38,88,90-96].

Here, we present a summary of major research and current understanding of mechanisms on crack healing behavior of MAX, and future opportunities in MAX applications.

\section{1 Crack healing in air}

MAX phases can repair damages (pores, scratches, and cracks) mainly through oxidation reaction mechanism in an oxidizing environment. Oxidation reaction induces the formation of oxides of $\mathrm{M}-\mathrm{O}$ and $\mathrm{A}-\mathrm{O}$ to fill the damages, thus recovering the properties. $\mathrm{Ti}_{3} \mathrm{AlC}_{2}$ was the first MAX phase reported with crack healing ability in 2008 [81]. It healed a crack with a size of $7 \mathrm{~mm}$ in length and $5 \mu \mathrm{m}$ in width created by tensile deformation. The crack was completely filled by a primary phase of $\alpha-\mathrm{Al}_{2} \mathrm{O}_{3}$ and some rutile- $\mathrm{TiO}_{2}$ after healing at $1100{ }^{\circ} \mathrm{C}$ for $2 \mathrm{~h}$ in air. The formed $\mathrm{Al}_{2} \mathrm{O}_{3}$ layer was well bonded to the matrix, but a larger fraction of $\mathrm{TiO}_{2}$ formed within the crack gap weakened the adhesion between matrix and oxides. Hence, the hardness and modulus measured in the healed zones in $\mathrm{Ti}_{3} \mathrm{AlC}_{2}$ increased by about $14 \%$ and $3 \%$, respectively. It should be realized that good bonding between crack-filling phases and healed zones can endow the healed materials with improved performance.

For Al-containing MAX phases, the selective-oxidation formed $\mathrm{Al}_{2} \mathrm{O}_{3}$ has strong adhesion to MAX matrices [82]. Therefore, the more $\mathrm{Al}_{2} \mathrm{O}_{3}$ is in cracks, the higher the recovery performance achieves. In the MAX phase family, $\mathrm{Ti}_{2} \mathrm{AlC}$ has about 25 at $\% \mathrm{Al}$, higher than $17 \%$ at $\% \mathrm{Al}$ for $\mathrm{Ti}_{3} \mathrm{AlC}_{2}$, indicating that more $\mathrm{Al}_{2} \mathrm{O}_{3}$ can be formed to fill cracks. In 2012, the crack healing behavior of $\mathrm{Ti}_{2} \mathrm{AlC}$ was firstly investigated [83]. Damages made by Knoop indentations and fatigue test in $\mathrm{Ti}_{2} \mathrm{AlC}$ caused a drop in strength, from $211 \mathrm{MPa}$ of the initial strength to $152 \mathrm{MPa}$. All damaged samples were fractured along the Knoop dents (Fig. 4(a)). After healing at $1200{ }^{\circ} \mathrm{C}$ for $2 \mathrm{~h}$ in air, the healed samples became
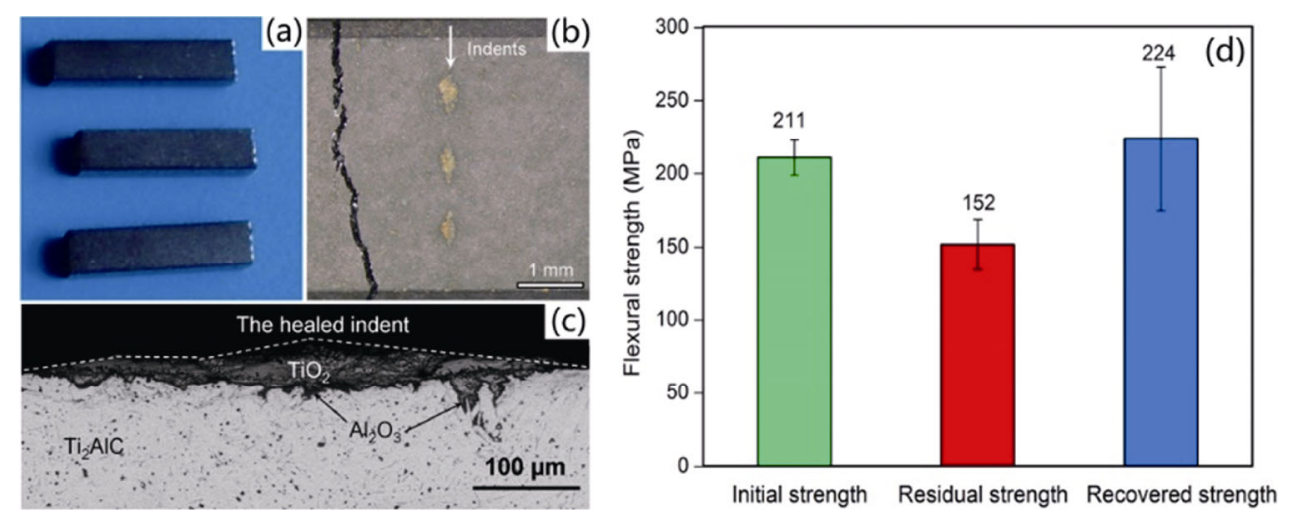

Fig. 4 Optical images of (a) the damaged samples after three-point bending test, which were fractured along the Knoop indents; (b) the healed sample after testing; (c) cross-sectional back-scattered SEM for the healed indent as shown in (b); (d) flexural strength of the virginal, damaged, and healed $\mathrm{Ti}_{2} \mathrm{AlC}$ samples. Error bars represent the standard deviation. Reproduced with permission from Ref. [83], (C) Elsevier Ltd. 2012. 
stronger due to the fact that these samples did not fracture through but just outside the damage-healed zones (Fig. 4(b)). The cross-sectional SEM micrograph demonstrates that the bottom of the Knoop dent was covered and the microcracks were filled by only $\mathrm{Al}_{2} \mathrm{O}_{3}$ (Fig. 4(c)). The $\mathrm{Ti}_{2} \mathrm{AlC}$ ceramic showed an attractive crack healing ability to recover the strength up to $224 \mathrm{MPa}$, even slightly exceeding the initial strength of $211 \mathrm{MPa}$ (Fig. 4(d)). The above feature indicates that the adhesion between $\mathrm{Al}_{2} \mathrm{O}_{3}$ in the crack gap and the $\mathrm{Ti}_{2} \mathrm{AlC}$ matrix is strong. Yang et al. [97] used in situ microcantilever bending test to conveniently evaluate the strength of $\mathrm{Ti}_{2} \mathrm{AlC}-\mathrm{Al}_{2} \mathrm{O}_{3}$ interface after healing at $1200{ }^{\circ} \mathrm{C}$ for 1.5 $\mathrm{h}$ in air. The experimental results demonstrated that the bonding strength of $\mathrm{Ti}_{2} \mathrm{AlC}-\mathrm{Al}_{2} \mathrm{O}_{3}$ interface is beyond the cleavage strength of $\mathrm{Ti}_{2} \mathrm{AlC}$ grains and the strength of healed grain boundary is two times the strength of original grain boundary, suggesting that the $\mathrm{Ti}_{2} \mathrm{AlC}$ ceramic may achieve full recovery of strength after healing at high temperatures.

Especially, the $\mathrm{Ti}_{2} \mathrm{AlC}$ MAX phase exhibits a repeatable crack healing ability [83]. A through-thickness crack with a length of $\sim 2.0 \mathrm{~mm}$ was introduced by single edge notched beam (SENB) method after loading in three-point bending. After healing at $1200{ }^{\circ} \mathrm{C}$ for $2 \mathrm{~h}$ in air, the millimeter-sized crack was completely healed (Fig. 5(a)). The $\mathrm{Ti}_{2} \mathrm{AlC}$ samples were repeatedly cracked and healed under the same conditions, but the healed crack gap became wider and a part of crack in the healed region was no longer completely filled in $2 \mathrm{~h}$ of healing at $1200{ }^{\circ} \mathrm{C}$ in air (Fig. 5(b)). Seven healing cycles after repeated cracking at a given location in $\mathrm{Ti}_{2} \mathrm{AlC}$ have been achieved. The fracture toughness $\left(K_{\mathrm{IC}}\right)$ recovery in a range of 3-6.7 $\mathrm{MPa} \cdot \mathrm{m}^{1 / 2}$ was also quantified during the repeatable healing cycles (Fig. 5(c)).

Interestingly, a prolonged healing time up to $100 \mathrm{~h}$ at $1200{ }^{\circ} \mathrm{C}$ in air still leads to the complete filling of the wider crack gap by $\mathrm{Al}_{2} \mathrm{O}_{3}$ and $\mathrm{TiO}_{2}$ (Fig. 6(a)). The thinner crack gap sections were mainly filled by $\mathrm{Al}_{2} \mathrm{O}_{3}$, but the wider crack sections were filled by a mixture of $\mathrm{Al}_{2} \mathrm{O}_{3}$ covering the two opposite crack surfaces and $\mathrm{TiO}_{2}$ distributing in the center of the healed zone (Figs. 6(b) and 6(c)). Sloof et al. [98] further investigated the rate and position dependence of crack repair in pristine $\mathrm{Ti}_{2} \mathrm{AlC}$ material and in previously healed cracks using the 4D in situ synchrotron X-ray tomographic microscopy. The repeated crack healing test results demonstrated that the healed cracks have sufficient mechanical integrity to make subsequent cracks form elsewhere upon reloading after healing.

Crack healing behavior of ceramics has been investigated over 50 years and demonstrated for single or one-time-only healing event per damage site. So far, the multiple healing performance has been only displayed in self-healing polymers with microvascular networks [99]. The $\mathrm{Ti}_{2} \mathrm{AlC}$ MAX ceramic is such a unique rigid material exhibiting repeatedly repairing ability. The crack healing ability combined with other attractive high-temperature properties makes $\mathrm{Ti}_{2} \mathrm{AlC}$ promising in critical high-temperature applications.
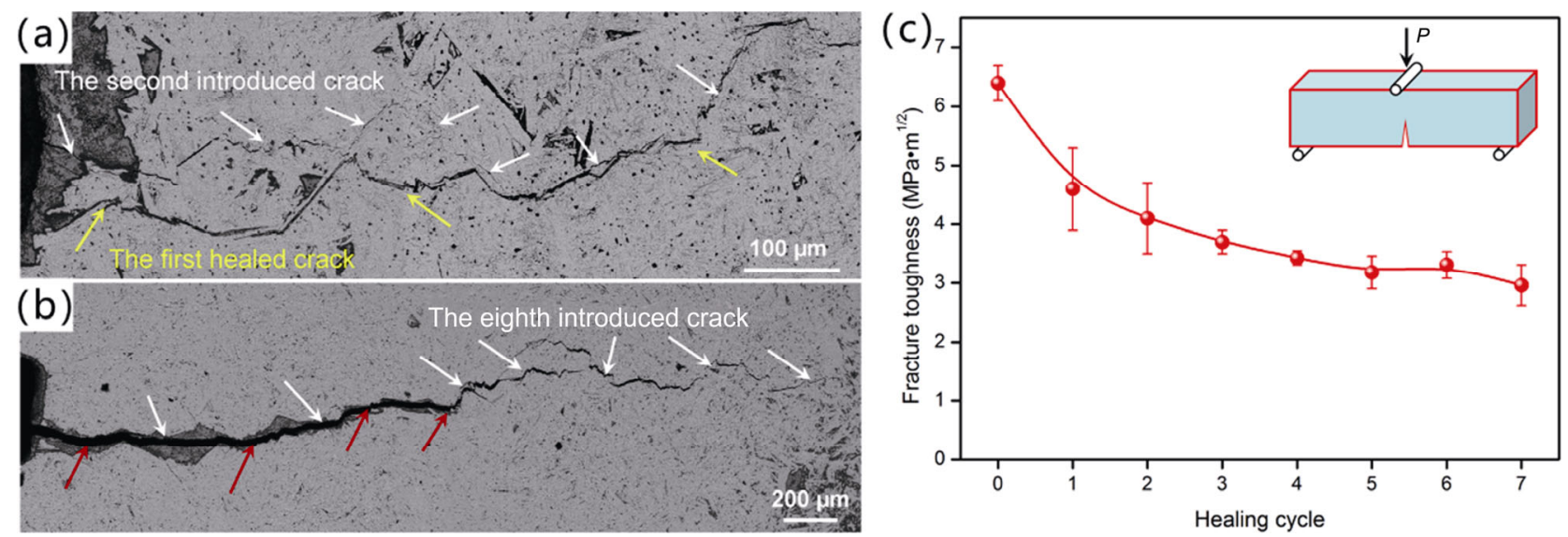

Fig. 5 Back-scattered SEM images of fracture and crack healing of $\mathrm{Ti}_{2} \mathrm{AlC}$ samples. (a) Crack path after one cycle of healing and subsequent fracture. The yellow arrows indicate the crack completely filled, and the white arrows indicate the new introduced crack. Note that the subsequent crack almost deflects around the healed zone of the first crack. (b) Crack path after seven cycles of healing and the subsequent fracture. The red arrows indicate the location of remnant crack parts. (c) Fracture toughness as a function of the number of fracture and healing cycles. The first value for the fracture toughness (i.e., for cycle number, 0) pertains to the virginal material. The error bars indicate the standard deviation. Reproduced with permission from Ref. [83], (C) Elsevier Ltd. 2012. 

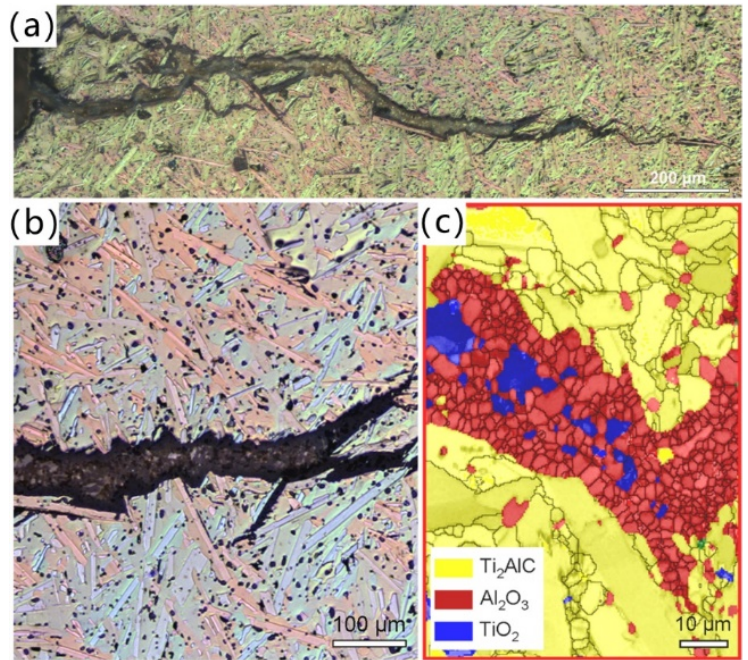

Fig. 6 Healing of the wide damage in $\mathrm{Ti}_{2} \mathrm{AlC}$ at $1200{ }^{\circ} \mathrm{C}$ for $100 \mathrm{~h}$. (a) A low magnification optical image of the healed crack. (b) A high magnification optical image taken from (a). Two opposite fracture surfaces were covered by the same $\mathrm{Al}_{2} \mathrm{O}_{3}$ layer (black) and the gap between two surfaces was fully filled by a mixture of $\mathrm{Al}_{2} \mathrm{O}_{3}$ (black) and $\mathrm{TiO}_{2}$ (large white particles). (c) EBSD image of the healed-damage zone. Reproduced with permission from Ref. [83], (C) Elsevier Ltd. 2012.

After that, the crack healing behavior of $\mathrm{Ti}_{2} \mathrm{AlC}$ and its solid solutions as filler and coating $[86,87,100,101]$ has been studied. Bei et al. [86] prepared $\mathrm{Ti}_{2} \mathrm{Al}_{1-x} \mathrm{Sn}_{x} \mathrm{C}$ solid solutions by substitution of $\mathrm{Al}$ by $\mathrm{Sn}$, and found that solution of $\mathrm{Sn}$ in $\mathrm{Ti}_{2} \mathrm{AlC}$ reduced the occurrence of oxidation reaction between $\mathrm{Al}$ and $\mathrm{O}$ from 900 to $460{ }^{\circ} \mathrm{C}$. They proposed that $\mathrm{Ti}_{2} \mathrm{Al}_{1-x} \mathrm{Sn}_{x} \mathrm{C}$ solid solutions may repair damages at reduced temperatures as exposed to air. Then they further investigated the crack healing in $\mathrm{Al}_{2} \mathrm{O}_{3}$ composites reinforced with 5-20 vol\% $\mathrm{Ti}_{2} \mathrm{Al}_{0.5} \mathrm{Sn}_{0.5} \mathrm{C}$ [87]. The experimental results revealed that the $\mathrm{Ti}_{2} \mathrm{Al}_{0.5} \mathrm{Sn}_{0.5} \mathrm{C}$ is an efficient repair filler to trigger oxidation-induced crack healing in $\mathrm{Al}_{2} \mathrm{O}_{3}$ ceramic composites at temperatures below $1000{ }^{\circ} \mathrm{C}$. The crack section near the surface of $\mathrm{Ti}_{2} \mathrm{Al}_{0.5} \mathrm{Sn}_{0.5} \mathrm{C} / \mathrm{Al}_{2} \mathrm{O}_{3}$ composite was completely filled with solid oxidation products of $\mathrm{TiO}_{2}, \mathrm{Al}_{2} \mathrm{O}_{3}$, and $\mathrm{SnO}_{2}$, but the crack section in deep was filled with $\mathrm{TiO}_{2}, \mathrm{Al}_{2} \mathrm{O}_{3}$, and $\mathrm{Sn}$ after healing at $900{ }^{\circ} \mathrm{C}$ for $3 \mathrm{~h}$ in air. With increasing $\mathrm{Ti}_{2} \mathrm{Al}_{0.5} \mathrm{Sn}_{0.5} \mathrm{C}$ filler content from 5 to $20 \mathrm{vol} \%$ and healing time, the recovered strength of healed composites increased correspondingly after healing at $900{ }^{\circ} \mathrm{C}$. For the $20 \mathrm{vol} \%$ $\mathrm{Ti}_{2} \mathrm{Al}_{0.5} \mathrm{Sn}_{0.5} \mathrm{C} / \mathrm{Al}_{2} \mathrm{O}_{3}$ composite, the strength recovered fully, even higher than the initial strength level, after healing at $900{ }^{\circ} \mathrm{C}$ for only $0.5 \mathrm{~h}$ in air.

Thereafter, Boatemaa et al. [100] also investigated the oxidation-induced crack healing of $\mathrm{Al}_{2} \mathrm{O}_{3}$ containing $20 \mathrm{vol} \%$ of $\mathrm{Ti}_{2} \mathrm{AlC}$. The $20 \mathrm{vol} \% \mathrm{Ti}_{2} \mathrm{AlC} / \mathrm{Al}_{2} \mathrm{O}_{3}$ can repair indentation induced surface cracks of $\sim 80 \mu \mathrm{m}$ in length and $0.5 \mu \mathrm{m}$ in width after healing at temperatures above $800{ }^{\circ} \mathrm{C}$. At such temperatures, the cracks are filled by both $\mathrm{TiO}_{2}$ and $\mathrm{Al}_{2} \mathrm{O}_{3}$ resulting from the oxidation reaction of the $\mathrm{Ti}_{2} \mathrm{AlC}$ filler. A fully recovered strength can be achieved after healing at $1000{ }^{\circ} \mathrm{C}$ for $1 \mathrm{~h}$ in air. Wang et al. [101] found that a $\mathrm{Ti}_{2} \mathrm{Al}_{0.6} \mathrm{Sn}_{0.4} \mathrm{C}$ solid solution coating can effectively repair microcracks induced by indentation after healing at $700{ }^{\circ} \mathrm{C}$ for $10 \mathrm{~h}$. The cracks were filled by $\mathrm{SnO}_{2}$ and some rutile $\mathrm{TiO}_{2}$. These studies suggest that $\mathrm{Ti}_{2} \mathrm{AlC}$ and its solid solutions are an efficient reinforcement to not only improve the performance of ceramic matrix composites (CMCs), but also endow $\mathrm{CMCs}$ with highly attractive crack healing ability.

Moreover, $\mathrm{Ti}_{3} \mathrm{SiC}_{2}, \mathrm{Cr}_{2} \mathrm{AlC}$, and $\mathrm{Ti}_{2} \mathrm{SnC}$ MAX phases have also demonstrated with crack healing ability. For example, $\mathrm{Ti}_{3} \mathrm{SiC}_{2}$ achieved an increase in strength after oxidation at $1000{ }^{\circ} \mathrm{C}$ for $2 \mathrm{~h}$ in air [102]. Filling the surface scratches and micro-pores by oxidation induced oxides of $\mathrm{TiO}_{2}$ and $\mathrm{SiO}_{2}$ should be one of the mechanisms for improving flexural strength from the initial value from $\sim 280$ to $\sim 650 \mathrm{MPa}$. Li et al. [85] studied the crack healing behavior of a fine-grained $\mathrm{Cr}_{2} \mathrm{AlC}(\sim 2 \mu \mathrm{m})$ ceramic with different sized cracks after annealing at $1100{ }^{\circ} \mathrm{C}$ in air for $4-100 \mathrm{~h}$, and reported that the strength recovery of $\mathrm{Cr}_{2} \mathrm{AlC}$ has a strong dependence on crack length and healing time, with better strength recovery after increasing healing time. The indentation induced crack was completely filled with only $\alpha-\mathrm{Al}_{2} \mathrm{O}_{3}$ after healing at $1100{ }^{\circ} \mathrm{C}$ for $4 \mathrm{~h}$ in air. Pei et al. [94] studied the crack healing behavior of $\mathrm{Cr}_{2} \mathrm{AlC}$ MAX phase with $\mathrm{X}$-ray tomography, and further confirmed the above conclusion. The advantage of only $\alpha-\mathrm{Al}_{2} \mathrm{O}_{3}$ presenting in the healed zones is the generation of compressive stresses around the crack-healed zone, producing by the thermal expansion mismatch between $\mathrm{Cr}_{2} \mathrm{AlC}(12 \times$ $\left.10^{-6}-13 \times 10^{-6}{ }^{\circ} \mathrm{C}^{-1}\right)$ and $\mathrm{Al}_{2} \mathrm{O}_{3}\left(7.5 \times 10^{-6}-9.6 \times 10^{-6}{ }^{\circ} \mathrm{C}^{-1}\right)$ upon cooling down from high temperatures. The compressive stresses mechanically lock the two sides of the crack and impart the healed material with an enhanced strength recovery.

Unlike the filling phases in $\mathrm{Ti}_{3} \mathrm{AlC}_{2}$ and $\mathrm{Ti}_{2} \mathrm{AlC}$, the only filling phase of $\alpha-\mathrm{Al}_{2} \mathrm{O}_{3}$ in the healed zones in $\mathrm{Cr}_{2} \mathrm{AlC}$ can bond the crack planes strongly, providing optimal strength recovery after healing. However, once the $\mathrm{Al}_{2} \mathrm{O}_{3}$ layers are formed on the crack surfaces, it 
would retard the outward diffusion of $\mathrm{Al}$ from $\mathrm{Cr}_{2} \mathrm{AlC}$ and inward diffusion of $\mathrm{O}$, inducing the slow growth of $\mathrm{Al}_{2} \mathrm{O}_{3}$ layers. The slow growth of $\mathrm{Al}_{2} \mathrm{O}_{3}$ in the damaged zones causes a long period of healing. Therefore, promotion of the rapid growth of $\mathrm{Al}_{2} \mathrm{O}_{3}$ should be considered in the crack healing of MAX materials. Berger and Boucher [103] reported that the addition of yttrium $(\mathrm{Y})$ is one of the ways to promote the growth of $\mathrm{Al}_{2} \mathrm{O}_{3}$ in $\mathrm{Cr}_{2} \mathrm{AlC}$. Y-containing $\mathrm{Cr}_{2} \mathrm{AlC}$ coating exhibits an excellent self-healing ability to repair microcracks of $43 \mu \mathrm{m}$ in length and $200 \mathrm{~nm}$ in width at $900{ }^{\circ} \mathrm{C}$ for $1 \mathrm{~h}$ in air [103]. To further improve the healing efficiency of MAX phases, controlling the crack-filling phases with chemical stability and mechanical match to the MAX phases and promoting growth of such filling phases is necessary to consider.

$\mathrm{Ti}_{2} \mathrm{SnC}$ is another attractive MAX phase with crack healing capability in an oxidizing environment [80]. $\mathrm{Ti}_{2} \mathrm{SnC}$ can repair thermal shock induced cracks of $\sim 3 \mathrm{~mm}$ in length at a relatively low temperature of $800{ }^{\circ} \mathrm{C}$ within only $1 \mathrm{~h}$ in air. The healed samples demonstrated that both the low flexural strength and electrical conductivity are almost fully recovered. During healing, a high oxygen partial pressure near the sample surface induces the oxidation of $\mathrm{Ti}_{2} \mathrm{SnC}$ to form $\mathrm{TiO}_{2}$ and $\mathrm{SnO}_{2}$. The large cracks on the surface are completely filled by $\mathrm{TiO}_{2}$ and $\mathrm{SnO}_{2}$, contributing to the recovered mechanical properties. The small cracks especially deep in the material provide a low oxygen partial pressure. Sn easily diffuses from $\mathrm{Ti}_{2} \mathrm{SnC}$ due to its low migration energy of $0.66 \mathrm{eV}$ [104]. Under such condition, $\mathrm{Sn}$ diffusion from $\mathrm{Ti}_{2} \mathrm{SnC}$ may not be triggered to oxidation but remains a metallic element to fill the small cracks. The presence of metallic Sn in the healed cracks should play a key role in the recovery of electrical conductivity. The healing temperature for $\mathrm{Ti}_{2} \mathrm{SnC}$ decreased greatly as compared with those of 1100-1200 ${ }^{\circ} \mathrm{C}$ required for Al-containing MAX phases $\left(\mathrm{Ti}_{3} \mathrm{AlC}_{2}, \mathrm{Ti}_{2} \mathrm{AlC}\right.$, and $\mathrm{Cr}_{2} \mathrm{AlC}$ ).

On the basis of the above studies, it can be found that Al-containing MAX phases are the promising crack healing materials due to the formation of stable $\mathrm{Al}_{2} \mathrm{O}_{3}$ filler which is well adhering to the crack planes. However, it should be noted that the $\mathrm{Al}_{2} \mathrm{O}_{3}$ scale is a good barrier for the outward diffusion of $\mathrm{M}$ and $\mathrm{Al}$ elements and inward diffusion of $\mathrm{O}$. Once the $\mathrm{Al}_{2} \mathrm{O}_{3}$ scale is formed on the crack surfaces, healing of wider cracks or multiple healing at the same damage zones requires a long period time. Therefore, the formation of suitable crack filling oxides (e.g., $\mathrm{ZrO}_{2}$ ), which allow continuous transport of $\mathrm{O}$ in MAX phases or solid solutions, may be another way to achieve the complete healing of wide cracks in the MAX phases.

In addition, the MAX phases containing low melting point of $\mathrm{A}$ elements $(\mathrm{A}=\mathrm{Ga}, \mathrm{Cd}, \mathrm{Sn}, \mathrm{In}$, and $\mathrm{Pb})$ may be of interest to achieve crack healing at relatively lower temperatures for a short time period due to low cohesive bonding energy and migration energy of these low melting point of A metals [104].

As compared with binary ceramics, some MAX phases can heal even millimeter sized cracks at temperatures below $1200{ }^{\circ} \mathrm{C}$ for $1-4 \mathrm{~h}$ in air. To improve the healing efficiency of MAX phases, relatively low temperatures and short time periods are required. In addition, the filling phases should be stable and have strong bonding with the crack planes to recover original performance and functionality. Furthermore, the above research mainly focused on the crack repair of MAX phases by the oxidation induced healing mechanism in oxidizing atmosphere. It is highly desirable to know whether MAX phases can heal cracks in vacuum or low oxygen partial pressures, and to understand the corresponding healing mechanisms.

\section{2 Crack healing in low oxygen partial pressures}

MAX ceramics and their structural components have potential applications ranging from combustion gas turbines to heat elements for industrial vacuum furnaces. The gas turbine generally operates under combustion gas with lower oxygen partial pressure than that in air, and vacuum furnace works under vacuum or inert atmosphere. Under such environments, it is not clear whether MAX phases can repair damages to prolong their service life and maintain the structural integrity and safety. There is little information focusing on the crack healing behavior of MAX phases in low oxygen partial pressures.

$\mathrm{Cr}_{2} \mathrm{AlC}$ was the first one in MAX phase family exhibiting crack healing ability in water (with low oxygen pressures) during thermal shock [88]. Upon quenching in water, the formed cracks are simultaneously filled by formation of $\mathrm{Al}_{2} \mathrm{O}_{3}$ and $\mathrm{Cr}_{7} \mathrm{C}_{3}$ from an intensive oxidation between $\mathrm{Cr}_{2} \mathrm{AlC}$ and $\mathrm{H}_{2} \mathrm{O}$. The reactants repair thermal shock cracks and adhere well to the crack faces, endowing $\mathrm{Cr}_{2} \mathrm{AlC}$ with abnormal strength increase after certain quenching temperatures. The crack healing mechanism clearly explains the abnormal thermal shock behavior (i.e., the residual 
strength of as-quenched samples decreases gradually with increasing quenching temperatures and then unbelievably increases after quenching from even higher temperatures) of MAX phases which puzzles researchers for many years.

$\mathrm{Ti}_{2} \mathrm{SnC}$ was another MAX phase to be demonstrated with crack healing ability in a low oxygen partial pressure of $5 \mathrm{~Pa}$ [89]. After healing at $800{ }^{\circ} \mathrm{C}$ for $1 \mathrm{~h}$ at $5 \mathrm{~Pa}$, only metallic $\mathrm{Sn}$ was detected cracks introduced by water-quenching (Figs. 7(a) and 7(b)). The low migration energy of Sn may trigger the precipitation of $\mathrm{Sn}$ from $\mathrm{Ti}_{2} \mathrm{SnC}$. The precipitation $\mathrm{Sn}$ induced crack healing is the main mechanism for $\mathrm{Ti}_{2} \mathrm{SnC}$ to achieve a completely recovered electrical conductivity at low oxygen partial pressures.

Oxidation-induced crack healing is the main mechanism in MAX phases in air, but precipitation induced crack healing plays a predominant role in MAX phases containing low melting point of $\mathrm{A}$ elements $(\mathrm{A}=\mathrm{Ga}, \mathrm{Cd}, \mathrm{Sn}, \mathrm{In}$, and $\mathrm{Pb})$ at low oxygen partial pressures. Other crack healing mechanisms may be existed upon healing of MAX phases in oxidizing environments or at low oxygen partial pressures, which still need to be further investigated.

\section{3 Potential applications of MAX phases}

The distinct crack healing ability $[80,81,83,85,87,89,98$, $100,103]$ and other attractive high temperature properties including high strength $[47,48]$, nonsusceptibility to thermal shock $[88,90,91]$, good oxidation resistance $[48,62,105]$, and good ablation resistance [95], make the MAX phases the materials of choice for applications in combustion gas turbines, heat elements, and liners
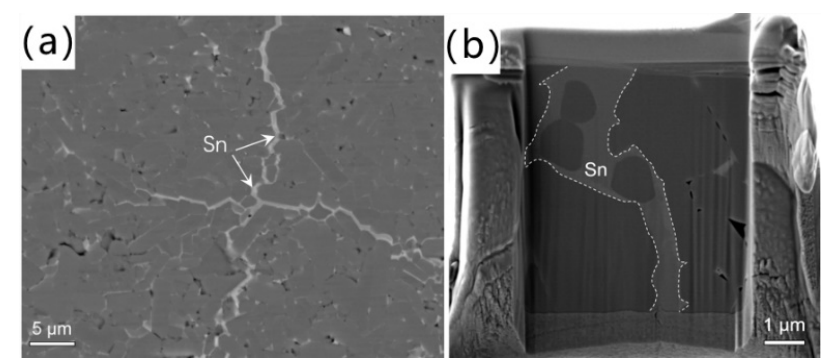

Fig. 7 (a) Back-scattered SEM image of polished surface of $\mathrm{Ti}_{2} \mathrm{SnC}$ after healing at $800{ }^{\circ} \mathrm{C}$ for $1 \mathrm{~h}$ at a low oxygen partial pressure of $5 \mathrm{~Pa}$. Cracks were filled with only metallic Sn. (b) Observation of the healed zones made by focused ion beam (FIB). The healed zone is filled with Sn marked by dashed lines. Reproduced with permission from Ref. [89], (C) Elsevier Ltd and Techna Group S.r.I. 2017. for industrial furnaces, nozzles, hypersonic vehicles, refractories, and coatings. In addition, MAX particles are also good healing agents in ceramic and metal matrix composites to repair damages. Key components made of such MAX phases with self-healing ability are highly expected to repair cracks in situ and thus restore initial mechanical performance, improve device reliability, and decrease replacement and maintenance costs.

$\mathrm{Ti}_{2} \mathrm{AlC}, \mathrm{Cr}_{2} \mathrm{AlC}$, and $\mathrm{Ti}_{3} \mathrm{AlC}_{2}$ are the most studied and developed products. For example, heating elements made of $\mathrm{Ti}_{2} \mathrm{AlC}$ were developed by the company 3-ONE-2, LLC (Fig. 8). Ti ${ }_{2} \mathrm{AlC}$ heating elements can in situ repair cracks induced by thermal cycling during use at high temperatures in oxidizing environments. Instantaneous crack healing during service may prolong their service life.

Except for applications of MAX phases as structural components, their self-healing coatings as oxidation and thermal barriers also attract much attention. For example, $\mathrm{Cr}_{2} \mathrm{AlC}$ MAX phases have been developed as high-temperature protective coating on refractory alloys [106]. MAX phase self-healing coatings may also be used on gas turbine components because service temperatures $\left(>1250{ }^{\circ} \mathrm{C}\right)$ are high enough to trigger oxidation-induced crack healing in coatings.

MAX reinforced metal $(\mathrm{Cu}, \mathrm{Fe}, \mathrm{Al}, \mathrm{Ni}, \mathrm{Ag}$, etc.) composites have been developed for electrical applications, including pantographs and contact materials. $\mathrm{Ti}_{3} \mathrm{SiC}_{2} / \mathrm{Cu}$ vacuum contactor materials are used in high power vacuum switches (Fig. 9) [107]. MAX/Cu composites have been developed as pantographs and applied successfully in high-speed trains with speeds of $250-300 \mathrm{~km} / \mathrm{h}$ in China [108]. Ti $\mathrm{i}_{2} \mathrm{SnC} / \mathrm{Ag}$ composites as electrical contacts have also been developed [105]. These key components with MAX self-healing agents may repair cracks by electrochemical oxidation induced crack healing mechanism.

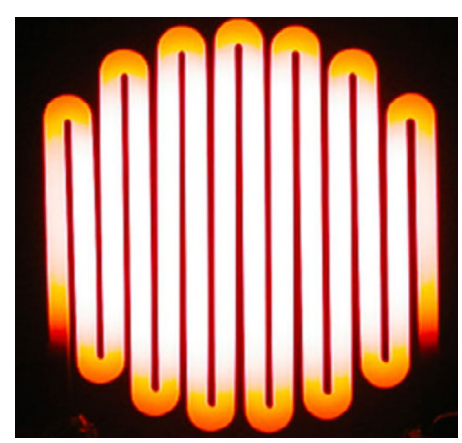

Fig. 8 Maxthal 211 heater glowing at 1723 K (3-ONE-2, LLC). 


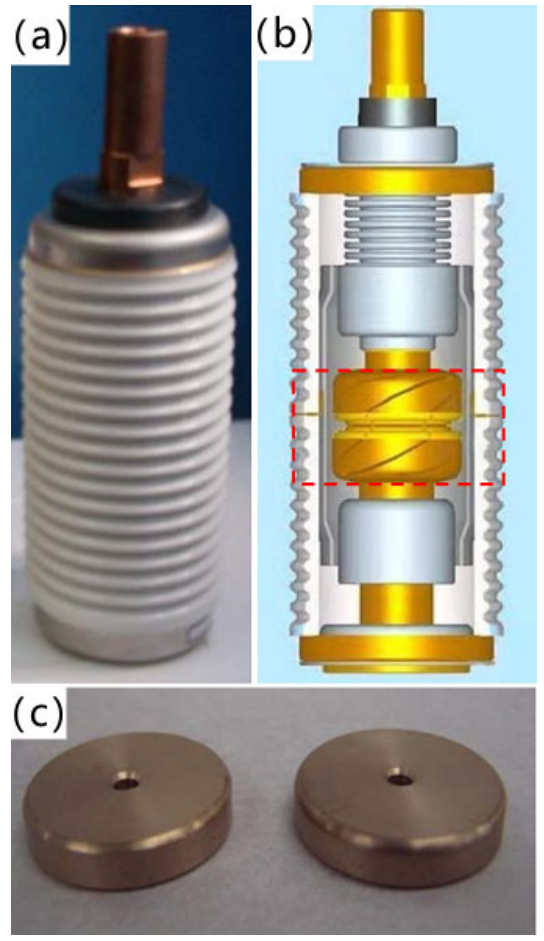

Fig. 9 (a) Photograph of a high power vacuum switch; (b) profile of the vacuum switch: the static and moving contacts are marked with a dashed rectangle; (c) $\mathrm{Ti}_{3} \mathrm{SiC}_{2} / \mathrm{Cu}$ vacuum contact materials. Reproduced with permission from Ref. [107], (C) The Author(s) 2008.

\section{Preparation of MXenes from MAX phases}

\section{1 HF solution etching}

Since the remarkable studies on preparing dense $\mathrm{Ti}_{3} \mathrm{SiC}_{2}$ samples by HIP [4], the research of $\mathrm{Ti}_{3} \mathrm{SiC}_{2}$ and other MAX phases attracted the worldwide attention from academia and industry. Most MAX phases were applied as structural materials in that period. However, novel functional applications of MAX phases were attempted by many groups. MAX phases have layered structure similar with graphite. Graphite has an important application as anode of lithium-ion-batteries (LIBs). Graphite is the first commercialized anode material of LIB. Considering the similarity between MAX phases and graphite, Prof. Barsoum cooperated with Prof. Gogotsi to apply a project from U.S. Department of Energy to research the application of MAX phases as anode of LIB.

Unfortunately, the research could not obtain desirable results at early stage. The measured capacities were always very low, because the interlayer bonds of MAX phases are too strong. Li ion cannot enter the interlayer space. Interlayer bonds of MAX phases need to be broken. Chemical etching is a common method to break chemical bonds. Many acids were tried to etch many MAX phases. HF acid was selected to etch $\mathrm{Ti}_{3} \mathrm{SiC}_{2}$, because $\mathrm{HF}$ is usually used to etch glass and both glass and $\mathrm{Ti}_{3} \mathrm{SiC}_{2}$ contain $\mathrm{Si}$. However, HF etching did not work on $\mathrm{Ti}_{3} \mathrm{SiC}_{2}$. However, it worked well on $\mathrm{Ti}_{3} \mathrm{AlC}_{2}$, another common MAX phase. $\mathrm{Al}$ was selectively etched off from $\mathrm{Ti}_{3} \mathrm{AlC}_{2}$. The first MXene, $\mathrm{Ti}_{3} \mathrm{C}_{2}$ MXene, was successfully prepared [6].

In that work, many bubbles were generated if $\mathrm{Ti}_{3} \mathrm{AlC}_{2}$ powders were put into HF solution. After $2 \mathrm{~h}$ etching, black powders were separated by centrifugation and rinsing from the etching solution. The black powders were characterized. It was found that $\mathrm{Al}$ element was etched off from $\mathrm{Ti}_{3} \mathrm{AlC}_{2}$. The black powders were the $\mathrm{Ti}_{3} \mathrm{C}_{2}$ left. However, due to high surface energy, the surface of $\mathrm{Ti}_{3} \mathrm{C}_{2}$ was terminated by $\mathrm{OH}^{-}$or $\mathrm{F}^{-} . \mathrm{Ti}_{3} \mathrm{C}_{2} \mathrm{~T}_{x}$ was used as the chemical formula of the etched product, where $\mathrm{T}$ represents $\mathrm{OH}$ and/or F. The SEM images of $\mathrm{Ti}_{3} \mathrm{AlC}_{2}$ before and after etching are shown in Figs. 10(a) and $10(\mathrm{~b})$, and the obtained sample had the accordionlike structure of stacked multilayer sheets. From the XRD patterns, almost all the peaks of $\mathrm{Ti}_{3} \mathrm{AlC}_{2}$ disappeared except the (002) peak shifted low angle. The strong (002) peak means that there is periodicity in $c$ direction due to the stacked multilayer structure. The low-angleshift of this peak means the increasing of lattice parameter $c$. The $c$ increased because $\mathrm{F}$ and/or $\mathrm{OH}$ replaced $\mathrm{Al}$ in the $\mathrm{Ti}_{3} \mathrm{AlC}_{2}$ crystal and the interlayer space between $\mathrm{Ti}_{3} \mathrm{C}_{2} \mathrm{~T}_{x}$ sheets was generated. The multilayer $\mathrm{Ti}_{3} \mathrm{C}_{2} \mathrm{~T}_{x}$ samples are electrically conductive and have interlayer space for Li storage and motion, which are desirable properties for anode of LIB. The reactions to convert $\mathrm{Ti}_{3} \mathrm{AlC}_{2}$ to $\mathrm{Ti}_{3} \mathrm{C}_{2} \mathrm{~T}_{x}$ MXene [6] were proposed as

$$
\begin{gathered}
\mathrm{Ti}_{3} \mathrm{AlC}_{2}+3 \mathrm{HF}=\mathrm{AlF}_{3}+3 / 2 \mathrm{H}_{2}+\mathrm{Ti}_{3} \mathrm{C}_{2} \\
\mathrm{Ti}_{3} \mathrm{C}_{2}+2 \mathrm{H}_{2} \mathrm{O}=\mathrm{Ti}_{3} \mathrm{C}_{2}(\mathrm{OH})_{2}+\mathrm{H}_{2} \\
\mathrm{Ti}_{3} \mathrm{C}_{2}+2 \mathrm{HF}=\mathrm{Ti}_{3} \mathrm{C}_{2} \mathrm{~F}_{2}+\mathrm{H}_{2}
\end{gathered}
$$

In Reaction (1), $\mathrm{Al}$ is removed from $\mathrm{Ti}_{3} \mathrm{AlC}_{2}$ to obtain $\mathrm{Ti}_{3} \mathrm{C}_{2} 2 \mathrm{D}$ sheets. In Reactions (2) and (3), the surfaces of $\mathrm{Ti}_{3} \mathrm{C}_{2}$ are terminated by $-\mathrm{F}$ and/or $-\mathrm{OH}$ due to the high surface energy of $\mathrm{Ti}_{3} \mathrm{C}_{2} 2 \mathrm{D}$ sheets.

Following this strategy, many MAX phases with $\mathrm{Al}$ as A elements, such as $\mathrm{Ti}_{2} \mathrm{AlC}, \mathrm{Ta}_{4} \mathrm{AlC}_{3},\left(\mathrm{Ti}_{0.5}, \mathrm{Nb}_{0.5}\right)_{2} \mathrm{AlC}$, $\left(\mathrm{V}_{0.5}, \mathrm{Cr}_{0.5}\right)_{3} \mathrm{AlC}_{2}$, and $\mathrm{Ti}_{3} \mathrm{AlCN}$, were etched by $\mathrm{HF}$ solution and corresponding 2D MXenes were prepared [8]. The SEM images of the some MXenes $\left(\mathrm{Ti}_{3} \mathrm{C}_{2}\right.$, 

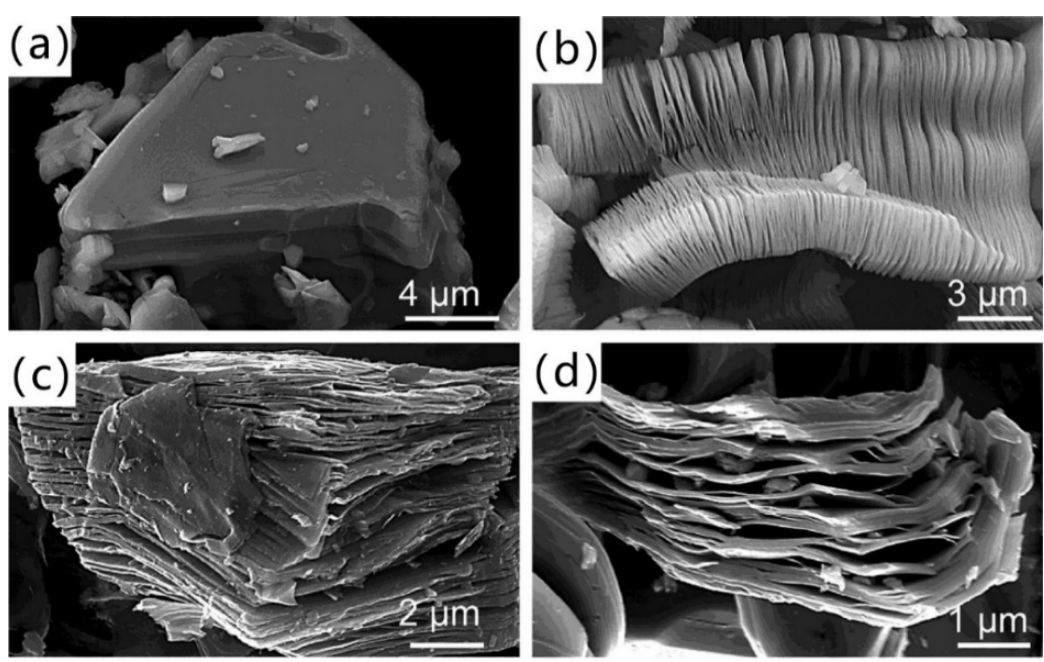

Fig. 10 SEM micrographs for (a) $\mathrm{Ti}_{3} \mathrm{AlC}_{2}$ particle, a typical MAX phase, (b) $\mathrm{Ti}_{3} \mathrm{C}_{2}$ MXene made by $\mathrm{HF}$ etching from $\mathrm{Ti}_{3} \mathrm{AlC} \mathrm{C}_{2}$, (c) $\mathrm{Ti}_{2} \mathrm{C}$ MXene, and (d) $\mathrm{Ta}_{4} \mathrm{C}_{3}$ MXene. Reproduced with permission from Ref. [8], (C) American Chemical Society 2012.

$\mathrm{Ti}_{2} \mathrm{C}$, and $\mathrm{Ta}_{4} \mathrm{C}_{3}$ ) are shown in Fig. 10. All the MXenes have stacked multilayer structure. The accordion-like multilayer structure is a feature microstructure of MXenes. The materials with this structure have some periodicity in the direction and only in the direction perpendicular to the layer plane. Thus, the XRD patterns of these materials only have diffraction peaks related with $(00 l)$ planes. The microstructure of MXenes is discussed in details in the following section.

In the first two important Refs. [6,8] on the synthesis of MXenes, the etching temperature was claimed to be "room temperature". The "room temperature" is not a fixed temperature. Especially, it is confusing for the researchers working on structural ceramics, such as MAX phases, because the temperature to synthesize or sinter MAX phases is generally above $1300{ }^{\circ} \mathrm{C}$. The temperature below $100{ }^{\circ} \mathrm{C}$ can be considered as room temperature by the researchers working on MAX phases. And these researchers easily ignored the impact of temperature on the etching reactions to synthesize MXenes. Thus, although the method to prepare MXenes was reported in 2011, only a few groups could experimentally prepared MXenes with high purity by the method before 2014 .

Thereafter, the impact factors on the etching reactions were researched to clarify the synthesis procedures. At a research in 2013 [109], $\mathrm{Ti}_{3} \mathrm{AlC}_{2}$ powders were etched by $50 \% \mathrm{HF}$ solution at different temperatures for $2 \mathrm{~h}$ or at room temperature for different time. The XRD patterns of the etched samples are shown in Fig. 11.
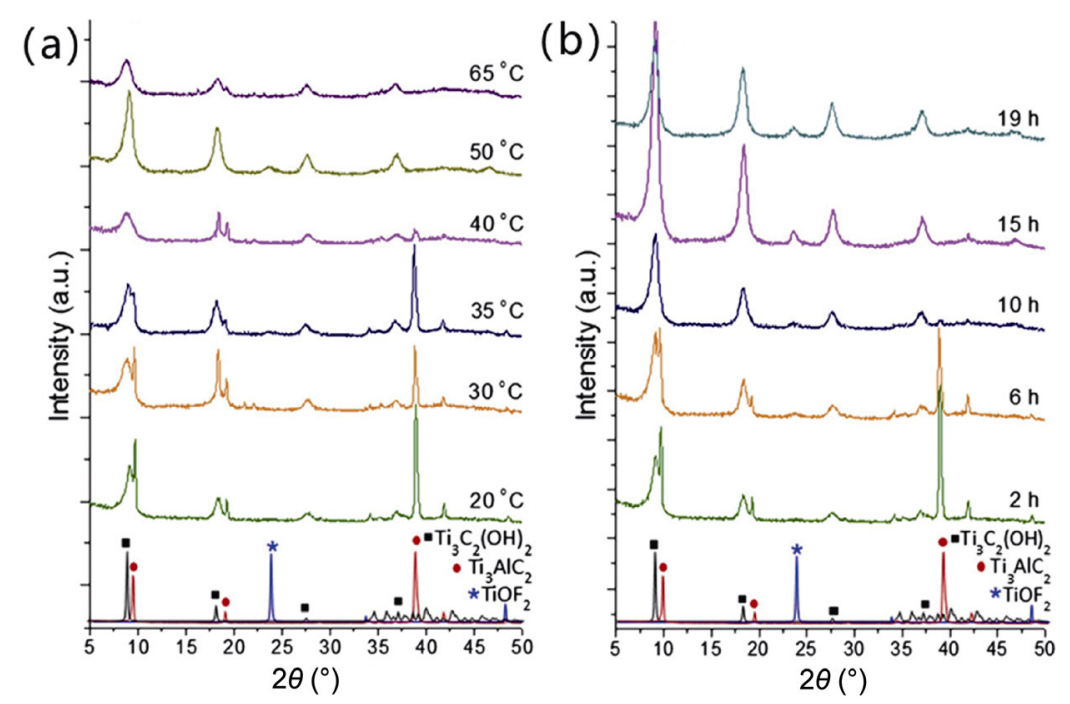

Fig. $11 \mathrm{XRD}$ patterns of $\mathrm{Ti}_{3} \mathrm{AlC}_{2}$ powders etched by $50 \% \mathrm{HF}$ solution as a function of (a) the temperature after $2 \mathrm{~h}$ and (b) the time at room temperature. Reproduced with permission from Ref. [109], (C) Elsevier B.V. 2013. 
The peak with $2 \theta=39^{\circ}$ corresponds to the (104) peak of $\mathrm{Ti}_{3} \mathrm{AlC}_{2}$. This peak diminishes with increasing temperature and time, disappearing above $50{ }^{\circ} \mathrm{C}$ and after $15 \mathrm{~h}$, respectively, indicating the completely consuming of $\mathrm{Ti}_{3} \mathrm{AlC}_{2}$. Concomitantly, the intensity of the (002) peak at $2 \theta \approx 9^{\circ}$, corresponding to the basal planes of the $2 \mathrm{D} \mathrm{Ti}_{3} \mathrm{C}_{2}$-based layers, increases. Therefore, higher temperatures, long reaction time, and small initial particle sizes, are favorable for the synthesis of MXenes.

Zhou and his coworkers [110,111] found that $\mathrm{Ti}_{3} \mathrm{AlC}_{2}$ was difficult to be selectively etched at "uncontrolled" room temperature. Below $15{ }^{\circ} \mathrm{C}$, the etched products always contained some $\mathrm{Ti}_{3} \mathrm{AlC}_{2}$ besides the desired $\mathrm{Ti}_{3} \mathrm{C}_{2}$ MXene. Therefore, the etching should be carried out in oil bath environment to control temperature. Higher temperature, such as $60{ }^{\circ} \mathrm{C}$, is favorable for the etching process. Two kinds of $\mathrm{Ti}_{3} \mathrm{AlC}_{2}$ powders were used for $\mathrm{Ti}_{3} \mathrm{C}_{2}$ MXene synthesis. Compared with hot-pressed $\mathrm{Ti}_{3} \mathrm{AlC}_{2}$ from element powders, pleasureless-synthesized $\mathrm{Ti}_{3} \mathrm{AlC}_{2}$ made by tube furnace from $\mathrm{TiH}_{2}$ as Ti source is a cheaper starting material to make MXene with highly preferred orientation. A suitable condition to synthesize MXene was $24 \mathrm{~h}$ at $60{ }^{\circ} \mathrm{C}$ in $49 \% \mathrm{HF}$ solution.

The MXene preparation can be expedited by controlling temperature and procedure. $\mathrm{Li}$ and his coworkers [112-114] reported a method to rapidly prepare $\mathrm{Ti}_{3} \mathrm{C}_{2}$ MXene. $\mathrm{Ti}_{3} \mathrm{AlC}_{2}$ powders were immersed in $40 \% \mathrm{HF}$ solution in a polytetrafluoroethylene (PTFE) container. To shorten the etching time and improve the reaction efficiency, a magnetic stirring device was used to maintain stirring and heating throughout the whole etching process. The time was only $0.5 \mathrm{~h}$ to prepare $\mathrm{Ti}_{3} \mathrm{C}_{2}$ MXene by exfoliating $\mathrm{Ti}_{3} \mathrm{AlC}_{2} \mathrm{HF}$ solution at $50{ }^{\circ} \mathrm{C}$.

\section{2 Fluoride $+\mathrm{HCl}$ etching}

HF acid is the first etchant to make MXenes by removing $\mathrm{Al}$ from Al-contained MAX phases. The etchant should remove $\mathrm{Al}$ while keep the $2 \mathrm{D}$ structure of MX layers. HF can achieve the purpose but it is too corrosive and dangerous. Thus, other acids were tried to replace HF. However, most common acids, such as $\mathrm{HCl}, \mathrm{HNO}_{3}, \mathrm{H}_{2} \mathrm{SO}_{4}$, cannot be used as etchants to make MXenes. It was found that $\mathrm{F}^{-}$and $\mathrm{H}^{+}$are required for an etching solution to make MXenes. In 2014, Ghidiu et al. [115] found a new etchant, $\mathrm{LiF}+\mathrm{HCl}$. This etchant solution contains $\mathrm{F}^{-}$and $\mathrm{H}^{+}$. Both $\mathrm{LiF}$ and $\mathrm{HCl}$ are milder and safer than HF. Additionally, the etchant can excellently exfoliate $\mathrm{Ti}_{3} \mathrm{AlC}_{2}$ to make $\mathrm{Ti}_{3} \mathrm{C}_{2}$ MXene. At the sample time, $\mathrm{Li}^{+}$in the etching solution can intercalate the multilayer $\mathrm{Ti}_{3} \mathrm{C}_{2}$ MXene to obtain the fully delaminated MXene with excellent performance.

In Ref. [115], $\mathrm{LiF}+\mathrm{HCl}$, instead of $\mathrm{HF}$, was used to make $\mathrm{Ti}_{3} \mathrm{C}_{2}$ MXene. This method is high-yield, safer, easier, and provides a faster route to delaminated MXene multilayers. As shown in Fig. 12, the $\mathrm{Ti}_{3} \mathrm{C}_{2}$ MXene made by this method was clay-like material. The multilayer structure was fully delaminated by the intercalation of $\mathrm{Li}^{+}$during the etching process. The single layers of MXene are hydrophilic, swell in volume when contact with water, and can be shaped like clay and dried into a highly conductive solid or rolled into films tens of micrometers thick. Therefore, MXene can be deemed as "conductive clay", for a host of applications.

Inspired by the idea that $\mathrm{HF}$ is replaced by $\mathrm{LiF}+\mathrm{HCl}$, other fluorides are also be used as etchant with $\mathrm{HCl}$ to make MXene. Liu et al. [116] reported the preparation of $\mathrm{Ti}_{3} \mathrm{C}_{2}$ MXene and $\mathrm{Ti}_{2} \mathrm{C}$ MXene by etching $\mathrm{Ti}_{3} \mathrm{AlC}_{2}$ and $\mathrm{Ti}_{2} \mathrm{AlC}$ with etching of $\mathrm{LiF}, \mathrm{NaF}, \mathrm{KF}$, and $\mathrm{NH}_{4} \mathrm{~F}$

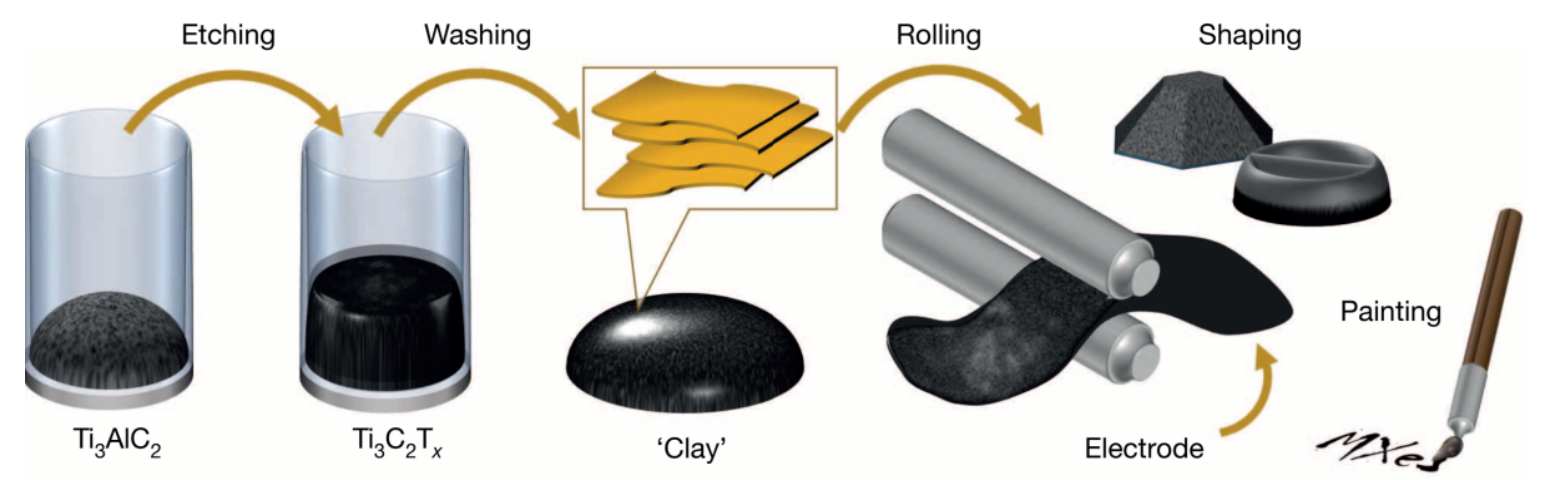

Fig. $12 \mathrm{Ti}_{3} \mathrm{C}_{2}$ MXene clay made by $\mathrm{LiF}+\mathrm{HCl}$ etching that can be processed by multi-methods to get different shapes. Reproduced with permission from Ref. [115], (c) Nature Publishing Group, a division of Macmillan Publishers Limited 2014. 
with $\mathrm{HCl}$. The influences of temperature and time on the exfoliating process were researched and clarified. Based on theoretical calculation and XPS results, the type of positive ions $\left(\mathrm{Li}^{+}, \mathrm{Na}^{+}, \mathrm{K}^{+}\right.$, or $\left.\mathrm{NH}_{4}^{+}\right)$in etchant solution affects the surface structure of prepared MXenes. Residual Li was detected on the surface of MXenes exfoliated by LiF with $\mathrm{HCl}$. However, almost no residual $\mathrm{K}$ and $\mathrm{Na}$ was detected on the surface of corresponding MXenes. The difference of residual positive ions, in turn, affects the methane adsorption properties of MXene.

The etchants making MXene have different etching abilities, which can be changed by controlling the ions other than $\mathrm{F}^{-}$or $\mathrm{H}^{+}$in the etchants. The "etching ability" includes "exfoliate ability" and "corrosivity". Exfoliate ability is the ability to exfoliate MAX phases to make MXenes. Corrosivity is the ability to destroy the MAX phase and obtain the MXenes. Generally, the corrosivity of $\mathrm{HF}$ is stronger than fluoride $+\mathrm{HCl}$. Due to the high corrosivity, some MXenes that are difficult to be made by HF etching, however, can be easily made by other etchants. For example, $\mathrm{V}_{2} \mathrm{C}$ MXene, another MXene, made by HF etching was always not pure. This is because HF has very strong corrosivity. Long time etching by HF destroys the structure of obtained $\mathrm{V}_{2} \mathrm{C}$ MXene; however, short time etching cannot fully exfoliate the precursor, $\mathrm{V}_{2} \mathrm{AlC}$. Zhou and his coworkers $[117,118]$ explored different etchants to make highly pure $\mathrm{V}_{2} \mathrm{C}$ MXene at $90{ }^{\circ} \mathrm{C}$. As shown in Fig. 13, only $\mathrm{NaF}+\mathrm{HCl}$ solution was effective for

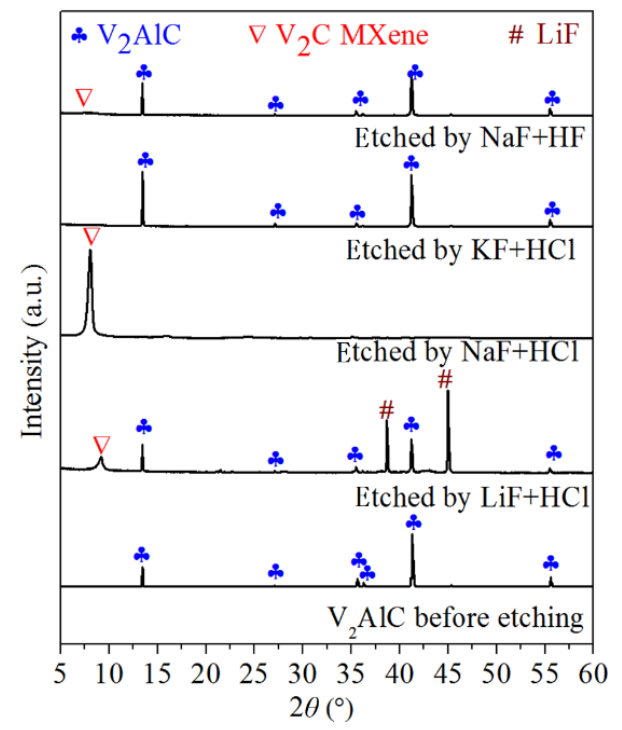

Fig. 13 XRD patterns of $\mathrm{V}_{2} \mathrm{AlC}$ samples before and after the etching in different solutions. Reproduced with permission from Ref. [117], (C) The Author(s) 2018. synthesizing highly pure $\mathrm{V}_{2} \mathrm{C}$ MXene. The existence of sodium $\left(\mathrm{Na}^{+}\right)$and chloridion $\left(\mathrm{Cl}^{-}\right)$in etching solution was essential for the synthesis of $\mathrm{V}_{2} \mathrm{C}$ MXene. The purity of as-synthesized $\mathrm{V}_{2} \mathrm{C}$ MXene was $>90 \mathrm{wt} \%$ with a few impurities of $\mathrm{Na}_{5} \mathrm{Al}_{3} \mathrm{~F}_{14}$ and $\mathrm{V}_{2} \mathrm{AlC}$. The $\mathrm{V}_{2} \mathrm{C}$ MXene made by $\mathrm{NaF}+\mathrm{HCl}$ etching at $90{ }^{\circ} \mathrm{C}$ was much purer than those made by $\mathrm{HF}$ etching at room temperature.

\section{3 Hydrothermal etching}

In the etching process, high temperature is generally beneficial to the synthesis of MXenes. However, the temperature cannot be higher than the boiling point of water, $100{ }^{\circ} \mathrm{C}$. That is why $90{ }^{\circ} \mathrm{C}$ was selected in the synthesis of $\mathrm{V}_{2} \mathrm{C}$ MXene in previous works [117,118]. If the etching process is carried out in a hydrothermal reactor, instead of opened environment (OE), such as an oil bath pan, the etching temperature can be higher than $100{ }^{\circ} \mathrm{C}$. This is the hydrothermal etching process. By this method, the exfoliating ability of etchant is further improved. And compared with the etching process in $\mathrm{OE}$, the etching proses in closed reactor is safer to the experiment operators. The hydrothermal etching can be used to make MXenes or other 2D materials [119].

In 2016, Wang et al. [120] developed the hydrothermal method to prepare $\mathrm{Ti}_{3} \mathrm{C}_{2}$ MXene. $\mathrm{NH}_{4} \mathrm{~F}$ was dissolved in deionized water as etching solution instead of $\mathrm{HF}$ acid. Then $\mathrm{Ti}_{3} \mathrm{AlC}_{2}$ and $\mathrm{NH}_{4} \mathrm{~F}$ solution was sealed in a Teflon-lined stainless-steel autoclave, kept at $150{ }^{\circ} \mathrm{C}$ for $24 \mathrm{~h}$, and then allowed to cool to room temperature naturally. By this method, highly pure $\mathrm{Ti}_{3} \mathrm{C}_{2}$ MXene can be made.

The hydrothermal etching can be carried out at higher temperatures and higher pressures, compared with traditional etching in OE. Thus, this method has higher ability to exfoliate MAX phases due to the temperature and pressure. Then mild etchant $\left(\mathrm{NH}_{4} \mathrm{~F}\right)$ can be used to replace strong etchant (HF).

Moreover, some MXenes that are difficult to be made can be made by this method. By this method, with fluoride $+\mathrm{HCl}$ as etching solution, $\mathrm{V}_{2} \mathrm{C}$ MXene was made from $\mathrm{V}_{2} \mathrm{AlC}[121,122]$ and $\mathrm{Mo}_{2} \mathrm{C}$ MXene was made from $\mathrm{Mo}_{2} \mathrm{Ga}_{2} \mathrm{C}$ [123]. Additionally, the effect of etching environment (opened for traditional method or closed for hydrothermal method) on the synthesis of $\mathrm{V}_{2} \mathrm{C}$ MXene was studied [122]. As shown in Fig. 14, in $\mathrm{OE}$, only $\mathrm{NaF}+\mathrm{HCl}$ etching solution can be used to synthesize highly pure $\mathrm{V}_{2} \mathrm{C}$ MXene. However, in closed 

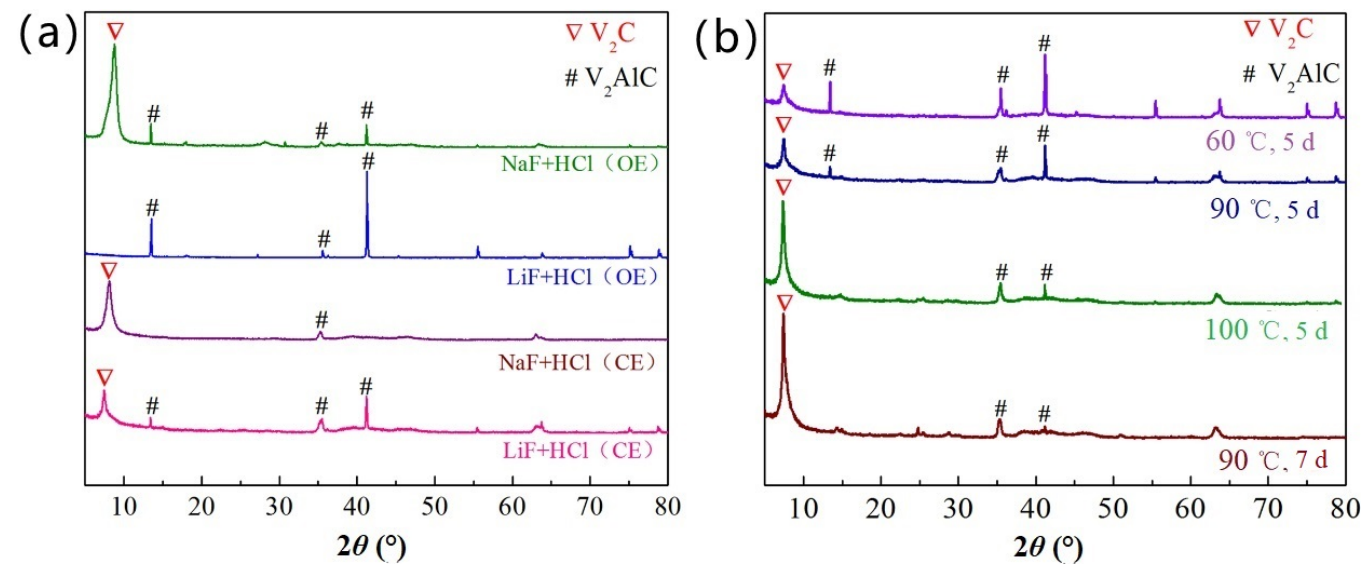

Fig. 14 XRD patterns of $\mathrm{V}_{2} \mathrm{C}$ MXene prepared under different process conditions: (a) etching at $90{ }^{\circ} \mathrm{C}$ for $5 \mathrm{~d}$ with $\mathrm{NaF}+\mathrm{HCl}$ or $\mathrm{LiF}+\mathrm{HCL}$ in $\mathrm{OE}$ or $\mathrm{CE}$; (b) etching in $\mathrm{CE}$ with $\mathrm{LiF}+\mathrm{HCl}$ for different days $(5$ and $7 \mathrm{~d}$ ) at different temperatures $(60,90$, and $\left.100{ }^{\circ} \mathrm{C}\right)$. Reproduced with permission from Ref. [122], (C) The Author(s) 2018.

environment (CE), both $\mathrm{LiF}+\mathrm{HCl}$ and $\mathrm{NaF}+\mathrm{HCl}$ etchants can be used to prepare $\mathrm{V}_{2} \mathrm{C}$ MXene. Moreover, the $\mathrm{V}_{2} \mathrm{C}$ MXene samples made in $\mathrm{CE}$ had higher purity and better layered structure than those made in $\mathrm{OE}$. Although the purity of $\mathrm{V}_{2} \mathrm{C}$ obtained by $\mathrm{LiF}+\mathrm{HCl}$ is lower than that of $\mathrm{V}_{2} \mathrm{C}$ obtained using $\mathrm{NaF}+\mathrm{HCl}$, it shows better electrochemical performance as anode of LIBs. Therefore, hydrothermal etching is a good method for preparing highly pure MXene.

\section{4 Molten salt etching at high temperatures}

In previous sections, aqueous solutions were used as etching solution to make MXene. Some alkalis and salts can be molten at high temperatures and be used to etch MAX phases to make MXenes. In 2013, inspired by the method to make porous active carbon, Sun et al. [124] attempted to etch $\mathrm{Ti}_{3} \mathrm{AlC}_{2}$ by $\mathrm{KOH}$ at $700{ }^{\circ} \mathrm{C}$. However, this attempt failed. The $\mathrm{KOH}$ etching method cannot make $\mathrm{Ti}_{3} \mathrm{C}_{2}$ MXene. In 2016, Urbankowski et al. [125] used molten fluoride salt $(\mathrm{KF} / \mathrm{LiF} / \mathrm{NaF})$ to etch $\mathrm{Al}$ from a $\mathrm{Ti}_{4} \mathrm{AlN}_{3}$ powder precursor at $550{ }^{\circ} \mathrm{C}$ under an argon atmosphere. By this method, $\mathrm{Ti}_{4} \mathrm{~N}_{3}$ was successfully made. The MXene made by this method was still terminated by $\mathrm{F}$.

In 2019, Li et al. $[19,126]$ used molten $\mathrm{ZnCl}_{2}$ as etchant to make MXene without $\mathrm{F} / \mathrm{OH}$ termination. First, novel MAX phases $\mathrm{Ti}_{3} \mathrm{ZnC}_{2}, \mathrm{Ti}_{2} \mathrm{ZnC}, \mathrm{Ti}_{2} \mathrm{ZnN}$, and $\mathrm{V}_{2} \mathrm{ZnC}$ were synthesized by the replacement reaction at $550{ }^{\circ} \mathrm{C}$ between the $\mathrm{Zn}$ element from molten $\mathrm{ZnCl}_{2}$ and the $\mathrm{Al}$ element in MAX phase precursors $\left(\mathrm{Ti}_{3} \mathrm{AlC}_{2}\right.$, $\mathrm{Ti}_{2} \mathrm{AlC}, \mathrm{Ti}_{2} \mathrm{AlN}$, and $\mathrm{V}_{2} \mathrm{AlC}$ ) [126]. Then, excess $\mathrm{ZnCl}_{2}$ was employed to derive Cl-terminated MXenes (such as $\mathrm{Ti}_{3} \mathrm{C}_{2} \mathrm{Cl}_{2}$ and $\mathrm{Ti}_{2} \mathrm{CCl}_{2}$ ) by a subsequent exfoliation of
$\mathrm{Ti}_{3} \mathrm{ZnC}_{2}$ and $\mathrm{Ti}_{2} \mathrm{ZnC}$ due to the strong Lewis acidity of molten $\mathrm{ZnCl}_{2}$ [19]. Moreover, in 2020, a redox-controlled A-site etching of MAX phases in Lewis acidic melts was proposed and validated by the synthesis of various MXenes from unconventional MAX-phase precursors with A elements, $\mathrm{Si}, \mathrm{Zn}$, and $\mathrm{Ga}$ [12].

Thus $\mathrm{ZnCl}_{2}$ etching can be used to make MXenes with $\mathrm{Cl}$ termination. Moreover, MXene with other terminations also can be synthesized by the etching of other molten salts. In 2020, Kamysbayev et al. [11] introduced a general strategy to install and remove surface groups by performing substitution and elimination reactions in molten inorganic salts. By this strategy, MXenes with $\mathrm{O}, \mathrm{NH}, \mathrm{S}, \mathrm{Cl}, \mathrm{Se}, \mathrm{Br}$, and Te surface terminations, as well as bare MXenes (no surface termination), were successfully synthesized. Br-terminated $\mathrm{Ti}_{3} \mathrm{C}_{2} \mathrm{Br}_{2}$ MXene and $\mathrm{Ti}_{2} \mathrm{CBr}_{2}$ MXene were prepared by molten $\mathrm{CdBr}_{2}$ etching at $610{ }^{\circ} \mathrm{C}$ for at least $6 \mathrm{~h}$. Then Br-terminated MXenes can efficiently engage in a new type of surface reactions where halide ions exchange for other atoms and functional groups. For example, $\mathrm{Ti}_{3} \mathrm{C}_{2} \mathrm{Br}_{2}$ MXene dispersed in $\mathrm{CsBr} / \mathrm{KBr} / \mathrm{LiBr}$ eutectic (m.p. $236{ }^{\circ} \mathrm{C}$ ) reacted with $\mathrm{Li}_{2} \mathrm{Te}$ and $\mathrm{Li}_{2} \mathrm{~S}$ to form new $\mathrm{Ti}_{3} \mathrm{C}_{2} \mathrm{Te}$ and $\mathrm{Ti}_{3} \mathrm{C}_{2} \mathrm{~S}$ MXenes, respectively.

\section{5 Other etching methods to make MXenes}

Besides aforementioned methods, many other etching methods were proposed and researched to make MXenes by more etchants from MAX phases. In 2017, electrochemical etching was used to form a layer of $\mathrm{Ti}_{2} \mathrm{CT}_{x}$ MXene on porous $\mathrm{Ti}_{2} \mathrm{AlC}$ electrodes in dilute hydrochloric acid [127]. Thereafter, Yang et al. [128] prepared $\mathrm{Ti}_{3} \mathrm{C}_{2}$ MXene by electrochemically etching 
method based on the anodic corrosion of $\mathrm{Ti}_{3} \mathrm{AlC}_{2}$ phases in an ammonium chloride and TMAOH electrolyte. In 2018, Li et al. [129] used alkaline-etching to synthesize $\mathrm{Ti}_{3} \mathrm{C}_{2}$ MXene without $\mathrm{F}$ termination from $\mathrm{Ti}_{3} \mathrm{AlC}_{2}$ by a high-temperature hydrothermal approach in $\mathrm{NaOH}$ solution at $270{ }^{\circ} \mathrm{C}$ for $12 \mathrm{~h}$. In 2020, Natu et al. [130] etched and delaminated $\mathrm{Ti}_{3} \mathrm{C}_{2}$ MXenes in the absence of water, by using organic polar solvents in the presence of $\mathrm{NH}_{4} \mathrm{HF}_{2}$.

\section{6 Summary on the preparation of MXenes}

In summary, MXenes can be prepared by selectively etching corresponding MAX phases. The etching process should remove A layers but keep intact of MX layers. Then impact factors were precursor MAX phases, etchant, temperature, pressure, etc. For the precursor MAX phases, most MXenes can be made and only can be made from Al contained MAX phases. However, $\mathrm{Mo}_{2} \mathrm{C}$ MXene cannot be made from corresponding Al-contained MAX phases, which only can be made from $\mathrm{Mo}_{2} \mathrm{Ga}_{2} \mathrm{C}$, a double A layer MAX phase [123,131,132]. For a MAX phase that can be used to make MXene, it must have strong $\mathrm{M}-\mathrm{X}$ bonds and weak $\mathrm{M}-\mathrm{A}$ bonds. During the etching process, $\mathrm{M}-\mathrm{A}$ bonds are broken and A layers are removed, while $\mathrm{M}-\mathrm{X}$ cannot be broken and the $\mathrm{M}_{n+1} \mathrm{X}_{n}$ layers can be kept. According to this criterion, $\mathrm{Ti}_{3} \mathrm{AlC}_{2}$ can be used to make MXene because $\mathrm{Ti}-\mathrm{Al}$ bonds are weak and $\mathrm{Ti}-\mathrm{C}$ bonds are strong. Compared with $\mathrm{Ti}_{3} \mathrm{AlC}_{2}, \mathrm{Ti}_{3} \mathrm{SiC}_{2}$ cannot be used because the Ti-Si bonds of $\mathrm{Ti}_{3} \mathrm{SiC}_{2}$ are stronger than $\mathrm{Ti}-\mathrm{Al}$ bonds of $\mathrm{Ti}_{3} \mathrm{AlC}_{2}$. Compared with $\mathrm{Ti}_{3} \mathrm{AlC}_{2}$, $\mathrm{Ti}_{3} \mathrm{AlN}_{2}$ cannot be used because the $\mathrm{Ti}-\mathrm{N}$ bonds of $\mathrm{Ti}_{3} \mathrm{AlN}_{2}$ are weaker than the $\mathrm{Ti}-\mathrm{C}$ of $\mathrm{Ti}_{3} \mathrm{AlC}_{2}$.

HF acid is the first etchant to make MXene. The MXenes made by HF etching generally have small interlayer space and $\mathrm{F}$ termination. Now, $\mathrm{LiF}+\mathrm{HCl}$ is a common etchant to make MXenes. The MXenes made by this method generally have large interlayer space due to the $\mathrm{Li}$ ion interaction and $\mathrm{O}$ termination. Moreover, other etchants, such as $\mathrm{NaOH}, \mathrm{NH}_{4} \mathrm{~F}$, and $\mathrm{ZnCl}_{2}$, were used to make MXenes with different terminations.

Generally, high temperature is beneficial to the exfoliation of MAX phases. However, too higher temperature may destroy or oxidize the MXene. Then the temperature should be carefully selected. For HF etching or $\mathrm{LiF}+\mathrm{HCl}$ etching in $\mathrm{OE}$, the temperature can be $40-70{ }^{\circ} \mathrm{C}$, which should be less than $90{ }^{\circ} \mathrm{C}$. In the $\mathrm{CE}$ of hydrothermal reactors, the temperature can be
120-200 ${ }^{\circ} \mathrm{C}$. Higher temperature can result in the oxidation of prepared MXenes. If molten salt was used as etchant, the etching reaction would be carried out in Ar atmosphere without oxygen. Thus the temperature can be high up to $500-600{ }^{\circ} \mathrm{C}$.

$\mathrm{CE}$ of hydrothermal reactors can provide better exfoliate ability to make MXene due to the high pressures and the CE. Thus hydrothermal etching can use mild etchant and can make some MXenes that are difficult to be made in $\mathrm{OE}$.

\section{Microstructure of MXenes}

Investigations into the structure of MXenes play essential roles in understanding the properties of MXenes. The layer structure and surface terminations impose a significant influence on mechanical properties and electronic structures of MXenes. To fully exploit the advantages of MXenes, it is critically important to fully understand the structure of MXenes. Until now, wide ranges of advanced characterization techniques, such as scanning electron microscopy (SEM), transmission electron microscopy (TEM), scanning transmission electron microscopy (STEM), have been widely used for distinguishing the microstructure of MXenes. A summary on the difference in microstructure of MXene from various characterization techniques is stated in the following section.

\section{1 Morphology of MXenes under SEM}

Generally, the transformation of MAX phases to MXenes with different shapes, sizes, and morphologies is related to the HF concentration, the HF-containing etchants, the reaction time and temperature, the delamination or intercalation agent (dimethyl sulfoxide, $\mathrm{NH}_{3} \cdot \mathrm{H}_{2} \mathrm{O}$, and urea), the source of available precursors (solid-liquid reaction synthesis method, molten salt method), the drying methods (oven drying, freeze drying, and supercritical drying), and the post-treatment of MXenes (heat treatment in various atmosphere, such as $\left.\mathrm{NH}_{3}, \mathrm{Ar}\right)[109,115,133,134]$.

MXenes are generally obtained through the selective etching of the reactive A layers from the MAX precursors. Notably, concentration of etching solutions, duration of immersion, and temperature affect the morphology of as-prepared MXenes. For example, high concentration HF solution-etched MXene (usually $>40 \%$ ) always exhibits a slack accordion-like morphology, while 
when the diluted HF solution (usually $<10 \%$ ) was adopted, the morphologies of MXenes changed into thicker multilayer lamellas with fewer inter-stack gaps, as shown in Figs. 15(a) and 15(b). More importantly, the low concentration HF etched-MXene always possesses more open interlayer space and accommodates more charge carrying ions between the interlayers, enabling more charge carrying ions to be more readily accessible to the active sites and deliver higher capacity. Moreover, another one important factor to affect the morphology of MXene is duration of immersion in HF solution and reaction temperature. The longer the etching duration, the thinner the stacked sheets were obtained. When the etching duration is long enough, the thin sheets are separated from each other $[109,135]$. As the etching temperature increases, the etching time decreases. Normally, MXenes with higher "M" atomic numbers require higher HF concentration or longer etching time to achieve complete conversion.

Although HF etching was widely used as a facile and versatile method to obtain MXenes, it was still a harsh way with high toxicity and danger to handle and probably resulting in plenty of defects on prepared MXenes. Therefore, an in situ formed HF, via mixing fluoride salts ( $\mathrm{LiF}, \mathrm{NaF}$, and $\mathrm{KF}$ ) and acids $(\mathrm{HCl}$, $\mathrm{H}_{2} \mathrm{SO}_{4}$ ), can be used to selectively etch the A atoms through similar reactions with less dangerousness. Recently, the as-synthesized multilayer $\mathrm{Ti}_{3} \mathrm{C}_{2} \mathrm{~T}_{x}$ and $\mathrm{Mo}_{2} \mathrm{CT}_{x}$ from the $\mathrm{HCl} / \mathrm{LiF}$ mixture solution route as initially proposed by Ghidiu et al. [115], can be fully and easily delaminated by mere sonication in water. This dramatically effective delamination has been attributed to intercalated water and possible cations between the multilayer MXenes acting as a spacer and lubricant that facilitated shearing. Consequently, the larger single- or few-layer MXene flakes with fewer defects are obtained readily by hand-shaking without any sonication or further intercalation [139]. The obtained flake sizes and shapes all keep the grain sizes and shapes of the precursor MAX phase powder
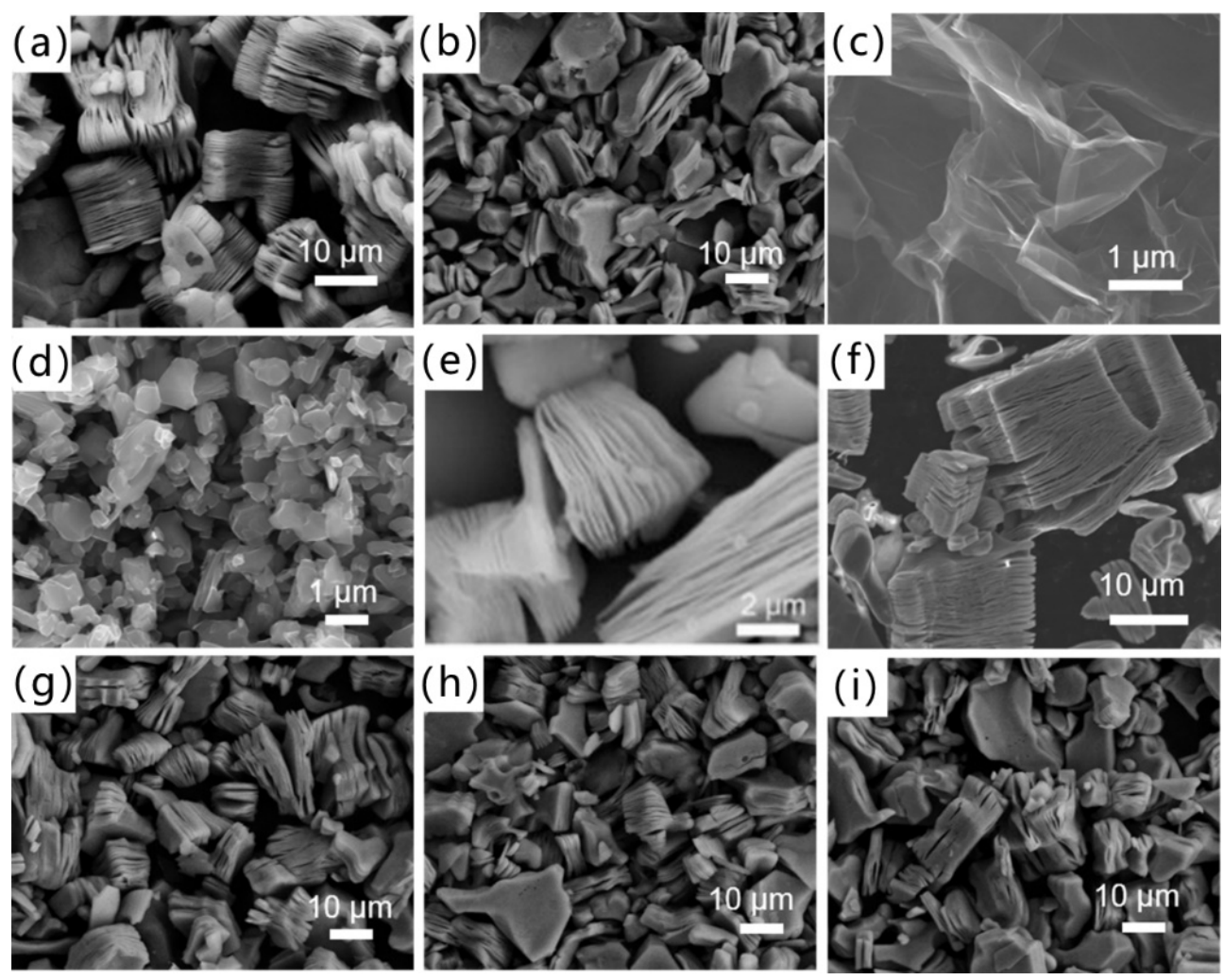

Fig. 15 Morphologies of MXenes in SEM. (a) SEM image from MXene etched with high concentration HF solution. (b) SEM image from MXene etched with diluted HF solution. Reproduced with permission from Ref. [136], (C) American Chemical Society 2019. (c) $\mathrm{LiF} / \mathrm{HCl}$ solution-etched MXene treatment by solvothermal method. (d) $\mathrm{Ti}_{3} \mathrm{C}_{2} \mathrm{~T}_{x}$ MXene obtained by etching submicron $\mathrm{Ti}_{3} \mathrm{AlC}_{2}$ grains grown in molten salt. Reproduced with permission from Ref. [137], (C) Royal Society of Chemistry 2018. (e) SEM image of multilayer MXene by freeze-drying. Reproduced with permission from Ref. [138], (C) Elsevier 2020. (f) Supercritical drying. SEM images of MXene samples annealed in (g) $\mathrm{Ar}\left(\mathrm{H}_{2}\right)$, (h) $\mathrm{Ar}\left(\mathrm{H}_{2} \mathrm{O}\right)$, and (i) $\mathrm{NH}_{3}$. Reproduced with permission from Ref. [136], (C) American Chemical Society 2019. 
[137]. Moreover, the obtained $\mathrm{Ti}_{3} \mathrm{C}_{2} \mathrm{~T}_{x}$ from the $\mathrm{HCl} / \mathrm{LiF}$ mixture solution route has a structure as thin as cicada's wings by means of microwave irradiation in glycerin, as shown in Fig. 15(c). Thus, one can choose the appropriate MAX phases to develop the required MXenes according to specific research goals.

In addition, reducing the initial particle size of the MAX phase precursor is an effective strategy to obtain submicron or nano-sized MXene. Naguib et al. [133] have demonstrated that the required etching duration can be effectively reduced, when $\mathrm{V}_{2} \mathrm{AlC}$ powders were subjected to attrition milling prior to chemical exfoliation. However, the obtained flake sizes and shapes are easy to destroy by that method. Thus, a bunch of efforts have been devoted to explore a molten salt method to synthesize nanosized and fine-grained $\mathrm{Ti}_{3} \mathrm{AlC}_{2}$ powders. Nanosized $\mathrm{Ti}_{3} \mathrm{C}_{2} \mathrm{~T}_{x}$ MXene is also easier to be prepared by etching the fine-grained $\mathrm{Ti}_{3} \mathrm{AlC}_{2}$ precursor in concentrated HF solution [140]. The SEM image of as-prepared nanosized $\mathrm{Ti}_{3} \mathrm{C}_{2} \mathrm{~T}_{x}$ MXene is shown in Fig. 15(d) [137].

Drying methods and the post-treatment of MXene are another valuable strategy to tailor the morphologies of MXene sheets. Drying methods, including oven drying, freeze drying, and supercritical drying, are one important factor to determine the morphologies of MXene. Many nanoparticles often arise on the surface of MXene via oven-drying. This is probably because residual $\mathrm{Al}^{3+}$ ions migrate with water to the surface of MXene and form $\mathrm{Al}_{2} \mathrm{O}_{3}$ nanocrystals due to oxidation. Freeze drying is a powerful technique that is utilized in preparing fine morphologies of MXene. During the rapid cooling process, liquid water will transform into solid ice and separate from the nanoarchitectures. The porous structures can be maintained without shrinking by the following sublimation of ice. Therefore, the MXene of freeze-drying always has a clean surface without oxide particles on the surface, as shown in Fig. 15(e) [138]. Similarly, supercritical drying has been demonstrated to be an efficient technique to obtain aerogels that maintain their native morphology at micro- and nano-scale [141]. The MXene obtained by supercritical drying displays clearly visible layered structure, as shown in Fig. 15(f).

Additionally, MXene heat treatment in various atmosphere or other solvents can greatly affect the morphologies of MXene. It was noted that annealing $\mathrm{Ti}_{2} \mathrm{CT}_{x}$ in various controlled atmospheres, such as $\mathrm{Ar}$, $\mathrm{N}_{2}$, or $\mathrm{N}_{2} / \mathrm{H}_{2}$, retained its initial chemical structure but caused slight thinning of the layers, thus resulting in a favorable mesoporous structure to allow more access to the aqueous electrolyte [142]. A similar phenomenon for $\mathrm{Ti}_{3} \mathrm{C}_{2} \mathrm{~T}_{x}$ was also reported by Refs. [136,143], laying the groundwork for modification and/or elimination of surface groups by using heat treatment in various gas environments to structurally alter the morphology of $\mathrm{Ti}_{3} \mathrm{C}_{2} \mathrm{~T}_{x}$, as shown in Figs. 15(g)-15(i). Zhao et al. [144] demonstrated a scalable, cost efficient, and rapid strategy to construct $3 \mathrm{D}$ porous $\mathrm{Ti}_{3} \mathrm{C}_{2} \mathrm{~T}_{x}$ network by simply adding alkali solutions to colloidal MXene suspensions to induce crumpling of $\mathrm{Ti}_{3} \mathrm{C}_{2} \mathrm{~T}_{x}$ nanosheets.

\section{2 Identification of MXene's microstructure under TEM}

TEM, one of the most widely used techniques, is a powerful technique to characterize the size, crystallinity, phase, and exposed facets of 2D materials [145]. Unlike SEM, electrons in TEM are generated from a higher voltage and thus have a shorter wavelength, giving rise to a much higher resolution than that of SEM. Thus, using TEM is highly desirable to fully understand various microstructural features of as-synthesized MXenes. Generally, the size, crystallinity, and exposed facets of MXenes prepared by different strategies would be different. For example, the size of $\mathrm{Ti}_{3} \mathrm{C}_{2} \mathrm{~T}_{x}$ for $\mathrm{HCl} / \mathrm{LiF}$ etching is more intact than that of preparing by $\mathrm{HF}$. Additionally, the MXene preparing by $\mathrm{HCl} / \mathrm{LiF}$ always has few defects, and keeps the grain sizes and shapes of the precursor MAX phase powder as shown in Figs. 16(a) and 16(b). If precursor MAX phase was synthesized by molten salt, the obtained MXene often possesses sub-micron or nano-sized shape in the 3D scale, with multilayer laminate structures (Fig. 16(c)).

More recently, Urbankowski et al. [125] managed to delaminate multilayer $\mathrm{Ti}_{4} \mathrm{~N}_{3} \mathrm{~T}_{x}$ into a mixture of single- and few-layered sheets using TBAOH as the intercalant, with the aid of sonication. The obtained MXene flakes possess rough edge with many small pieces on surface of MXene flake, as shown in Fig. 16(d).

Due to unsaturated $\mathrm{M}$ enabling spontaneous donation of electrons, precursor of metals, such as $\mathrm{HAuCl}_{4}$, $\mathrm{H}_{2} \mathrm{PdCl}_{4}, \mathrm{AgNO}_{3}$, and $\mathrm{H}_{2} \mathrm{PtCl}_{6}$, tailoring the morphologies of MXene sheets would be a fashionable strategy to control their functionality and properties. For instance, Cheng et al. [147] have demonstrated that MXenes with appropriate terminations are capable of reducing 


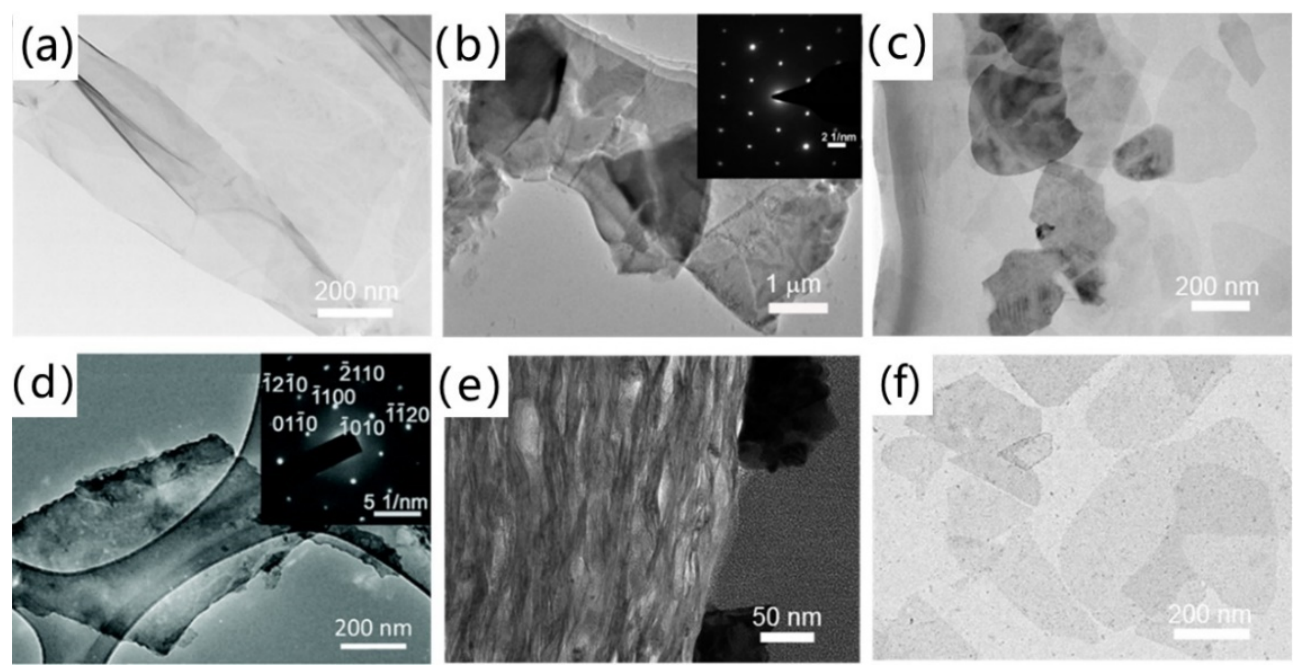

Fig. 16 Microstructure of MXene in TEM. (a) TEM image of $\mathrm{Ti}_{3} \mathrm{C}_{2} \mathrm{~T}_{x}$ MXene prepared by HCl/LiF. Reproduced with permission from Ref. [146], (C) American Chemical Society 2020. (b) TEM image of $\mathrm{Ti}_{3} \mathrm{C}_{2} \mathrm{~T}_{x}$ prepared by HF etching, (c) TEM image of $\mathrm{Ti}_{3} \mathrm{C}_{2} \mathrm{~T}_{x}$ obtained by etching submicron $\mathrm{Ti}_{3} \mathrm{AlC}_{2}$ grains grown in molten salt, and (d) TEM image of $\mathrm{Ti}_{4} \mathrm{~N}_{3} \mathrm{~T}_{x}$. Reproduced with permission from Ref. [125], (C) Royal Society of Chemistry 2016. (e) The cross-sectional microstructure of Au anchored on $\mathrm{Ti}_{3} \mathrm{C}_{2} \mathrm{~T}_{x}$ membrane. Reproduced with permission from Ref. [147], (C) Elsevier 2020. (f) TEM image of Pt anchored on $\mathrm{Ti}_{3} \mathrm{C}_{2} \mathrm{~T}_{x}$ nanosheet. Reproduced with permission from Ref. [148], C WILEY-VCH Verlag GmbH \& Co. KGaA, Weinheim, 2020.

noble metal ions into zero-valent metals, and the MXenes still remain their native morphologies at microsacle. There is no obvious change in the cross-section structure of MXene anchored by precious metal (Fig. 16(e)). Similarly, Pt nanoparticles $/ \mathrm{Ti}_{3} \mathrm{C}_{2} \mathrm{~T}_{x}$ composites were obtained by the direct self-reduction of $\mathrm{H}_{2} \mathrm{PtCl}_{6}$ with $\mathrm{Ti}_{3} \mathrm{C}_{2} \mathrm{~T}_{x}$ due to the strong reductive activity on the unsaturated $\mathrm{Ti}$ [148]. As shown in Fig. 16(f), there is a negligible change in the $\mathrm{Ti}_{3} \mathrm{C}_{2} \mathrm{~T}_{x}$ flakes after Pt single atoms anchoring on surface of MXene.

\section{3 Atomic structures of MXene under STEM}

The STEM technology provides a very powerful technique to image separate atoms in ultrathin $2 \mathrm{D}$ materials, especially after the introduction of aberration-corrected optics in this technique [149]. More importantly, atomic resolution images can be obtained in high-angle annular dark-field scanning transmission electron microscopy (HAADF-STEM) images where the contrast of the atoms is directly proportional to the atomic number of the atoms, thus making it easy to identify the defects, vacancies, and doping atoms in a nanosheet [150]. HF-etched MXene shows a layered structure with a nonuniform interlayer spacing, as verified by HAADF-STEM (Fig. 17(a)). The possible reason for inhomogeneous interlayer spacing is the different interactions between different terminations, which also imply the coexisting feature of functional groups. Annealing in ammonia or intercalation of cations, for example, $\mathrm{NH}_{4}{ }^{+}$can swell the structure of the MXene and increase the homogeneity of the layered domains, which is confirmed by HAADF-STEM image, as shown in Fig. 17(b). In HAADF-STEM images of the annealed $\mathrm{Ti}_{3} \mathrm{C}_{2} \mathrm{~T}_{x}$ MXene, the smooth and flat $\mathrm{Ti}_{3} \mathrm{C}_{2} \mathrm{~T}_{x}$ units are arranged periodically. Similar phenomenon is also observed in the $\mathrm{HCl} / \mathrm{LiF}$ etched MXene before and after annealing in ammonia [143].

It is experimentally observed that MXenes are not structurally perfect. As a typical example, Sang et al. [154] have demonstrated that terminal Ti atoms are somewhat lost, leaving Ti vacancies, as shown in Fig. 17(c). The $\mathrm{HF}$ concentration used in the etching process can tune the concentration of vacancies in single-layer $\mathrm{Ti}_{3} \mathrm{C}_{2} \mathrm{~T}_{x}$ MXene. High concentration structural $M$ vacancies could be generated by selectively etching off M1 (or M2) and A from the MAX phases with double $M$ elements, $(\mathrm{M} 1, \mathrm{M} 2)_{m} \mathrm{AX}_{m-1}$. For instance, most $\mathrm{Al}$ and $\mathrm{Sc}$ atoms are etched off by immersing $\left(\mathrm{Nb}_{2 / 3} \mathrm{Sc}_{1 / 3}\right)_{2} \mathrm{AlC}$ powders in concentrated $\mathrm{HF}$ solutions, leading to a great deal of $\mathrm{Nb}$ vacancies distributed in $\mathrm{Nb}_{4 / 3} \mathrm{CT}_{x}$ [151], as shown in Fig. 17(d). The M vacancies are not necessarily disordered, whose distribution highly depends on the distribution status of solution atoms in the MAX phases. In solution-atom ordered $\left(\mathrm{Mo}_{2 / 3} \mathrm{Y}_{1 / 3}\right)_{2} \mathrm{AlC}$ [155], $\left(\mathrm{W}_{2 / 3} \mathrm{Y}_{1 / 3}\right)_{2} \mathrm{AlC}$ [156], and $\left(\mathrm{Mo}_{2 / 3} \mathrm{Sc}_{1 / 3}\right)_{2} \mathrm{AlC}$ [29], $\mathrm{Y} / \mathrm{Sc}$ 


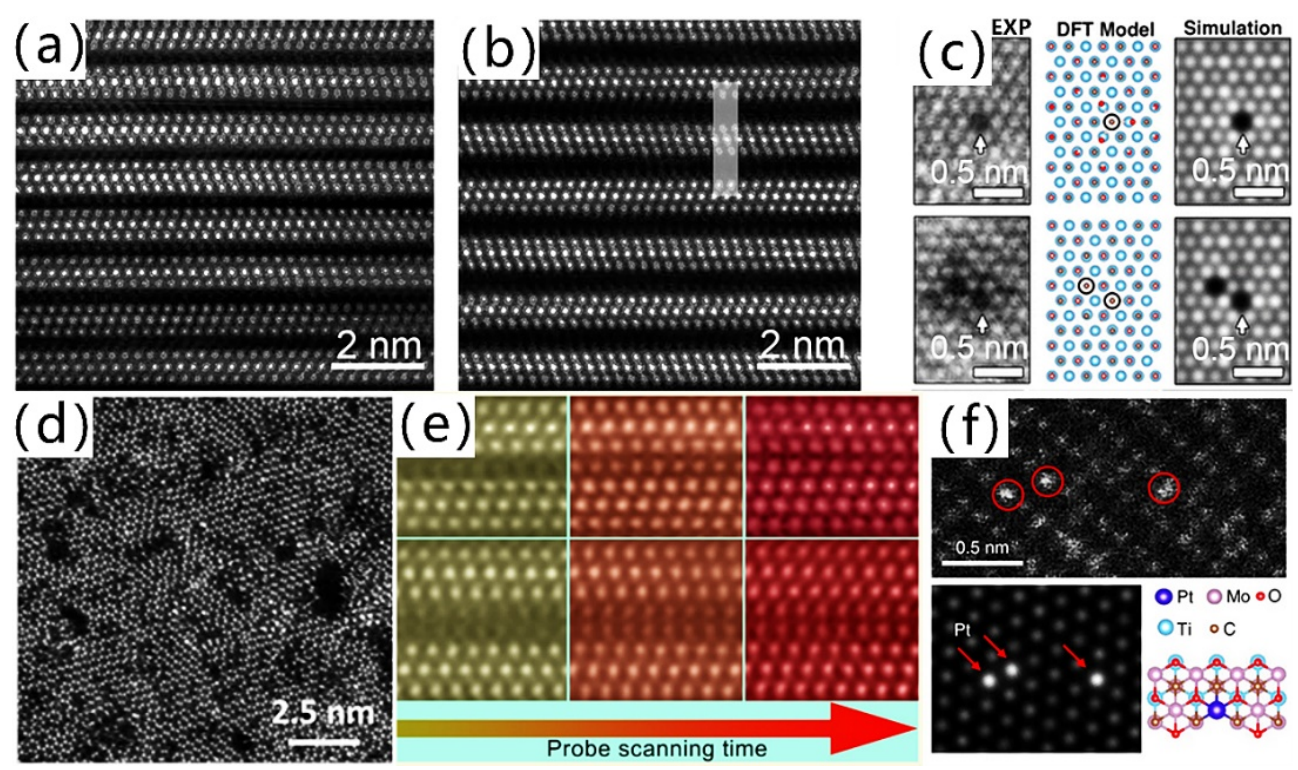

Fig. 17 Atomic structures of MXene in STEM. STEM images of (a) $\mathrm{Ti}_{3} \mathrm{C}_{2} \mathrm{~T}_{x}$ and (b) annealed $\mathrm{Ti}_{3} \mathrm{C}_{2} \mathrm{~T}_{x}$ in ammonia along the $[1 \overline{\overline{2}} 0]$ zone axis. Reproduced with permission from Ref. [143], (C) Royal Society of Chemistry 2020. (c) Comparison between experimental HAADF-STEM image, defect crystal structure determined from density functional theory (DFT), and simulated HAADF-STEM image of $\mathrm{V}_{\mathrm{Ti}}$ (top) and two adjacent $\mathrm{V}_{\mathrm{Ti}}$ within the same sublayer (bottom). (d) STEM micrograph of a $\mathrm{Nb}_{1.33} \mathrm{CT}_{x}$ single flake. Reproduced with permission from Ref. [151], (C) American Chemical Society 2018. (e) Atomic resolution HAADF-STEM images of one region in $\mathrm{Ti}_{3} \mathrm{C}_{2} \mathrm{~T}_{x}$ with the irradiation of electron probe. Reproduced with permission from Ref. [152], (C) American Chemical Society 2019. (f) Magnified HAADF-STEM image of $\mathrm{Mo}_{2} \mathrm{TiC}_{2} \mathrm{~T}_{x}-\mathrm{Pt}_{\mathrm{SA}}$ and its corresponding simulated image, and illustration of the structure of $\mathrm{Mo}_{2} \mathrm{TiC}_{2} \mathrm{~T}_{x}-\mathrm{Pt}_{\mathrm{SA}}$ showing the isolated $\mathrm{Pt}$ atoms. Reproduced with permission from Ref. [153], (C) The Author(s) 2018.

is ordered in the basal plane. Ordered $M$ vacancies are obtained by selectively etching off $\mathrm{Al}$ and $\mathrm{Sc} / \mathrm{Y}$ atoms. Utilizing STEM, Xia et al. [157] demonstrated the mechanism of ambient degradation of $\mathrm{Ti}_{3} \mathrm{C}_{2} \mathrm{~T}_{x}$ MXene where titanium oxide starts to grow in the vicinity of basal and edge atomic defects. Positively charged titanium vacancies induce the formation of amorphous carbon, while oxidation of Ti cations and the following formation of $\mathrm{TiO}_{2}$ occur at nearby positions. Meanwhile, $\mathrm{Nb}$ adatoms at the $\mathrm{Nb}_{2} \mathrm{CT}_{x}$ MXene surface contact with ambient $\mathrm{O}$, forming oxide nanoclusters that start to destroy local structural order with following degradation of the entire MXene sheet [158]. Zhang et al. [152] identified that electron probes can controllably impart metal atoms in the carbide slabs to the functional group slabs in MXene multilayers (Fig. 17(e)). Defects in MXenes aforementioned usually irreversibly react with active cations and lower the electrochemical performance when they are employed in batteries [159]. Therefore, Cheng et al. [160] have developed an effective strategy to achieve vanadium patching up Ti vacancies, giving rise to an enhancement of lithium ion storage capability. Additionally, $\mathrm{Mo}_{2} \mathrm{TiC}_{2} \mathrm{~T}_{x}$ MXene with Mo vacancies immobilizing single Pt atoms is an efficient catalyst for the hydrogen evolution reaction (Fig. 17(f)) [153]. The above results imply that defects give us a chance to control the surface properties of MXenes for energy storage.

\section{Preparation and characterization of MXene composites}

\section{1 Type of MXene composites}

MXene composites can be divided into two types: (1) MXene nanosheets are dispersed in other matrix materials as reinforcement; (2) MXene nanosheets are mixed with other materials to form composites without continuous matrix. The first type of composites are generally in dense bulk shape, including MXene/polymer composites [161,162], MXene/metal composites [113], and MXene/ceramic composites [163,164]. Considering the 2D nanoflake-like microstructure, MXenes are the ideal materials for the structural and functional reinforcements.

The second type of composites can be in the shape of dense/porous bulks, films, or powders. They are made by mixing MXene nanosheets with the second phase. 
There is no obvious matrix or reinforcement in the composites. The composites generally have better functional performance than pure MXene in many fields, such as batteries [165,166], capacitors [167], sensors [168,169], photocatalysts [170], adsorption [171], electromagnetic shielding, or wave absorption [172].

Because there are many reviews on the second type of MXene composites [173-175], and the function applications of MXene are reviewed in Sections 7 and 8 , this section mainly reviews the preparation and performance of the MXene composites reinforced by MXene nanosheets (the first type), with a short review on the preparation of MXene composites without matrix (the second type).

\section{2 Preparation and performance of bulk composites reinforced by MXenes}

MXenes have high chemical activity and abundant surface oxygen-containing functional groups, so they are easily oxidized at high temperatures. Since high temperatures are often involved in the preparation of metal-matrix or ceramic-matrix composites, MXenes have been most widely reported as reinforcements in the field of polymer-matrix composites.

\subsubsection{Polymer-matrix composites}

So far, a large number of hydrophilic or hydrolyzable polar polymers (such as poly(vinyl alcohol) (PVA) [176-178], polyurethane (PU) [179], polyethyleneimine (PEI) [180], and polyacrylamide (PAM) [181]) are mixed with the aqueous dispersion $[176,182]$ or polar dispersion (e.g., N,N-dimethylformamide (DMF) [183] and dimethylsulfoxide (DMSO) [184]) of MXene by solution blending to prepare composite materials. The solution blending method can be that the polymer is directly added to the dispersion of MXene, or the polymer and MXene are dispersed in the same or different miscible dispersions and finally mixed. For example, Ling et al. [176] prepared the MXene/PVA composite by mixing the water dispersion of MXene and PVA. Naguib et al. [181] dispersed MXene with DMSO and dissolved PAM with water, and then mixed the two mixtures or solutions to obtain the corresponding MXene/PAM composite, as shown in Fig. 18. When the polymer is weakly polar or non-polar, it is necessary to modify the surface of MXene to increase the dispersibility between the materials. For instance, Si et al. [185] modified the surface of MXene with long-chain cationic bromide to make it better dispersed in DMF,

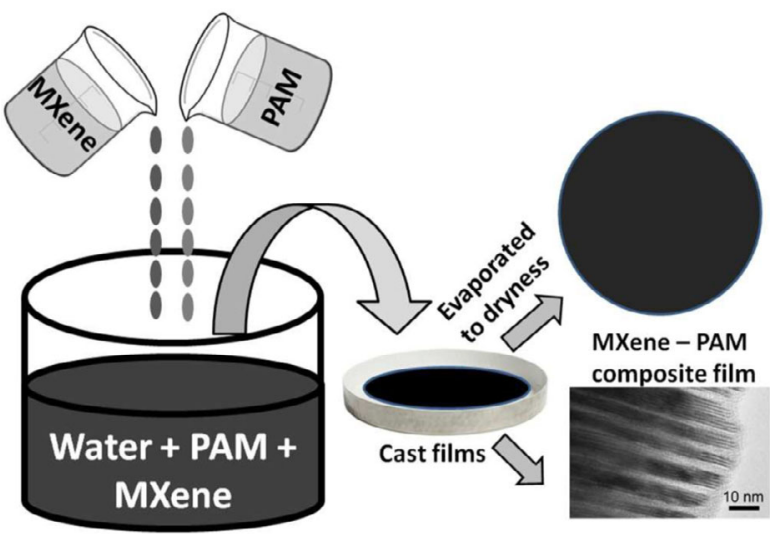

Fig. 18 Schematic of the synthesis of MXene-PAM nanocomposite films. Reproduced with permission from Ref. [181], (C) Royal Society of Chemistry 2016.

thereby improving the dispersibility of MXene in polystyrene (PS).

For hydrophobic polymers (such as epoxy resin), MXene is often prepared into powder (multilayer MXene powders obtained by vacuum drying or delaminated MXene powders obtained by freeze drying $[186,187])$, and then mixed with polymer materials. In order to improve the mixing efficiency, sometimes a volatile solvent such as acetone [188] is used to disperse the MXene powder and then mixed with the polymer materials. Wang et al. [189] prepared MXene powder by freeze-drying and then mixed the acetone suspension of MXene powder with epoxy resin to successfully prepare MXene/epoxy composite material. Carey et al. [190] prepared MXene/epoxy composite by adding multilayer MXene directly into an epoxy resin. However, the dried MXene was agglomerated and difficult to be dispersed. It is still a challenge to disperse a few-layered MXene in the obtained composite material. In order to find a better decentralization strategy, Liu et al. [161] put multilayer MXene in an epoxy curing agent for ultrasonic peeling to obtain a few-layered MXene uniformly dispersed curing agent solution, and then mixed with the epoxy resin liquid to prepare MXene/epoxy composite, as shown in Fig. 19. Similar to epoxy resin, the small molecule monomer, initiator, or curing agent is fully mixed with MXene nanosheets, and then the small molecules are polymerized into large molecules in-situ, which is also called in-situ polymerization blending. By this method, MXenes were mixed with many polymers to make composites, such as polyaniline (PANI) [191], polypyrrole (PPy) [192], and polydopamine (PDA) [193]. In-situ polymerization blending could improve the dispersion of MXene in 


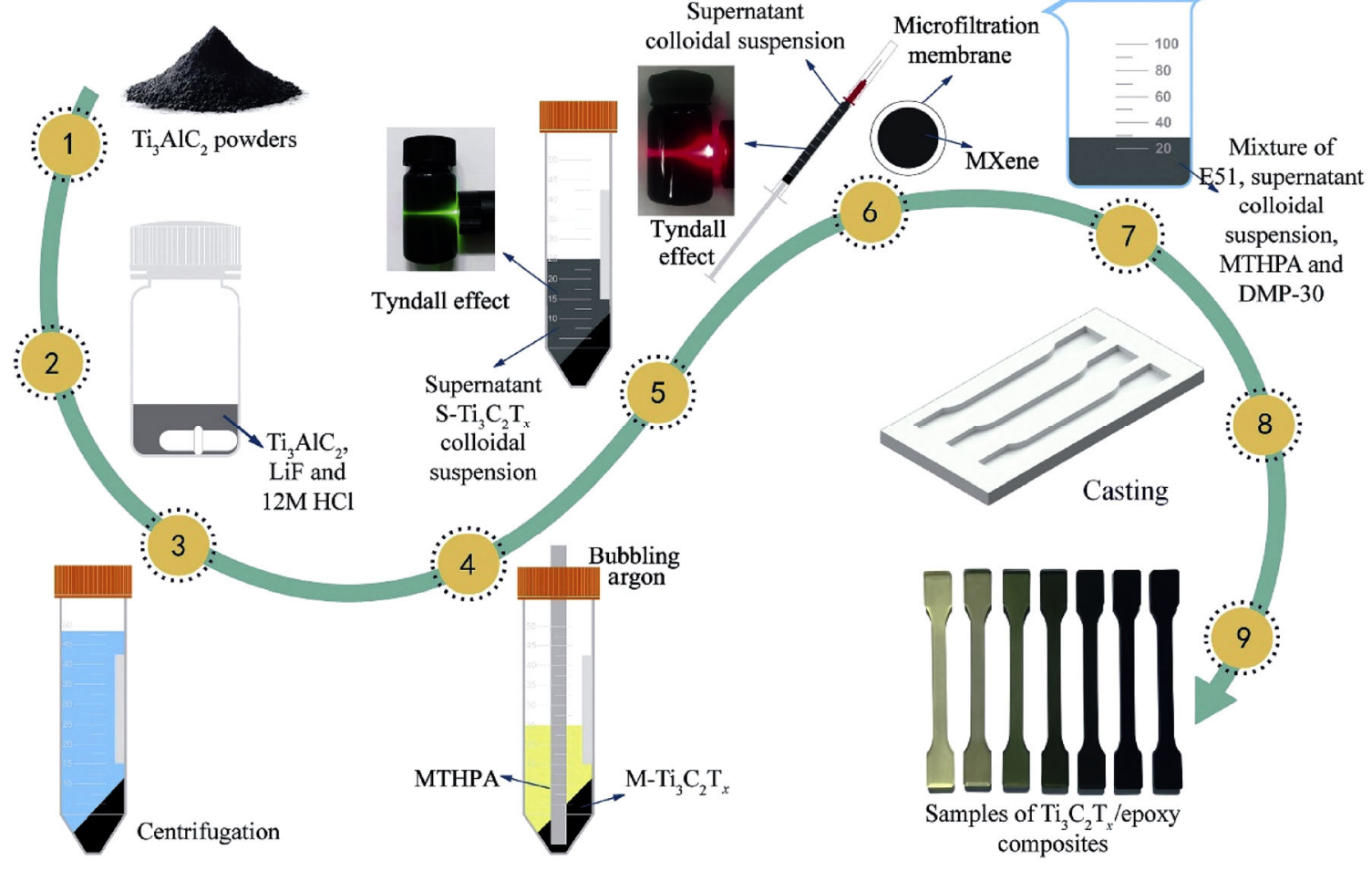

Fig. 19 Preparation process of MXene/epoxy composites. Reproduced with permission from Ref. [161], (C) The Author(s) 2020 .

polymers, strengthen the interfacial adhesion between MXene and the polymer matrix, and improve the electrical, thermal, and mechanical properties of polymers [194,195].

Melt blending technology can also be used to prepare MXene/polymer composites, as shown in Fig. 20. Sheng et al. [196] pretreated the MXene nanosheets with polyethylene glycol (PEG) by using water as the

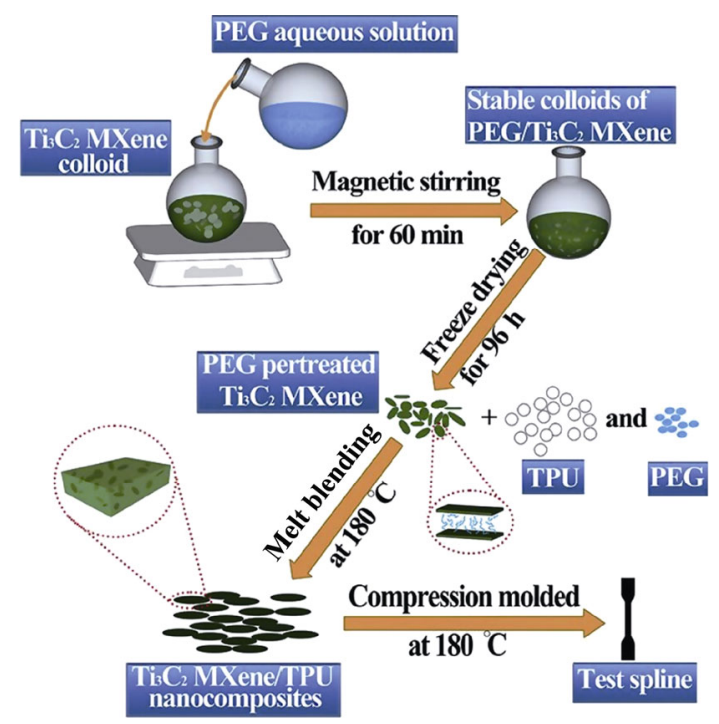

Fig. 20 Schematic of fabrication of MXene/TPU with melt blending. Reproduced with permission from Ref. [196], (C) Elsevier Ltd. 2019. processing solvent, and prepared a series of MXene/ polyurethane (TPU) nanocomposites showing uniform dispersion of MXene by melt blending TPU and PEG-pretreated MXene. High-speed mechanical agitation has also been used in the preparation of MXene/polymer composites, Zhang et al. [162] mixed ultrahigh molecular weight polyethylene (UHMWPE) powders and $\mathrm{Ti}_{3} \mathrm{C}_{2}$ powders with isopropyl(dioctylphosphate) titanate (DN-101) surface-modified homogeneously through a high-speed mixer, and then used a press vulcanizer to prepare the composites to study their thermal and mechanical properties.

\subsubsection{Metal-matrix composites}

Although MXenes have mostly been employed to reinforce polymer-matrix materials, agglomeration and poor wettability have been a big problematic challenge in metal matrix composites. Ball milling is a simple and efficient powder dispersion process. Hu et al. [113] prepared $\mathrm{Ti}_{3} \mathrm{C}_{2} \mathrm{~T}_{x} / \mathrm{Al}$ composites by pressureless sintering followed by hot extrusion technique. Firstly, the mixed powders were cold-pressed into green compacts. Then the green compacts were pressureless sintered at $650{ }^{\circ} \mathrm{C}$ for $1 \mathrm{~h}$ in $\mathrm{Ar}$, and finally subjected to hot extrusion at $460{ }^{\circ} \mathrm{C}$. The rich surface functional groups of $\mathrm{Ti}_{3} \mathrm{C}_{2} \mathrm{~T}_{x}$ enhance the wettability between $\mathrm{Ti}_{3} \mathrm{C}_{2} \mathrm{~T}_{x}$ and $\mathrm{Al}$, and 
improve the mechanical properties and friction resistance of the composite. However, the ball milling process has problems such as deformation of metal particles and damage to the morphology of the enhanced phase. Mai et al. [197] used a facile electrodeposition technique at room temperature to prepare $\mathrm{MXene} / \mathrm{Cu}$ composite coating materials, which improved the tribological properties of $\mathrm{Cu}$. For metals such as $\mathrm{Li}$ that cannot be used with ball milling or electrodeposition techniques, Kamysbayev et al. [198] heated lightweight metals Mg and $\mathrm{Li}$ to liquid metals gelled state, and then processed $\mathrm{Ti}_{3} \mathrm{C}_{2} \mathrm{~T}_{x}$ MXene powders in $\mathrm{Mg}-\mathrm{Li}$ alloy at $700{ }^{\circ} \mathrm{C}$ to prepare MXene reinforced metal matrix composites. Xue et al. [199] used $\mathrm{Sn}-\mathrm{Ag}-\mathrm{Cu}-\mathrm{Ti}_{3} \mathrm{C}_{2}$ composites as textured surfaces of CSS-42L bearing steel to improve the tribological properties at high temperatures. The composites were made from the mixtures of $\mathrm{Ti}_{3} \mathrm{C}_{2}$ and $\mathrm{Sn}-\mathrm{Ag}-\mathrm{Cu}$ by vacuum infiltration technology at $500{ }^{\circ} \mathrm{C}$.

\subsubsection{Ceramic-matrix composites}

Ceramic preparation processes are generally pressureless sintering, hot pressing sintering, and spark plasma sintering, which often involve high-temperature engineering. MXenes are prone to oxidation at high temperatures, resulting in less reported MXene reinforced ceramic composites. Fei et al. [163] used a ball mill to mix MXene and $\mathrm{Al}_{2} \mathrm{O}_{3}$ powders, and prepared MXene-reinforced ceramic materials after sintering; however, MXene was severely oxidized. Wozniak et al. [164] fabricated a MXene-reinforced silicon carbide ( $\mathrm{SiC}$ ) matrix nanocomposite by a powder metallurgy route. Guo et al. [200] successfully prepared MXene-reinforced ceramic materials using cold-press sintering technology, as shown in Fig. 21. The $\mathrm{Ti}_{3} \mathrm{C}_{2} \mathrm{~T}_{x}$ MXene and $\mathrm{ZnO}$ mixed powders were put into the steel die and heated at $300{ }^{\circ} \mathrm{C}$ under the press of $250 \mathrm{MPa}$ for $1 \mathrm{~h}$, and the densification of $\mathrm{ZnO}-\mathrm{Ti}_{3} \mathrm{C}_{2} \mathrm{~T}_{x}$ was obtained. The hardness and elastic modulus of the composite with only $0.5 \mathrm{wt} \% \mathrm{Ti}_{3} \mathrm{C}_{2} \mathrm{~T}_{x}$ MXene increased by $40 \%-50 \%$.

Besides structural ceramics, MXene 2D sheets also can be used to made functional ceramic-matrix composites. Lu et al. [201] used a self-assembly protocol to deliver a homogeneous dispersion of $\mathrm{Ti}_{3} \mathrm{C}_{2}$ MXene in $(\mathrm{Bi}, \mathrm{Sb})_{2} \mathrm{Te}_{3}$ (BST) matrix. By controlling the $\mathrm{pH}$ value to 3.0 , the zeta potential for BST nanoplates and MXene nanosheets are +34 and -39 , respectively. Therefore, the two different nanoparticles assembled spontaneously. The MXene/BST composite powders were densified by SPS at $693 \mathrm{~K}$. After sintering, the relative density values for all specimens are higher than $94 \%$. The incorporation of MXene into BST can simultaneously achieve the improved power factor and greatly reduced thermal conductivity. A peak thermoelectric figure of merit (ZT) of up to 1.3 and an average $\mathrm{ZT}$ value of 1.23 from 300 to $475 \mathrm{~K}$ are realized for the $1 \mathrm{vol} \%$ MXene/BST composite. Combined with the high-performance composite and rational device design, a record-high thermoelectric conversion efficiency of up to $7.8 \%$ is obtained under a temperature gradient of $237 \mathrm{~K}$.

\section{3 Preparation of MXene composites without continuous matrix}

MXenes have a good dispersion uniformity in water due to their hydrophilic functional groups such as $-\mathrm{OH}$. Moreover, water is usually used to obtain MXene colloids in the process of preparing few-layer or single-layer MXene. Therefore, MXene is often doped with other materials in aqueous solution or polar solvent. Thereafter, the mixed solutions were processed by vacuum filtration, spraying coating, spin coating, layer-by-layer (LbL) self-assembly, wet-spinning, and printing (inkjet printing and $3 \mathrm{D}$ printing) to obtain green bodies with desired shape. Then the green bodies were dried by vacuum drying, freeze-drying, or inert gas blowing to obtain the composites. Stirring or ultrasonic dispersion is the simplest method. Xu et al. [202] used simple ultrasound to mix the GO water dispersion and MXene dispersion for $1 \mathrm{~h}$. GO/ $\mathrm{Ti}_{3} \mathrm{C}_{2} \mathrm{~T}_{x}$ dispersion was filtered by vacuum-assisted method, and then reduced to porous $\mathrm{rGO} / \mathrm{Ti}_{3} \mathrm{C}_{2} \mathrm{~T}_{x}$ films. Yue et al. [203] mixed

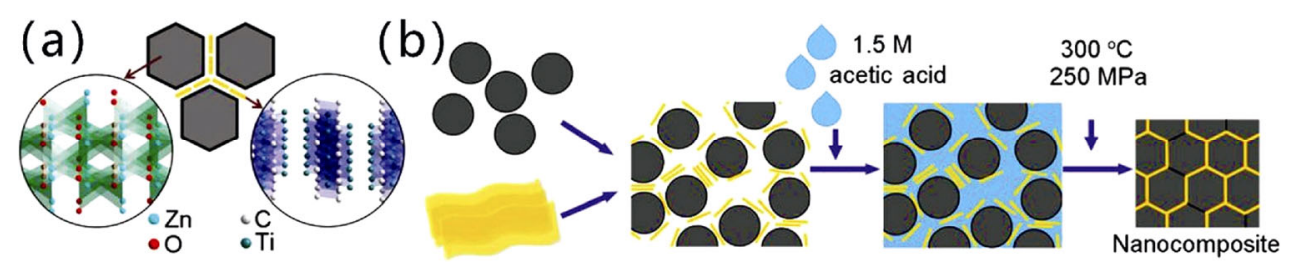

Fig. 21 Schematic illustration showing the fabrication process via cold sintering. Reproduced with permission from Ref. [200], (C) WILEY-VCH Verlag GmbH \& Co. KGaA, Weinheim 2018. 
GO solution and MXene solution and then further sonicated to further obtain a homogeneous solution. Finally, the solution was freeze-dried to obtain 3D composite aerogel. Hydrothermal method is also a simple method. Xu et al. [204] synthesized the petal-like $\mathrm{MoS}_{2} / \mathrm{MXene}$ composite by one-step hydrothermal method, and the electrode capacity of the composite was significantly improved. In addition, Cao et al. [205] manufactured an ultrathin and flexible carbon nanotubes/ MXene/cellulose nanofibers composite paper through alternate vacuum-assisted filtration process for electro magnetic interference (EMI) shielding research. Layered MXene composites can also be realized by spraying coating, spin coating, and LbL self-assembly, and the thickness is controllable. Shen et al. [206] spin-coated the PEBA solution on the surface of the MXene nanofilm for five cycles to produce gas separation films. MXene solution is negatively charged, so it can self-organize with positively charged materials through electrostatic LbL. Tian et al. [207] used alternately deposition of positively charged material PEI and negatively charged material MXene to manufacture supercapacitors and found that the performance was greatly improved compared with non-LbL structures. Layer thickness can be easily controlled by controlling the number of spin coating or alternate deposition. Yang et al. [208] got flexible and highly conductive MXene/rGO hybrid fibers through wet-spinning method. Printing can realize the establishment of specific pattern and structure. Rastin et al. [209] formulated a new conductive cell-laden bioink composed of $\mathrm{Ti}_{3} \mathrm{C}_{2}$ MXene nanosheets/hyaluronic acid/alginate, and demonstrated its performance of extrusion-based 3D bioprinting.

\section{4 Characterization of MXene composites}

There are many methods for composite characterization, and herein we only introduce the special methods for the characterization due to the introduction of MXene in the composites. First, the $c$-lattice parameters $(c$-LP) for the MXene in the composites are usually considerably in the preparation processing in which the X-ray diffraction (XRD) always can find small changes. Second, the functional groups on the MXene surface are usually changed due to the combination of other phases. The X-ray photoelectron spectroscopy (XPS) is commonly used to track changes in MXene surface functional groups during composite preparation.

During composite preparation, phase stability is the main issue to be considered. After the preparation of the MXene composites, structural changes during service life of the composites need to be considered. The structure change affects the performance of the composites. Generally, MXenes have good thermal conductivity. MXene composites, especially MXene-reinforced polymer composites, often need to be tested for thermal properties. Thermal analyzers are commonly used to test thermogravimetry, and electricity heat drum wind-drying oven is used for thermal oxidative aging test. Dynamic thermomechanical analyzer (DMA) was used to detect the creep properties and glass transition temperature of composite materials [210]. The friction coefficient can be tested by universal friction and wear testing machine [162].

MXenes with 2D sheet structures have good rigidity and strength to improve the mechanical strength of the materials. For example, the addition of a small amount of MXene can improve the tensile properties, bending properties, and fracture toughness of epoxy [176], and increase the hardness of ceramic materials [189], etc. Typically, the universal testing machine is used to test the tensile, compression, bending, fracture toughness, and other mechanical properties of composite materials. The hardness tester is used to characterize the hardness of composite materials. DMA also can be considered for the characterization of the storage modulus and other dynamic mechanical properties of MXene composite materials.

\section{Application of MXenes in energy storage}

MXenes can be applied in many areas as functional materials with high performance. In this review, we focused in two most important areas: energy storage (Section 7) and electromagnetic interference shielding (Section 8).

For the purpose to apply MAX phases as anode of LIBs, A element was selectively etched off from MAX phase to generate the room for lithium storage. Thus MXenes were created as anode of LIBs [6,7]. Therefore, energy storage (LIBs, sodium-ion batteries, super-capacitors, etc.) is the first and most extensively researched area for MXenes' application.

\section{1 LIB}

LIB was first introduced by Sony Corporation in 1991. LIB is the secondary battery (rechargeable battery) that works by moving lithium ions between the positive 
and negative electrodes. LIBs have been widely used in portable electronics, electric vehicles, and many other fields due to their high energy density and high reliability [211,212]. According to the results of theoretical calculation, the LIB can reach a high theoretical specific energy density of $421 \mathrm{Wh} \cdot \mathrm{kg}^{-1}$ [213]. However, the energy density of commercial LIBs is far from theoretical value. At the same time, the cycling stability of LIBs has been waiting for further improvement. In order to solve these problems, in recent years, researchers devote to exploring and developing new anode materials with good cycling stabilities and higher specific capacities rather than current graphite or lithium titanate anodes, which showed high theoretic specific capacities of 372 and $175 \mathrm{mAh} \cdot \mathrm{g}^{-1}$, respectively [214,215].

MXenes are considered to be a promising electrode material for LIBs due to their high specific surface area, good conductivity, and fast diffusion rate of lithium ions [8,122]. In 2012, Naguib et al. [7] firstly reported the $\mathrm{Ti}_{2} \mathrm{C}$ MXene as anode materials for LIB with a stable capacity of $225 \mathrm{mAh} \cdot \mathrm{g}^{-1}$ at $0.04 \mathrm{C}$. Cyclic voltammetry (CV) curves demonstrated lithium intercalation and extraction peaks at 1.6 and $2 \mathrm{~V}$, respectively.

Based on the theoretical calculations, Tang et al. [216] concluded that the theoretical capacity of $\mathrm{Ti}_{3} \mathrm{C}_{2}$ MXene (without any functional group) was $320 \mathrm{mAh} \cdot \mathrm{g}^{-1}$. However, once the surface of MXene was covered with functional groups ( $\mathrm{F}$ or $\mathrm{OH})$, the theoretical capacity was significantly reduced to 130 or $67 \mathrm{mAh} \cdot \mathrm{g}^{-1}$. It was suggested that MXene with pure F groups may be a way to further enhance its specific capacities. In the preparation process, MXene inevitably contains $\mathrm{O}, \mathrm{OH}$, F, and other surface functional groups. In 2014, Sun et al. [111] synthesized an exfoliated $\mathrm{Ti}_{3} \mathrm{C}_{2}$ MXene with $\mathrm{F}$ termination as anode achieved $123.6 \mathrm{mAh} \cdot \mathrm{g}^{-1}$ at $1 \mathrm{C}$, which is close to the theoretical capacity of $\mathrm{Ti}_{3} \mathrm{C}_{2} \mathrm{~F}_{2} \mathrm{Li}$ $\left(130 \mathrm{mAh} \cdot \mathrm{g}^{-1}\right)$. MXenes were prepared by hydrofluoric acid or fluorine salt solution etching, resulting in abundant functional groups $(\mathrm{OH}, \mathrm{F}$, or $\mathrm{O})$ on the surface of MXenes. These functional groups have a great influence on the physical and chemical properties of MXenes. Therefore, surface design and structure adjustment are effective strategies to obtain electrode materials with excellent electrochemical performance for LIBs.

These results are encouraging and suggest that the other MXenes such as $\mathrm{Ta}_{4} \mathrm{C}_{3},\left(\mathrm{Ti}_{0.5}, \mathrm{~V}_{0.5}\right)_{2} \mathrm{C},\left(\mathrm{Ti}_{0.5}, \mathrm{~V}_{0.5}\right)_{3} \mathrm{C}_{2}$, $\left(\mathrm{Ti}_{0.5}, \mathrm{Nb}_{0.5}\right)_{2} \mathrm{C},\left(\mathrm{V}_{0.5}, \mathrm{Cr}_{0.5}\right)_{3} \mathrm{C}_{2},\left(\mathrm{Nb}_{0.5}, \mathrm{~V}_{0.5}\right)_{4} \mathrm{C}_{3}, \mathrm{Mo}_{2} \mathrm{TiC}_{2} \mathrm{~T}_{x}$,
$\mathrm{Mo}_{2} \mathrm{Ti}_{2} \mathrm{C}_{3} \mathrm{~T}_{x}, \mathrm{Cr}_{2} \mathrm{TiC}_{2} \mathrm{~T}_{x}, \mathrm{Ti}_{3} \mathrm{CN}, \mathrm{Nb}_{2} \mathrm{C}, \mathrm{V}_{2} \mathrm{C}, \mathrm{Nb}_{4} \mathrm{C}_{3}$, $\mathrm{Mo}_{2} \mathrm{C}, \mathrm{Zr}_{3} \mathrm{C}_{2}, \mathrm{Hf}_{3} \mathrm{C}_{2}$, and $\mathrm{Ti}_{4} \mathrm{~N}_{3}$, could be used as $\mathrm{Li}^{+}$ intercalation electrode in LIBs. Sun et al. [217] studied the lithium storage performance of eight MXenes $\left(\mathrm{V}_{2} \mathrm{C}\right.$, $\mathrm{Cr}_{2} \mathrm{C}, \mathrm{Ta}_{2} \mathrm{C}, \mathrm{Sr}_{2} \mathrm{C}, \mathrm{Ti}_{2} \mathrm{C}, \mathrm{Zr}_{2} \mathrm{C}, \mathrm{Nb}_{2} \mathrm{C}$, and $\mathrm{Hf}_{2} \mathrm{C}$ ) with $\mathrm{O}$ group through theoretical calculation, and predicted that $\mathrm{V}_{2} \mathrm{C}$ MXene with $-\mathrm{O}$ termination had the best lithium storage performance $\left(735 \mathrm{mAh} \cdot \mathrm{g}^{-1}\right)$ in these eight MXenes. Hence, Naguib et al. [133] synthesized $\mathrm{V}_{2} \mathrm{C}$ MXene by selective etching of $\mathrm{V}_{2} \mathrm{AlC}$ with $\mathrm{HF}$ etching agent. The obtained $\mathrm{V}_{2} \mathrm{C}$ MXene exhibited great potential as electrode materials for LIBs with capacity of $260 \mathrm{mAh} \cdot \mathrm{g}^{-1}$ at $1 \mathrm{C}$ rate. Subsequently, Liu et al. [118] prepared $\mathrm{V}_{2} \mathrm{C}$ MXene with high purity via etching $\mathrm{V}_{2} \mathrm{AlC}$ with sodium fluoride and hydrochloric acid at $90{ }^{\circ} \mathrm{C}$ for $72 \mathrm{~h}$. Compared with the HF etching route, the $\mathrm{NaF}-\mathrm{HCl}$ etching approach is a milder etching method and produces a purer $\mathrm{V}_{2} \mathrm{C}$ MXene. The obtained highly pure $\mathrm{V}_{2} \mathrm{C}$ MXene exhibited superior electrochemical performance as anode of LIBs with specific capacity of $260 \mathrm{mAh} \cdot \mathrm{g}^{-1}$ at the current density of $370 \mathrm{~mA} \cdot \mathrm{g}^{-1}$, as shown in Fig. 22. The purity of $\mathrm{V}_{2} \mathrm{C}$ is also an important parameter affecting the electrochemical performance of the $\mathrm{V}_{2} \mathrm{C}$ MXene-based electrode material. It is an effective strategy to explore a new method to prepare highly pure MXene as anode material for LIBs.

In 2021, Zhang et al. [218] synthesized N/S co-doped $\mathrm{V}_{2} \mathrm{C}$ MXene by an annealing method. As anode for LIB, the obtained N/S co-doped $\mathrm{V}_{2} \mathrm{C}$ MXene demonstrated outstanding electrochemical performance with a highly reversible capacity of $590 \mathrm{mAh} \cdot \mathrm{g}^{-1}$ after 100 cycles at the current density of $0.1 \mathrm{~A} \cdot \mathrm{g}^{-1}$. As increased the current density to $2 \mathrm{~A} \cdot \mathrm{g}^{-1}$, the specific capacity still reaches $298 \mathrm{mAh} \cdot \mathrm{g}^{-1}$ after 300 cycles, which is superior to the previously reported $\mathrm{V}_{2} \mathrm{C}$ MXene-based anode. Not just $\mathrm{N}$ and $\mathrm{S}$, but other heteroatoms (e.g., O, B, or P) doping could also decorate the surface chemical functionalities, which is beneficial to reducing the band gap of MXene, thereby reducing its resistance and accelerating the diffusion of electrolyte ions on the surface of MXenes.

Naguib et al. [133] reported a $2 \mathrm{D} \mathrm{Nb}_{2} \mathrm{C}$ material, which was synthesized by treating $\mathrm{Nb}_{2} \mathrm{AlC}$ in aqueous HF. The obtained $\mathrm{Nb}_{2} \mathrm{C}$ MXene exhibited excellent reversible specific capacity $\left(170 \mathrm{mAh} \cdot \mathrm{g}^{-1}\right.$ at $1 \mathrm{C}$ rate $)$ at low lithiation potentials. The $\mathrm{Nb}_{2} \mathrm{C}$ MXene could maintain high specific capacity at a high cycling rate 

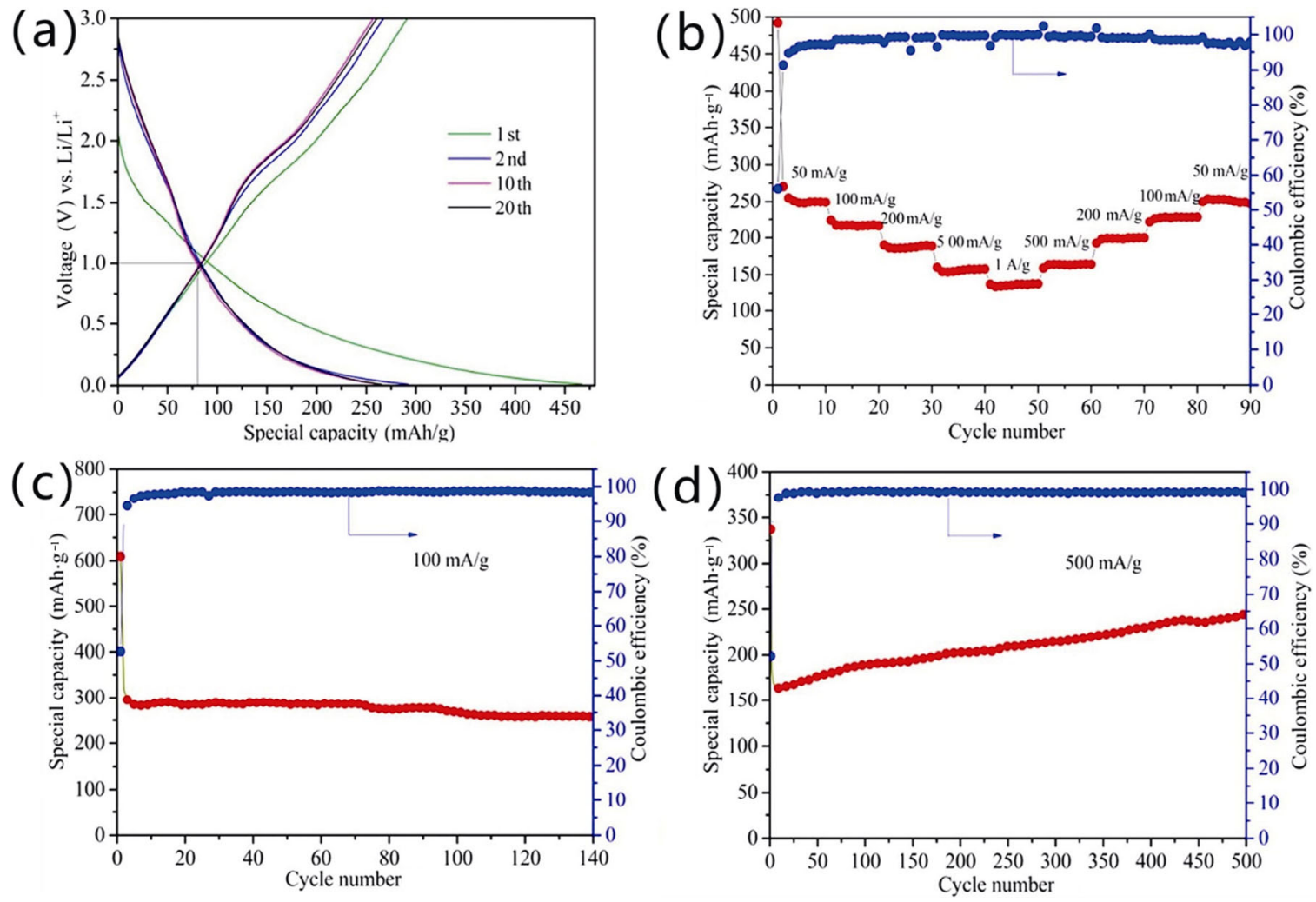

Fig. 22 (a) Voltage profile of $\mathrm{V}_{2} \mathrm{C}$ MXene; (b) specific capacity of $\mathrm{V}_{2} \mathrm{C}$ MXene at 50, 100, 200, and 500 and $1000 \mathrm{~mA} \cdot \mathrm{g}^{-1}$; (c, d) cycling performance of $\mathrm{V}_{2} \mathrm{C}$ MXene at 100 and $500 \mathrm{~mA} \cdot \mathrm{g}^{-1}$, respectively. Reproduced with permission from Ref. [118], (C) The Electrochemical Society 2017.

(10 C), indicating fast lithium ion diffusion between MXene layers.

In 2015, Jin et al. [219] introduced a new ternary nanolaminated carbide MAX phase, i.e., $\mathrm{Mo}_{2} \mathrm{Ga}_{2} \mathrm{C}$, which shows a hexagonal structure with two Ga layers, and exhibits similar chemical and physical properties to other MAX phases. Hence, $\mathrm{Mo}_{2} \mathrm{Ga}_{2} \mathrm{C}$ MAX phases can be etched to obtain $\mathrm{Mo}_{2} \mathrm{C}$ MXene. Herein, Mei et al. [220] reported a UV-induced selective etching approach to prepare $\mathrm{Mo}_{2} \mathrm{C}$ MXene from $\mathrm{Mo}_{2} \mathrm{Ga}_{2} \mathrm{C}$ MAX phase. The obtained fluorine-free $\mathrm{Mo}_{2} \mathrm{C}$ MXene as anode materials for LIBs exhibited high specific capacity $\left(\sim 150 \mathrm{mAh} \cdot \mathrm{g}^{-1}\right)$, good rate performance, and long cycle life. In addition, the fabricated flexible $\mathrm{Mo}_{2} \mathrm{C}$ MXene-based battery devices demonstrated good specific capacity retention in the state of muti-angle bending. This work introduces a new method for the preparation of fluorine-free $\mathrm{Mo}_{2} \mathrm{C}$ MXene materials by UV-induced selective etching method, which can also be extended to the preparation of other new MXenes.

\section{2 Supercapacitors}

Supercapacitors (SCs) have attracted attention due to its high-power density, fast charge-discharge rate, easy maintenance, wide operating temperature range, excellent cycle life, and high security [221,222]. Therefore, SCs have been widely used in electric vehicles, portable electronics, military products, intelligent instruments, and storage power stations. Generally, based on the energy storage mechanism, SCs can be divided into two types: electrical double layer capacitors (EDLC, by electrostatic adsorption) and faradic pseudocapacitors (by rapid surface redox reactions). Besides the above two types of SCs, hybrid supercapacitors are called the third type of SCs, which is a combination of EDLCs and LIBs. This hybrid SC not only has the characteristics of EDLC (fast charging and long cycle life), but also has the advantages of high energy density of LIB.

2D MXenes combine the metallic conductivity of transition metal carbides with the hydrophilic nature of their hydroxyl or oxygen terminated surfaces. These properties make MXene as a promising electrode for SC applications. First-principles calculations based on DFT theory revealed that MXene sheets had high mechanical strength when they were drawn along the basal plane, which prevented structural collapse during 
charge and discharge processes, resulting in good cyclic stability of MXenes. In 2013, Lukatskaya et al. [223] first explored the application of MXene as an electrode material for SCs. In this work, titanium carbide MXene was investigated in various electrolytes, and delivered high specific volumetric capacitance of $300 \mathrm{~F} \cdot \mathrm{cm}^{-3}$, which is superior than that of carbon materials. This work provides a basis for exploring a big family of 2D carbides and carbonitrides MXenes in electrochemical energy storage applications using single and multivalent ions.

Hu et al. [224] prepared a binder-free $\mathrm{Ti}_{3} \mathrm{C}_{2}$ MXene film and evaluated it in $1 \mathrm{M} \mathrm{H}_{2} \mathrm{SO}_{4}$ electrolyte, which showed a volumetric capacitance of $226 \mathrm{~F} \cdot \mathrm{cm}^{-3}$ at a scan rate of $2 \mathrm{mV} \cdot \mathrm{s}^{-1}$. The lower resistance of $\mathrm{Ti}_{2} \mathrm{CT}_{x}$ MXene, due to its thinner lamellae than $\mathrm{Ti}_{3} \mathrm{C}_{2} \mathrm{~T}_{x}$ MXene, means that $\mathrm{Ti}_{2} \mathrm{CT}_{x}$ MXene has a higher specific capacity than $\mathrm{Ti}_{3} \mathrm{C}_{2} \mathrm{~T}_{x}$ MXene. Rakhi et al. [142] synthesized $\mathrm{Ti}_{2} \mathrm{CT}_{x}$ MXene by an HF-etching route from $\mathrm{Ti}_{2} \mathrm{AlC}$ max phase and annealed the $\mathrm{Ti}_{2} \mathrm{CT}_{x}$ MXene in air, Ar, $\mathrm{N}_{2}$, and $\mathrm{N}_{2} / \mathrm{H}_{2}$ atmosphere for $2 \mathrm{~h}$ to remove the functional groups on the surface of MXenes. The as-prepared $\mathrm{Ti}_{2} \mathrm{CT}_{x}$ MXene delivered specific capacitance of $51 \mathrm{~F} \cdot \mathrm{g}^{-1}$ at $1 \mathrm{~A} \cdot \mathrm{g}^{-1}$ in $30 \mathrm{wt} \% \mathrm{KOH}$ electrolyte.

Generally, most of the electrolyte solutions used in previous studies consist of dangerous, toxic, and expensive organic and inorganic chemicals. However, if these SC devices are leaked during use, they will cause harm to human body and pollute the environment. Moreover, most of the electrode materials in the acid or alkaline electrolytes are not stable for a long time. However, most electrode materials can maintain good chemical stability in neutral solution. Generally, lithium, potassium, and sodium salts provide low ionic resistivity, fast ion diffusion kinetics, and are friendly to human body and environment. Therefore, as a rich reserve of seawater, it has great potential as an electrolyte for SCs.

The electrochemical properties of $\mathrm{Ti}_{3} \mathrm{C}_{2}$ MXene were evaluated using seawater as an electrolyte by a three-electrode system, as shown in Fig. 23 [225]. Figure 23(a) shows the $\mathrm{CV}$ curves of $\mathrm{Ti}_{3} \mathrm{C}_{2}$ MXene at various scan rates in seawater electrolyte. All the CV curves retain nearly rectangular loops, which are caused by the electro-sorption/desorption of $\mathrm{Na}^{+}$cations from seawater electrolyte. The specific capacitances of $\mathrm{Ti}_{3} \mathrm{C}_{2}$ MXene were calculated from the discharge curves (Fig. 23(b)). Specific capacitance reached $67.7 \mathrm{~F} \cdot \mathrm{g}^{-1}$ at $1 \mathrm{~A} \cdot \mathrm{g}^{-1}$, corresponding to the volumetric specific capacitance of $121.8 \mathrm{~F} \cdot \mathrm{cm}^{-3}$ (Fig. 23(c)). $\mathrm{Ti}_{3} \mathrm{C}_{2}$ electrodes were tested at a high current density of $10 \mathrm{~A} \cdot \mathrm{g}^{-1}$ for 5000 cycles. $\mathrm{The}^{\mathrm{Ti}} \mathrm{C}_{2}$ electrode still exhibits nearly 96.6\% retention (Fig. 23(d)), demonstrating excellent cycle stability in seawater electrolyte, which is comparable to that reported MXene-based SCs. This
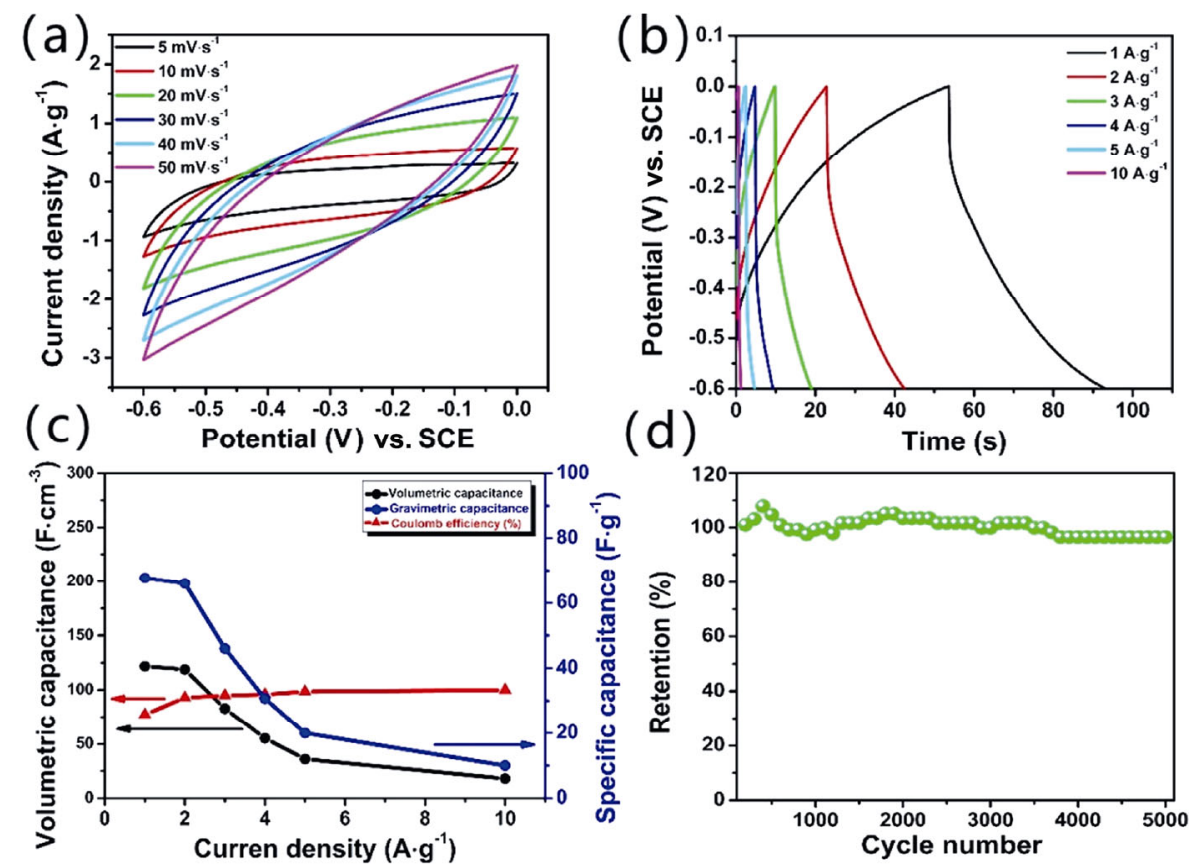

Fig. 23 (a) CV curves at various scan rates, (b) galvanostatic charge/discharge curves at different current densities, (c) specific capacitance and coulombic efficiency at various current densities, and (d) cycling performance of the $\mathrm{Ti}_{3} \mathrm{C}_{2}$ electrode at a current density of $10 \mathrm{~A} \cdot \mathrm{g}^{-1}$. Reproduced with permission from Ref. [225], C Royal Society of Chemistry 2018. 
excellent configuration can still be applied to other MXenes. He et al. [226] developed a $\mathrm{NaF}+\mathrm{HCl}$ etching to obtain highly pure $\mathrm{V}_{2} \mathrm{C}$ MXene. The $\mathrm{V}_{2} \mathrm{C}$ MXene also delivered a high capacitance of $317.8 \mathrm{~F} \cdot \mathrm{cm}^{-3}$ in seawater electrolyte.

There have been many reports of nitrogen-doped graphene used as electrode materials for SCs. Based on the same principle, nitrogen doped MXene has been reported to be used as electrode materials for SCs and obtains enhanced electrochemical performance. Wen et al. [227] demonstrated a facile method to synthesize $\mathrm{N}$-doped $\mathrm{Ti}_{3} \mathrm{C}_{2}$ MXene by post-etch annealing $\mathrm{Ti}_{3} \mathrm{C}_{2}$ in ammonia. The doping of $\mathrm{N}$ to replace $\mathrm{C}$ atoms in the MXene properly increased the interlayer spacing between $\mathrm{Ti}_{3} \mathrm{C}_{2}$ nanosheets and narrowed the band gap of MXene, and further improved its electrical conductivity. The doping of elemental nitrogen also provided more active sites. These benefits resulted in a 4.6-fold increase in the capacitance of $\mathrm{N}$-doped MXene compared to pristine MXene.

With the development of science and technology, the demand for flexible wearable electronic products is more and more vigorous. Flexible and wearable SC devices have recently attracted more and more attention. Yu et al. [228] demonstrated a route to using $2 \mathrm{D} \mathrm{Ti}_{3} \mathrm{C}_{2}$ MXene as a flexible, conductive, and electrochemically active binder for one-step assembly of MXene-bonded activated carbon as a flexible electrode for SCs in an organic electrolyte, as shown as Fig. 24. As a result, the flexible MXene-based electrode delivered a high specific capacitance of $126 \mathrm{~F} \cdot \mathrm{g}^{-1}$ at $0.1 \mathrm{~A} \cdot \mathrm{g}^{-1}$ and with a retention of $57.9 \%$ at a high current density of $100 \mathrm{~A} \cdot \mathrm{g}^{-1}$ in an organic electrolyte.

The development of high capacitance and low-cost
MXene-based electrodes will promote the wide application of such SCs. To explore a method for preparing a low-cost, flexible, tough, and upgradeable SC electrode, the silk was directly carbonized to make a conductive independent textile substrate [229]. By gently baking the surfactant-free $\mathrm{Ti}_{3} \mathrm{C}_{2}$ nanosheet suspension loaded on the carbonized silk, a uniform, nanometer thick bonding coating of $\mathrm{Ti}_{3} \mathrm{C}_{2}$ flakes was formed on the conductive fabric support, forming a MXene-coated flexible textile electrode. The assembled electrode exhibited a high areal capacitance of $362 \mathrm{mF} \cdot \mathrm{cm}^{-2}$ with excellent cycling stability and outstanding foldability.

\section{3 New secondary battery}

As a rechargeable secondary battery, LIBs have achieved great commercial success and are widely used in portable electronic products, electric vehicles, and the defense industry, etc., for their advantages of high operating voltage, high energy density, long cycle life, and environmental friendliness [175,230]. However, shortage of lithium resources can be a future problem. It is urgent to develop a new generation of rechargeable secondary batteries with low cost and high performance [231]. Na and K not only have similar chemical and physical properties to $\mathrm{Li}$, but also have the economic advantages such as abundant reserves and low cost. Therefore, sodium ion batteries (SIBs) and potassium ion batteries (PIBs) are considered as primary alternatives to LIBs. However, the radii of $\mathrm{K}^{+}(1.38 \AA)$ and $\mathrm{Na}^{+}$ $(1.02 \AA)$ are much larger than that of $\mathrm{Li}^{+}(0.76 \AA)$, which leads to slow reaction kinetics and huge volume changes when potassium and sodium ions are repeatedly inserted/extracted from electrodes, causing irreparable

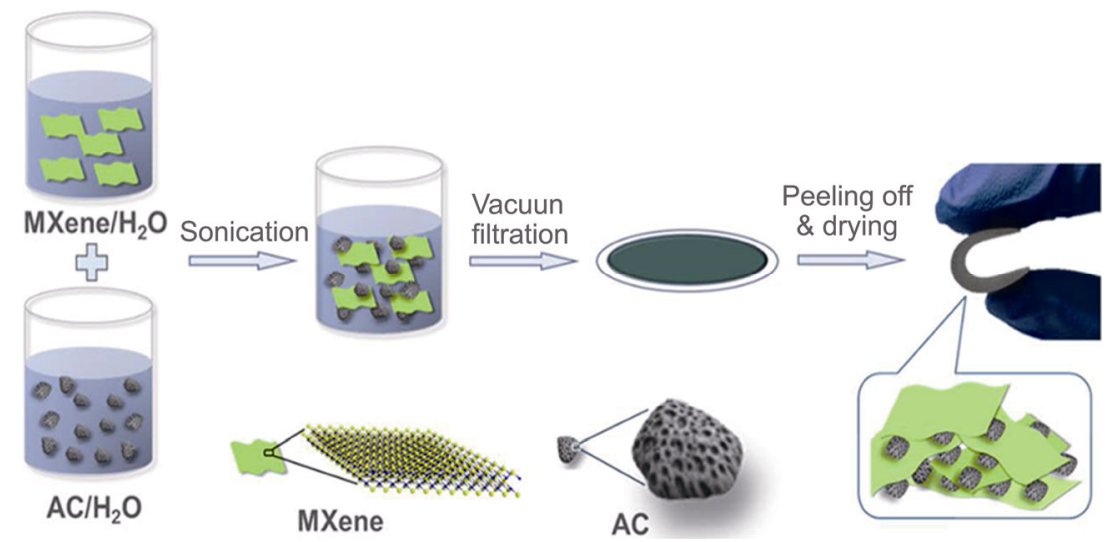

Fig. 24 Schematic diagram for the fabrication of MXene-bonded AC films, including mixing MXene flakes and AC particles in water, vacuum-assisted filtration, peeling-off, and drying. Reproduced with permission from Ref. [228], (C) American Chemical Society 2018. 
damage to their structure. Hence, design and development of suitable electrode materials for SIB and PIB is the key to solve this problem. 2D MXene materials provide many merits as electrode materials for alkali metal-ion batteries due to their large number of accessible active sites, tunable structure, and chemical compositional diversity [232]. MXenes have rapid electrolyte ion diffusion features, whose diffusion kinetics is quite high for many electrolyte ions such as $\mathrm{Li}^{+}, \mathrm{Na}^{+}, \mathrm{K}^{+}$, and $\mathrm{Ca}^{2+}[233]$.

Based on DFT calculations, $\mathrm{Ti}_{3} \mathrm{C}_{2}$ MXene exhibits great potentials for SIBs and PIBs with a theoretical capacity of 351.8 and $191.8 \mathrm{mAh} \cdot \mathrm{g}^{-1}$, respectively [234]. Naguib et al. [232] experimentally prepared $\mathrm{Ti}_{3} \mathrm{CNT}_{z}$ MXene as an anode material for PIBs. Figure 25(a) demonstrates a first cycle potassiation and de-potassiation capacity of 710 and $202 \mathrm{~mA} \cdot \mathrm{h} \cdot \mathrm{g}^{-1}$, respectively. Figure 25(b) shows three peaks at 1.25 , 0.81 , and $\sim 0 \mathrm{~V}$ during the 1 st potassiation cycle, which are corresponding to the de-potassiation peaks of 1.50 , 0.80, $0.50 \mathrm{~V}$, respectively. As shown as Fig. 25(d), the MXene material exhibits excellent rate performance with minimal drops at a high current density $\left(500 \mathrm{~mA} \cdot \mathrm{g}^{-1}\right)$, which should be attributed to the intercalation mechanism into the layered structure. From Fig. 25(e), at the 1st discharge cycle (potassiation), the $\mathrm{K}$ ions intercalated between the MXene layers cause an increase in the $c$-lattice direction parameter. The trapped $\mathrm{K}$ ions act as pillars between the MXene layers that decrease large expansion/contraction during charge/discharge process.
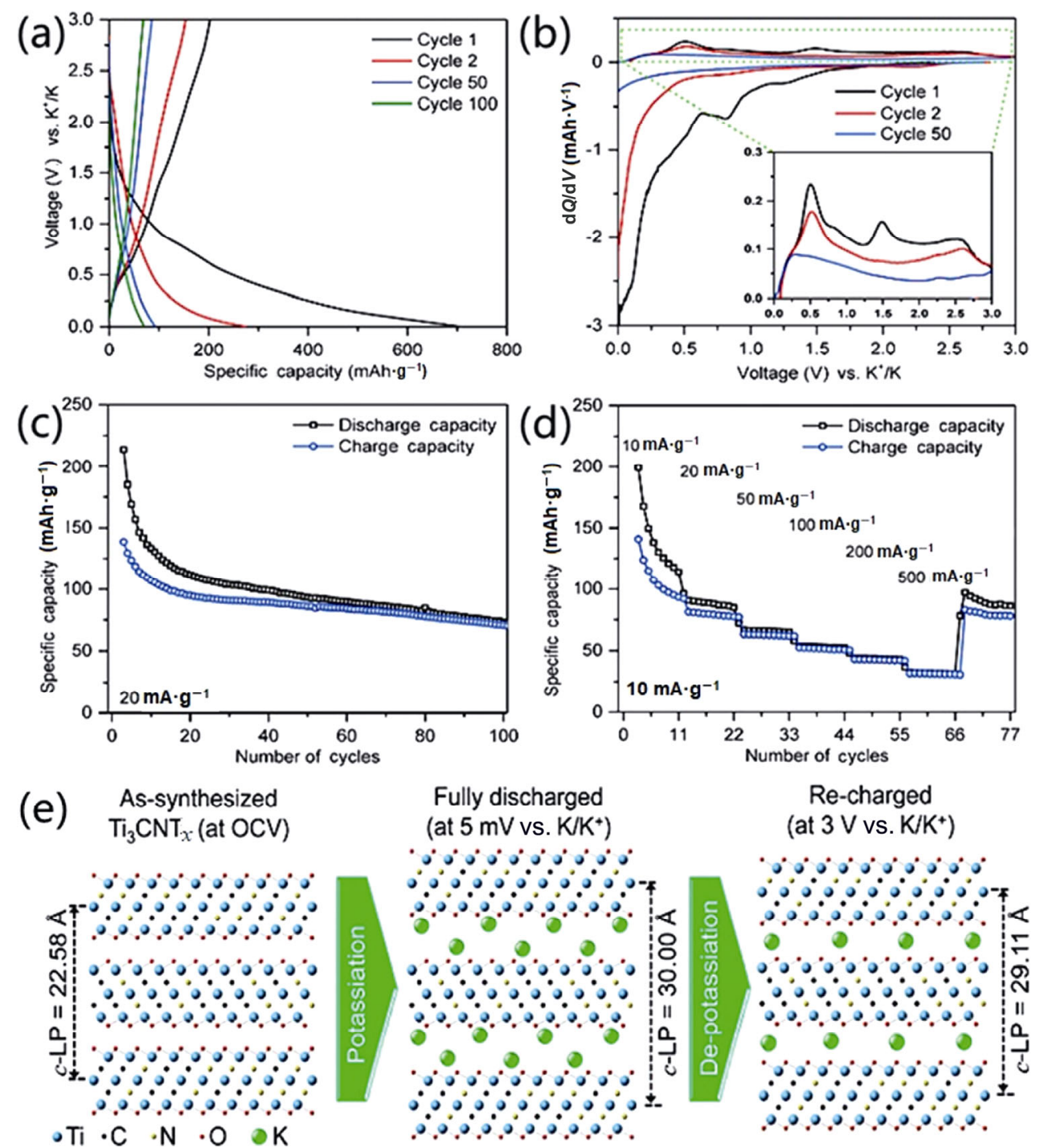

Fig. 25 (a-d) Electrochemical performance of the $\mathrm{Ti}_{3} \mathrm{CNT}_{x}$ electrode. (e) Schematic for the structure of $\mathrm{Ti}_{3} \mathrm{CNO}_{2}$ before and after electrochemical potassiation and de-potassiation. Reproduced with permission from Ref. [232], (C) Royal Society of Chemistry 2017. 
Lithium sulfur batteries (LSBs) are holding promise for the next-generation energy storage devices that can provide ultrahigh theoretical energy density of $2600 \mathrm{Wh} \cdot \mathrm{kg}^{-1}$ [235]. Dong et al. [236] introduced an MXene-based flexible and integrated sulfur cathode, and $\mathrm{Ti}_{3} \mathrm{C}_{2}$ MXene as sandwich layer on a separator (polypropylene, PP). This configuration makes for an LSB with high energy density and good cycling stability. Especially, the $\mathrm{Ti}_{3} \mathrm{C}_{2}$ framework with open interconnected microporous structrue and the fully exposed surface ensures a large load of sulfur and rapid ion transportation for improving lithiation/delithiation kinetics. In this novel design, no metal is needed as a current collector, and the integrated $\mathrm{Ti}_{3} \mathrm{C}_{2}-\mathrm{S} / d-\mathrm{Ti}_{3} \mathrm{C}_{2} / \mathrm{PP}$ electrode is directly used for LSBs, which is delivered a high capacity of $1062 \mathrm{mAh} \cdot \mathrm{g}^{-1}$ at $0.2 \mathrm{C}$ rate. Furthermore, the all MXene-based integrated cathodes displayed an outstanding rate capacity of $288 \mathrm{mAh} \cdot \mathrm{g}^{-1}$ at $10 \mathrm{C}$ rate and excellent cycle stability.

These novel and interesting 2D MXene materials have been proven to be an excellent electrode material for a variety of electrochemical energy storage devices, including LIBs, SCs, KIBs, NIBs, and LSBs, encouraging further exploration of the applications of MXene in electrochemical energy storage. Therefore, the production of new MAX phases and its further exfoliation into 2D MXenes has become an important strategic direction for the intensive study of MXene. We expect that there are still many MXenes that are more suitable as electrodes for electrochemical energy storage devices, and worth investigating.

\section{Applications of MXenes as electromagnetic interference shielding materials}

At the very beginning of the advent of MXenes [6], the interest for them was primarily in electrochemical applications [234,237-239]. With the further exploration on their properties, MXenes were found to be promising in other technologically important domains. In 2016, Shahzad et al. [240] demonstrated that flexible $\mathrm{Ti}_{3} \mathrm{C}_{2} \mathrm{~T}_{x}$ films $(1-45 \mu \mathrm{m})$ exhibited excellent electrical conductivity and electromagnetic interference (EMI) shielding capabilities (as contained in Figs. 26(a) and 26(b), better than any known synthetic materials with similar thicknesses), and paved the way for MXenes to be used as EMI shielding materials.

EMI can disrupt electronic devices and equipment that operated in medicine, telecommunication, military, aerospace, and many other domains [241]. In addition to the impact on devices and systems, EMI might even influence human health [242,243]. An EMI shielding material can protect devices against incident EM waves,
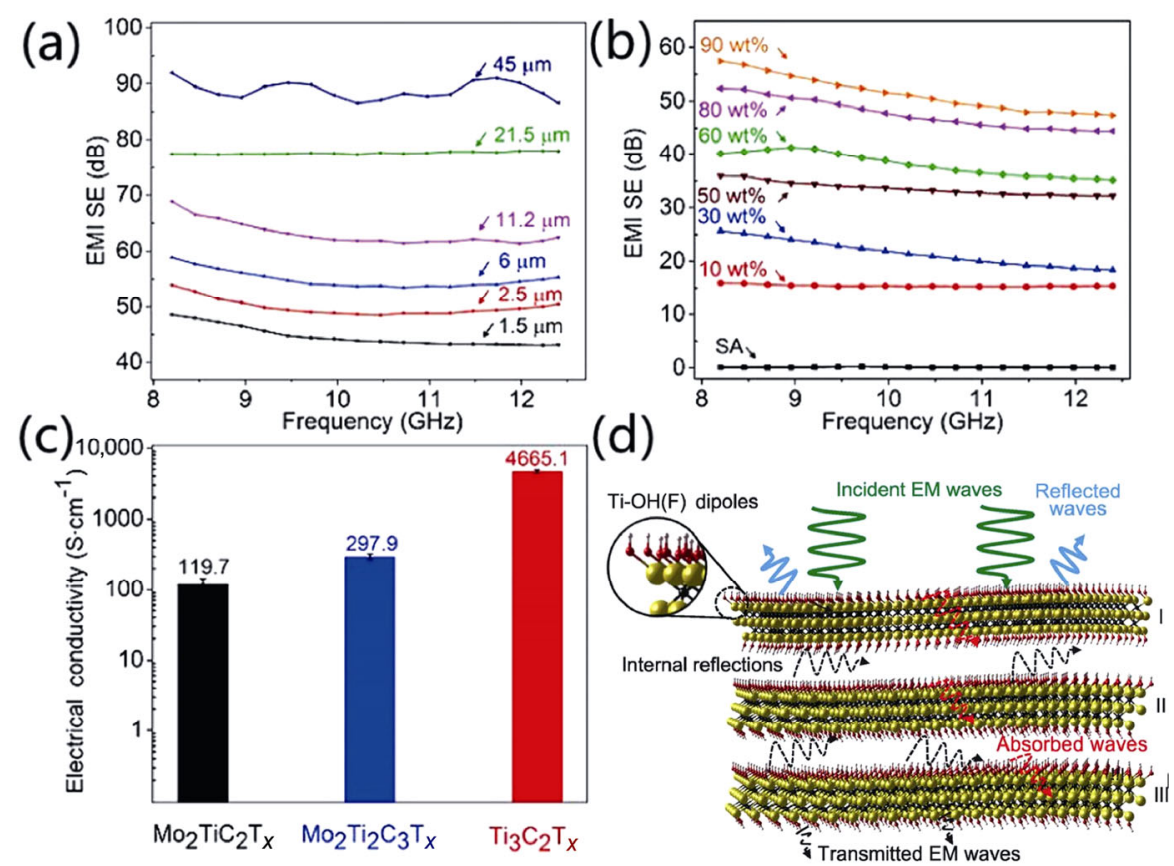

Fig. 26 (a) EMI SE of $\mathrm{Ti}_{3} \mathrm{C}_{2} \mathrm{~T}_{x}$ films. (b) EMI SE of $\mathrm{Ti}_{3} \mathrm{C}_{2} \mathrm{~T}_{x}-\mathrm{SA}$ composites at thicknesses of 8-9 $\mu \mathrm{m}$. (c) Electrical conductivity of $\mathrm{Mo}_{2} \mathrm{TiC}_{2} \mathrm{~T}_{x}, \mathrm{Mo}_{2} \mathrm{Ti}_{2} \mathrm{C}_{3} \mathrm{~T}_{x}$, and $\mathrm{Ti}_{3} \mathrm{C}_{2} \mathrm{~T}_{x}$. (d) Proposed EMI shielding mechanism for MXenes. Reproduced with permission from Ref. [240], (C) American Association for the Advancement of Science 2016. 
and its shielding effectiveness (EMI SE) is expressed as a ratio between the transmitted and incident powers on a logarithmic scale, as shown in Eq. (4):

$$
\mathrm{SE}_{\mathrm{T}}(\mathrm{dB})=10 \log \frac{P_{\mathrm{T}}}{P_{\mathrm{I}}}=20 \log \frac{E_{\mathrm{T}}}{E_{\mathrm{I}}}
$$

where $P$ and $E$ refer to power and electric field intensity, respectively; their subscripts I and T indicate incident and transmitted EM waves, respectively [244]. The interaction between an incident EM wave from air and shielding material is usually explained by reflection, absorption, and multiple reflection, as illustrated in Fig. 26(d) [240]. Total EMI shielding effectiveness (EMI $\mathrm{SE}_{\mathrm{T}}$ ) is the sum of the attenuation produced by reflection $\left(\mathrm{SE}_{\mathrm{R}}\right)$, absorption $\left(\mathrm{SE}_{\mathrm{A}}\right)$, and multiple reflection $\left(\mathrm{SE}_{\mathrm{M}}\right)$, as shown in Eq. (5) [244]:

$$
\mathrm{SE}_{\mathrm{T}}=\mathrm{SE}_{\mathrm{R}}+\mathrm{SE}_{\mathrm{A}}+\mathrm{SE}_{\mathrm{M}}
$$

The high conductivity of the material can significantly improve the reflection loss, while the porous structure, electron, and magnetic coupling can increase the absorption loss, and the efficient multiple reflection loss can be achieved by constructing a porous or multilayer structure. The merits of MXenes as stated in the forgoing sections just fit the requirements for the electromagnetic shielding materials. In addition to their high electrical conductivity (Fig. 26(c)) and good electronic coupling between the layers, their 2D structure has been proven to play a key role on their outstanding EMI shielding effectiveness. In particular, the fact that MXenes have the exceptionally high absorption of electromagnetic waves is attributed to their layered, metamaterial-like structure [243]. This fact deserves more explorations, and a comprehensive understanding of the fundamental interaction mechanisms between electromagnetic waves and their 2D structure will provide effective guidance for designing advance EMI shielding materials by employing these 2D materials [240,243]. To adapt to various application scenarios and also enhance their EMI shielding performance, a number of MXene-based materials/structures were designed and tested for the EMI shielding application, including solo MXene films, MXene composite films, and foams and aerogels constructed from MXenes. In general, all the formats of reported MXene-based EMI shielding materials fall into two categories: films and 3D porous structures (e.g., foams and aerogels). Herein, representative MXene-based EMI shielding materials are discussed by citing the highly cited references published in recent years.

\section{1 MXene and its composite films}

Shahzad et al. [240] synthesized $\mathrm{Ti}_{3} \mathrm{C}_{2} \mathrm{~T}_{x}$ ultrathin films and $\mathrm{Ti}_{3} \mathrm{C}_{2} \mathrm{~T}_{x}-\mathrm{SA}$ (sodium alginate) composite films, and demonstrated that the EMI SE of the $\mathrm{Ti}_{3} \mathrm{C}_{2} \mathrm{~T}_{x}$ film (thickness of $45 \mu \mathrm{m}$ ) reached $92 \mathrm{~dB}$ (Fig. 26(a)), and the EMI SE of the $\mathrm{Ti}_{3} \mathrm{C}_{2} \mathrm{~T}_{x}-\mathrm{SA}$ composite film (8 $\mu \mathrm{m}, 10 \mathrm{wt} \% \mathrm{SA})$ exhibited $57 \mathrm{~dB}$ (Fig. 26(b)). This performance originates from the excellent electrical conductivity of $\mathrm{Ti}_{3} \mathrm{C}_{2} \mathrm{~T}_{x}$ films (4665.1 S $\mathrm{cm}^{-1}$, Fig. 26(c)) and multiple internal reflections from $\mathrm{Ti}_{3} \mathrm{C}_{2} \mathrm{~T}_{x}$ flakes in free-standing films (Fig. 26(d)). Such a high EMI SE opened the $\mathrm{Ti}_{3} \mathrm{C}_{2} \mathrm{~T}_{x}$ material in EMI application research, and brought the explosion of research on this topic.

Mechanical performance is the basic requirements for the appropriate service of EMI shielding materials. To enhance its mechanical performance, Wan et al. [245] incorporated $\mathrm{Ti}_{3} \mathrm{C}_{2} \mathrm{~T}_{x}$ with poly(3,4-ethylenedioxythiophene)/poly(styrenesulfonate) (PEDOT/PSS) and then treated it with concentrated sulfuric acid to remove the insulating PSS. An introduction of $30 \mathrm{wt} \%$ PEDOT:PSS into the $\mathrm{Ti}_{3} \mathrm{C}_{2} \mathrm{~T}_{x}$-based film rendered it a high tensile strength of $38.5 \pm 2.9 \mathrm{MPa}$, which was 1.55 times that of solo $\mathrm{Ti}_{3} \mathrm{C}_{2} \mathrm{~T}_{x}$ films. And the as-prepared mechanically strong composite film offered an excellent EMI SE up to $40.5 \mathrm{~dB}(\sim 6.6 \mu \mathrm{m})$. Bacterial cellulose (BC) was employed to fabricate ultrathin, strong, and highly flexible $\mathrm{Ti}_{3} \mathrm{C}_{2} \mathrm{~T}_{x} / \mathrm{BC}$ composite films by Wan et al. [246], using a scalable in-situ biosynthesis method. They uniformly dispersed $\mathrm{Ti}_{3} \mathrm{C}_{2} \mathrm{~T}_{x}$ nanosheets into the $3 \mathrm{D}$ BC network, resulting in a mechanically entangled structure that endowed the $\mathrm{Ti}_{3} \mathrm{C}_{2} \mathrm{~T}_{x} / \mathrm{BC}$ composite films with excellent tensile strength (297.5 MPa at $25.7 \mathrm{wt} \%$ $\mathrm{Ti}_{3} \mathrm{C}_{2} \mathrm{~T}_{x}$ ) and flexibility. Importantly, a $4 \mu \mathrm{m}$-thick $\mathrm{Ti}_{3} \mathrm{C}_{2} \mathrm{~T}_{x} / \mathrm{BC}$ composite film with $76.9 \mathrm{wt} \% \mathrm{Ti}_{3} \mathrm{C}_{2} \mathrm{~T}_{x}$ content gave a specific EMI SE of $29,141 \mathrm{~dB} \mathrm{~cm} \cdot \mathrm{g}^{-1}$, which surpasses those of most previously reported MXene-based polymer composites with similar MXene contents and also, the most reported carbon-based polymer composites.

As the portable and wearable electronics rigorously develop, lightweight, flexible, and stable films with high EMI SE are highly demanded. This is usually achieved by assembling MXenes with other functional nanomaterials by electrostatic interaction, van der Waals ( $\mathrm{vdW}$ ) interaction, and hydrogen bond. LbL assembly is an advanced fabrication method for nanocomposites, and Weng et al. [247] developed an spin spray layerby-layer (SSLbL) technique, which can rapidly assemble MXenes and carbon nanotubes (CNT) together, yielding 
a composite with hierarchical architectures with desirable cross-functionalities. For the MXene-CNT composite realized by SSLbL route, a high stability and tensile strength was endowed via electrostatically bonded polymer fillers, and the as-prepared semitransparent MXene-CNT composite films also showed high conductivities up to $130 \mathrm{~S} \cdot \mathrm{cm}^{-1}$ (the highest values achieved among LbL composite films to date). The authors showed that the MXene-CNT film has a maximum specific EMI shielding effectiveness (SSE/t) of $58,187 \mathrm{~dB} \cdot \mathrm{cm}^{2} \cdot \mathrm{g}^{-1}$, which is among the highest reported $\mathrm{SSE} / t$ values. Ultrathin, lightweight, and flexible CNT and MXene $\left(\mathrm{Ti}_{3} \mathrm{C}_{2} \mathrm{~T}_{x}\right)$ buckypaper with an enhanced EMI SE was obtained by Yang et al. [248] through a facile electrophoretic deposition process. The prepared $\mathrm{Ti}_{3} \mathrm{C}_{2} \mathrm{~T}_{x} @$ CNT hybrid bucky paper of $100 \mu \mathrm{m}$ exhibited an outstanding EMI SE of $60.5 \mathrm{~dB}$ in the X-band, and the hybrid bulkypaper with a $\mathrm{Ti}_{3} \mathrm{C}_{2} \mathrm{~T}_{x}$ content of $49.4 \mathrm{wt} \%$ even exhibited an EMI SE of $50.4 \mathrm{~dB}$ across the X-band with a thickness of only 15 $\mu \mathrm{m}$, which means its EMI SE is $105 \%$ higher than that of the pristine CNT buckypaper. And as the thickness of the hybrid paper was decreased to merely $5 \mu \mathrm{m}$, it still demonstrated an average specific EMI SE value of $5.7 \times 10^{4} \mathrm{~dB} \cdot \mathrm{cm}^{2} \cdot \mathrm{g}^{-1}$.

Due to their high electrical conductivity, good mechanical properties, and outstanding EMI SE, a number of metal-based EMI shielding materials have been extensively applied for modern integrated electronic and telecommunication systems ranging from military domains to civilian areas. However, their relatively high density, low flexibility, poor chemical corrosion resistance, and poor processability are hindering their widespread applications, particularly in the emerging technological territories. MXenes' rich terminating groups were harnessed by Ma et al. [249] to fabricate an ultraflexible and mechanically strong aramid nanofiber $\mathrm{Ti}_{3} \mathrm{C}_{2} \mathrm{~T}_{x}$ MXene/silver nanowire (ANF-MXene/AgNW) nanocomposite. Hydrogen-bonding interactions are confirmed between the components of the as-prepared ANF-MXene/AgNW nanocomposite. The authors used a facile two-step vacuum-assisted filtration followed by hot-pressing approach (Fig. 27(a)). The as-fabricated double layered nanocomposite paper with a low MXene/AgNW content of $20 \mathrm{wt} \%$ which delivered an excellent electrical conductivity of $922.0 \mathrm{~S} \cdot \mathrm{cm}^{-1}$, desirable mechanical properties with a tensile strength of $235.9 \mathrm{MPa}$ and a fracture strain of $24.8 \%$, superior EMI SE of $48.1 \mathrm{~dB}$, and a high EMI SE/t of $10,688.9$ $\mathrm{dB} \cdot \mathrm{cm}^{-1}$. Its highly efficient double-layered structures, high-performance ANF substrate, and extensive hydrogen-bonding interactions are responsible for the
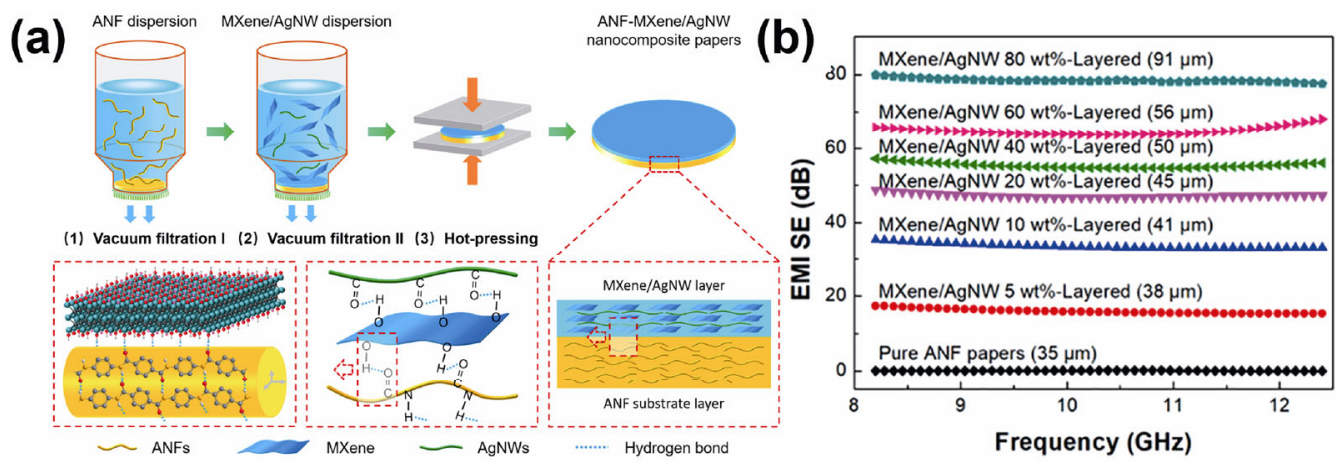

(c)
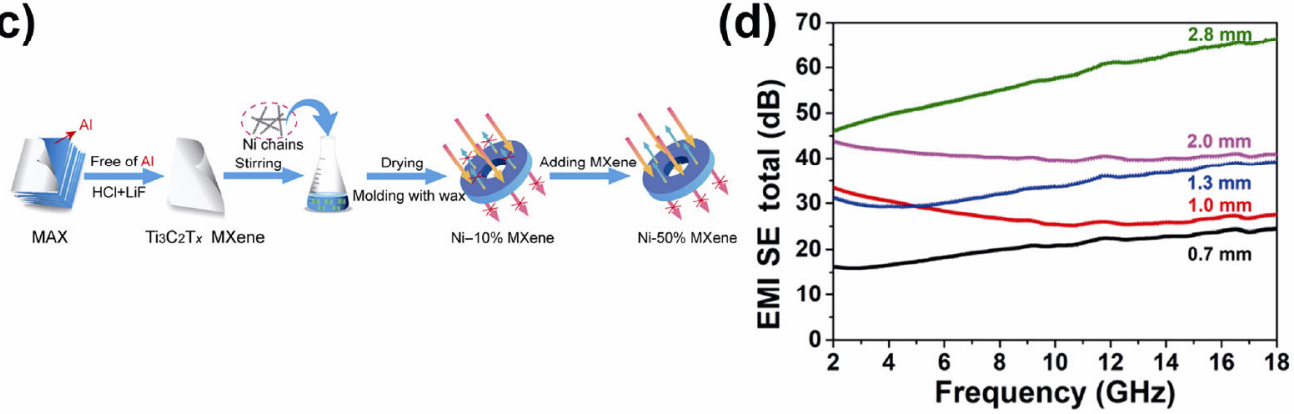

Fig. 27 (a) Illustration of the fabrication for ANF-MXene/AgNW nanocomposite papers. (b) EMI SE of ANF-MXene/AgNW nanocomposite and pure ANF paper. Reproduced with permission from Ref. [249], (C) American Chemical Society 2020. (c) Illustration of the fabrication of MXene/Ni hybrids. (d) The EMI SE total curve of Ni-50\% MXene with different thicknesses. Reproduced with permission from Ref. [250], (C) American Chemical Society 2019. 
outstanding comprehensive properties. Specifically, the nanocomposite papers showed a maximum electrical conductivity of $3725.6 \mathrm{~S} \cdot \mathrm{cm}^{-1}$ and EMI SE of $\sim 80 \mathrm{~dB}$ (Fig. 27(b)) at a MXene/AgNW content of $80 \mathrm{wt} \%$. It is noted that this structure has an absorption-dominant shielding mechanism, which can be explained by the massive ohmic losses in the highly conductive MXene/ $\mathrm{AgNW}$ layer, multiple internal reflections between $\mathrm{Ti}_{3} \mathrm{C}_{2} \mathrm{~T}_{x}$ MXene nanosheets and polarization relaxation of localized defects, and abundant terminal groups.

Liang et al. [250] designed and realized a MXene/Ni chain hybrid with excellent electromagnetic wave absorption and shielding capacity. The hybrid consisted of one-dimensional $\mathrm{Ni}$ nanochains and $2 \mathrm{D} \mathrm{Ti}_{3} \mathrm{C}_{2} \mathrm{~T}_{x}$ nanosheets (Fig. 27(c)). Simply, by only adjusting the ratio of conductive $\mathrm{Ti}_{3} \mathrm{C}_{2} \mathrm{~T}_{x}$ nanosheets and magnetic $\mathrm{Ni}$ nanochains, the authors demonstrated the adjustable EM wave absorption and shielding properties of the MXene/Ni chain hybrid. The minimum reflection loss of $-49.9 \mathrm{~dB}$ was recorded by a sample loaded with $10 \mathrm{wt} \%$ MXene and with a thickness of $1.75 \mathrm{~mm}$ at $11.9 \mathrm{GHz}$, increasing the MXene content to $50 \mathrm{wt} \%$, and the optimal EMI SE reaches $66.4 \mathrm{~dB}$ with an $\mathrm{SE}_{\mathrm{A}}$ of $59.9 \mathrm{~dB}$, showing an evident dependence on the sample thickness (Fig. 27(d)). The interaction mechanism between the incident electromagnetic waves and the hybrid was considered to be severalfold, as illustrated in Fig. 28. The synergistic effect of the conductivity loss, multiple scattering, eddy current loss, dipole polarization, and interface polarization is responsible for the satisfactory EMI SE of the hybrid.

Intelligent garment is a highly promising area of wearable electronics, which are developed by integrating multifunctionalities into textile. Starting from the superb intrinsic electrical conductivity, tunable surface groups, and layered structure of MXenes, via a dip-coating approach, Wang et al. [251] fabricated highly conductive, hydrophobic, and flexible MXene-decorated poly(ethylene terephthalate) (PET) textiles with exceptional EMI shielding efficiency and Joule heating performance. They obtained a multifunctional textile exhibiting high electrical conductivity of $1000 \mathrm{~S} \cdot \mathrm{m}^{-1}$, and simultaneously an exceptional EMI SE of $90 \mathrm{~dB}$ at a thickness of $1.3 \mathrm{~mm}$. Particularly, as the society is going to an age of Internet of Things (IoT), the proliferation of wireless devices may raise nonnegligible safety issues for human health. And therefore, it demands stretchable materials that are capable of shielding EMI. Li et al. [252] fabricated an ultrastretchable conductor by depositing a crumble-textured coating composed of 2D $\mathrm{Ti}_{3} \mathrm{C}_{2} \mathrm{~T}_{x}$ nanosheets (MXene) and single-walled carbon nanotubes (SWNTs) onto latex. This ultrastretchable conducting MXene-SWNT (S-MXene)/latex material can be fashioned into wearable antennas and EMI shields with high performance. The device made from this material survived an $800 \%$ areal strain and exhibited strain-insensitive resistance profiles during a 500 -cycle fatigue test. By incorporating SWNTs into MXene films, the resultant construction gained a synergy for both mechanical and EMI shielding performance. Therefore, a single layer of stretchable S-MXene conductors demonstrated an EMI shielding performance of $30 \mathrm{~dB}$ up to $800 \%$ areal strain, and the shielding performance was strain-independent; and the shielding performance was further improved to 47 and $52 \mathrm{~dB}$ by stacking 5 and 10 layers of the S-MXene conductors, respectively.

Developing electronic ink is highly demanded for

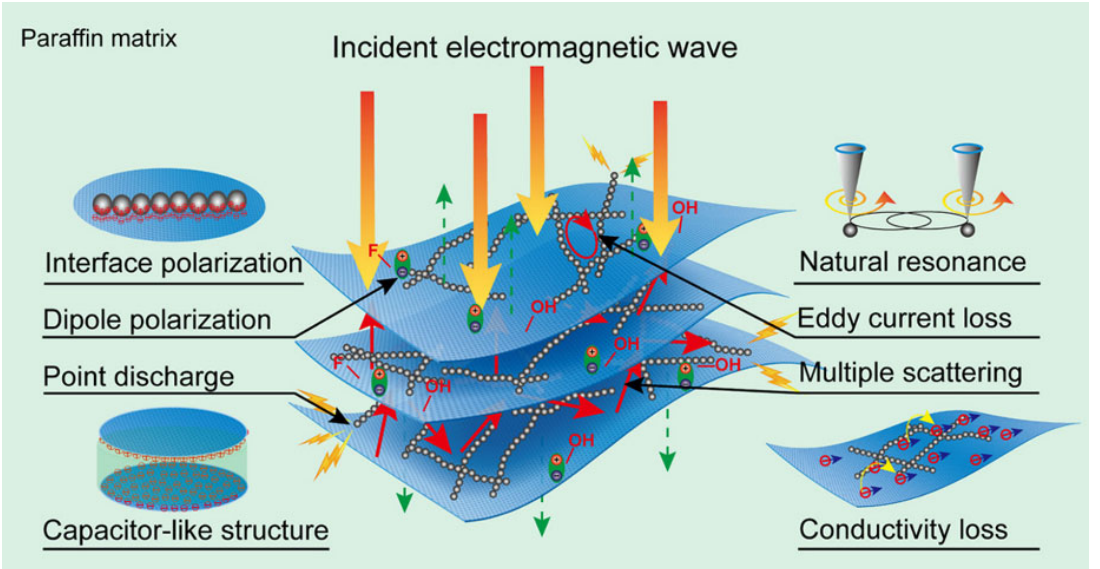

Fig. 28 EM wave loss mechanism of the MXene/Ni hybrid. Reproduced with permission from Ref. [250], (C) American Chemical Society 2019. 
applications in printable and flexible electronics. Vural et al. [253] employed tandem repeat synthetic proteins based on squid ring teeth (SRT) as templates of molecular self-assembly to engineer MXene inks, and the binder protein molecules can form sequence controlled assemblies with hydrogen bonding 2D crystals during printing, and therefore assemble MXenes together, as illustrated in Fig. 29(a). The authors demonstrated that the resulting ink formulations could be effectively printed on a number of substrates (e.g., cellulose paper, glass, and PET), yielding electrode patterns. The MXene-electrodes printed on flexible PET substrates had the electrical conductivity of $1080 \pm 175 \mathrm{~S} \cdot \mathrm{cm}^{-1}$ for films with an average thickness of $2.25 \mu \mathrm{m}$ (Fig. 29(b)), corresponding to the highest electrical conductivity reported among electrodes that are inkjet-printed using 2D materials. Thanks to the intrinsic excellent conductivity of MXenes and the flexibility of the MXene-ink, the highly conductive electrodes printed on flexible PET substrates remained integrated and maintained their electrical conductivity under bending deformation, and therefore, it provided outstanding EMI SE $(50 \mathrm{~dB}$, a film thickness of $1.35 \mu \mathrm{m}$, Fig. 29(c)).

\section{2 MXene and its composite foams and aerogels}

Foam-like structures can take advantage of impedance matching to take in more EM waves, and multiple reflection and scattering within the materials would cause enhanced EM absorption [254]. Bian et al. [255] demonstrated a facile, freeze-casting route for preparing MXene aerogels starting from MXene colloidal solution (Fig. 30(a)). The as-prepared MXene aerogels had micro-sized pores inherited the morphology of ice crystals, and remarkably, they showed excellent EMI shielding performance (up to $75 \mathrm{~dB}$ ), with exceptionally high absorption loss $\left(\mathrm{SE}_{\mathrm{R}}<1 \mathrm{~dB}\right)$. In particular, thanks to the ultralow density of the aerogels, their SEE/t can be as high as $9904 \mathrm{~dB} \cdot \mathrm{cm}^{-3} \cdot \mathrm{g}^{-1}$ (Fig. 30(b)).

To guarantee the stability of MXenes in a moist or wet service environment, Liu et al. [256] fabricated hydrophobic MXene foam with reasonable strength by assembling MXene sheets into films and then expanding them via a hydrazine-induced foaming process, as illustrated in Fig. 30(c). And the as-prepared MXene foams, in contrast to well-known hydrophilic MXene materials, exhibited hydrophobic surfaces and outstanding water resistance and durability. Compared with its unfoamed film counterpart $(53 \mathrm{~dB})$, a much higher
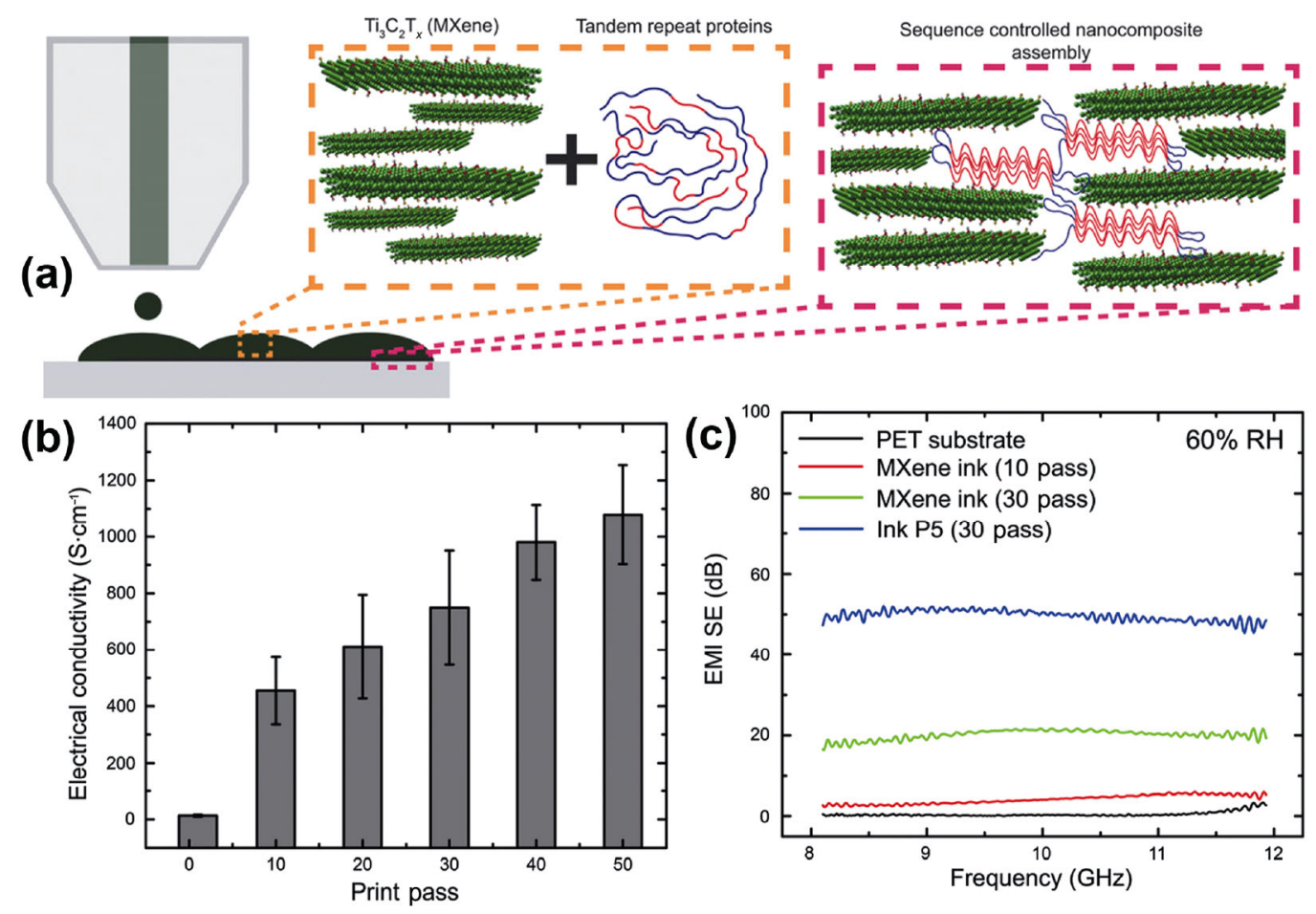

Fig. 29 (a) Illustration of protein-mediated assembly of MXene sheets during inkjet printing. (b) Electrical conductivity of large area electrodes inkjet-printed on PET. (c) EMI SE of large area (circle, $\varphi=2 \mathrm{~cm}$ ) electrodes inkjet-printed on PET using various ink solutions (MXene ink, ink P5) at dry condition (60\% relative humidity). Reproduced with permission from Ref. [253], (C) WILEY-VCH Verlag GmbH \& Co. KGaA, Weinheim 2018. 

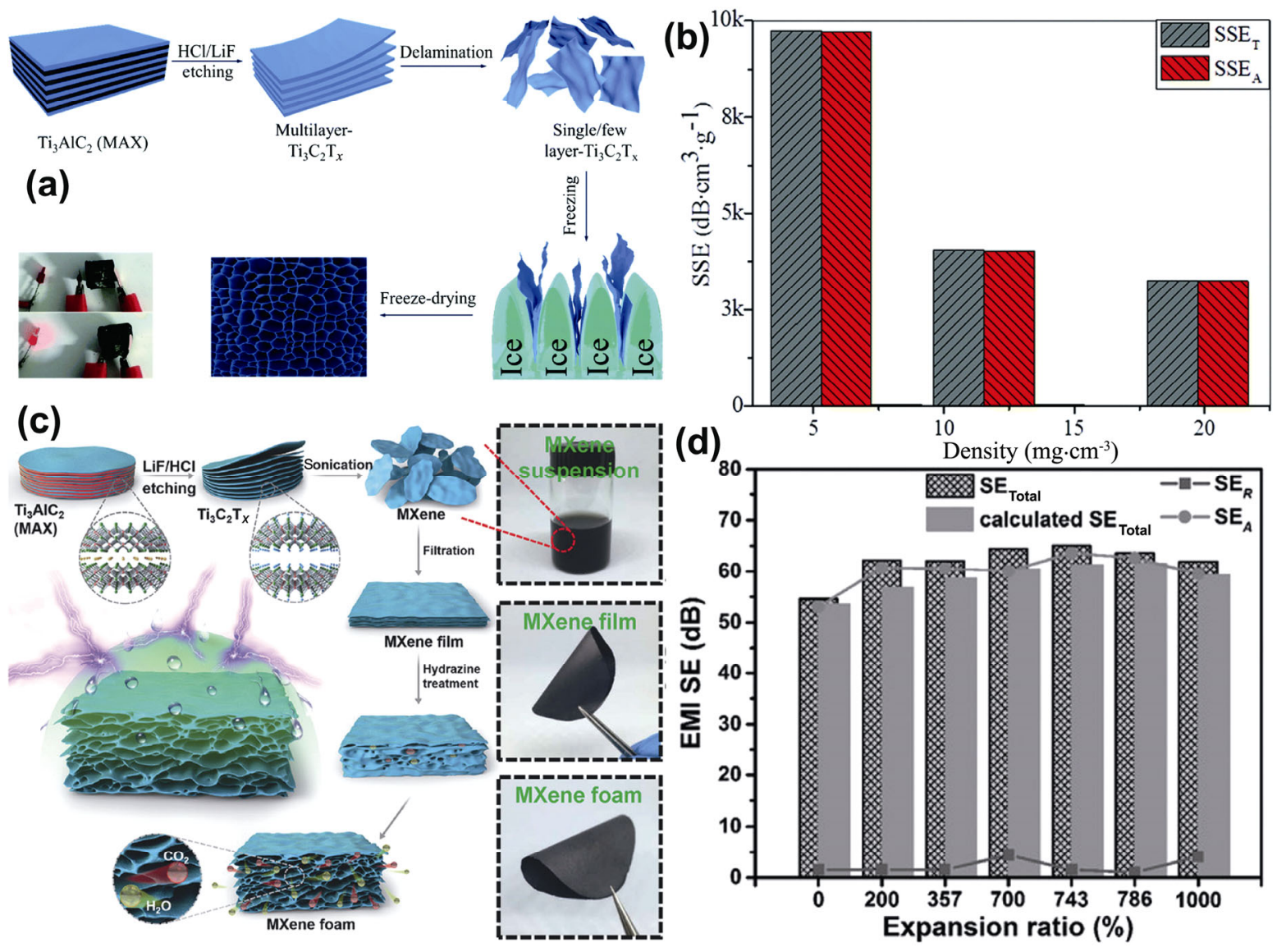

Fig. 30 (a) Flowchart for fabrication of MXene aerogels and (b) EMI SSE of MXene aerogels at 8.2 GHz. Reproduced with permission from Ref. [255], (C) Royal Society of Chemistry 2019. (c) Illustration of the fabrication of the hydrophobic and flexible MXene foam. (d) Effects of the expansion ratio on the measured and calculated EMI SE of the MXene foams. Reproduced with permission from Ref. [256], (C) WILEY-VCH Verlag GmbH \& Co. KGaA, Weinheim 2017.

enhanced EMI SE of $70 \mathrm{~dB}$ (Fig. 30(d)) was recorded for the lightweight MXene foam, which is attributed to its highly efficient wave attenuation in the favorable porous structure. Therefore, the MXene foam with excellent EMI SE is highly promising for applications in aerospace and portable and wearable smart electronics, where the weight matters.

Lightweight, compressible, and conductive materials are demanded in EMI shielding gaskets, wearable electronics, sensors, and other specific areas. Based on the superb properties of MXenes, Wu et al. [257] fabricated the compressible and electrically conductive polydimethylsiloxane (PDMS)-coated MXene foams. The fabrication route employed by the authors is schematically shown in Fig. 31(a). 3D MXene aerogel architectures were preformed under the assistance of SA, and followed by coating a thin layer of PDMS to render the porous architecture structural stability and durability. The resultant lightweight MXene/SA hybrid aerogel had an outstanding conductivity of $2211 \mathrm{~S} \cdot \mathrm{m}^{-1}$ and a high average EMI SE of $70.5 \mathrm{~dB}$. Furthermore, the PDMS coating endowed the hybrid aerogel with excellent compressibility and durability, and a PDMScoated MXene foam with $6.1 \mathrm{wt} \%$ of MXene reserved its high EMI shielding efficiency of $48.2 \mathrm{~dB}$ after 500 compression-release cycles. Sun et al. [258] fabricated the highly conductive MXene@PS nanocomposites via electrostatic assembly of the negative MXene nanosheets on the positive PS microspheres followed by compression molding, as illustrated in Fig. 31(b). The interfaces of large PS microspheres were covered by the highly conductive MXene nanosheets, forming a continuous and highly efficient conduction network, affording superb electrical conductivity and excellent EMI shielding performances. A low percolation threshold of 0.26 vol $\%$ was achieved and the PS nanocomposite with $1.90 \mathrm{vol} \%$ of $\mathrm{Ti}_{3} \mathrm{C}_{2} \mathrm{~T}_{x}$ exhibited a superb electrical conductivity (up to $1081 \mathrm{~S} \cdot \mathrm{m}^{-1}$ ), providing the nanocomposites with excellent EMI SE. An EMI SE of above $54 \mathrm{~dB}$ over the whole X-band with a maximum 


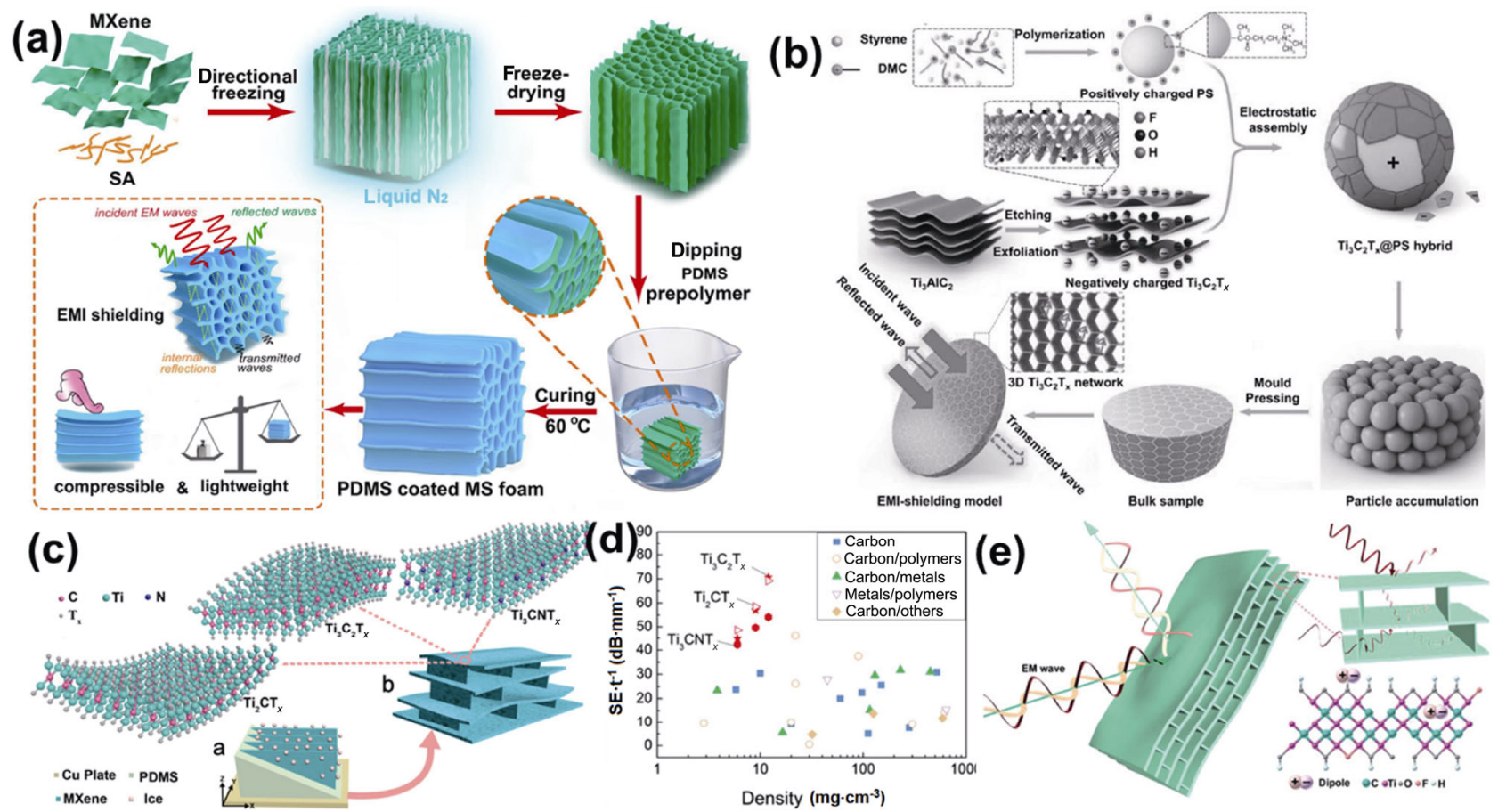

Fig. 31 Preparation process: (a) MS hybrid aerogel and its PDMS-coated MS foam. Reproduced with permission from Ref. [257], (C) Elsevier B.V. 2020. (b) $\mathrm{Ti}_{3} \mathrm{C}_{2} \mathrm{~T}_{x}$ (a) PS nanocomposites. Reproduced with permission from Ref. [258], (C) WILEY-VCH Verlag GmbH \& Co. KGaA, Weinheim 2017. (c) Schematic illustration of bidirectional freeze-casting mechanism. (d) Comparison of EMI shielding performance of MXene aerogels with the reported foam materials and (e) EMI shielding mechanisms. Reproduced with permission from Ref. [259], (C) WILEY-VCH Verlag GmbH \& Co. KGaA, Weinheim 2019.

of $62 \mathrm{~dB}$ was realized by a PS nanocomposite with only $1.90 \mathrm{vol} \%$ of $\mathrm{Ti}_{3} \mathrm{C}_{2} \mathrm{~T}_{x}$, which was among the best performances yet reported for the polymer nanocomposites.

EMI shielding performance usually refers to the sum of EM wave reflection and absorption, and the conventional EMI shielding materials, e.g., metallic materials, have high EMI SE, and are predominated by reflection loss. And it is a long-sought goal to control the ratio of EM reflection and absorption for an EMI shielding material. Based on MXenes, a series of aerogels with lamellar structure and long-range ordering were constructed by Han et al. [259] via a bidirectional freeze-casting under dual temperature gradients, as illustrated in Fig. 31(c). The as-fabricated aerogels were anisotropic and compressible, with low density, resulting in outstanding EMI shielding performance and, especially, tunable ratio of reflection to absorption. EMI SE of 70.5, 69.2, and $54.1 \mathrm{~dB}$ were achieved for $\mathrm{Ti}_{3} \mathrm{C}_{2} \mathrm{~T}_{x}, \mathrm{Ti}_{2} \mathrm{CT}_{x}$, and $\mathrm{Ti}_{3} \mathrm{CNT}_{x}$ aerogels, respectively, with the compression thickness of $1 \mathrm{~mm}$ and a density of only $11.0 \mathrm{mg} \cdot \mathrm{cm}^{-3}$. An SEE $/ t$ of $8818.2 \mathrm{~dB} \cdot \mathrm{cm}^{-3} \cdot \mathrm{g}^{-1}$ was recorded, which was among the best values reported for EMI shielding materials (Fig. 31(d)). More importantly, due to their 3D skeletons with well-arranged cellular structure, as illustrated in Fig. 31(e), these MXene aerogels maintained stable total shielding effectiveness with the increasing ratio of reflection to absorption under compression from 3 to $1 \mathrm{~mm}$.

To take the advantages of outstanding EMI shielding performance of Ag and MXenes, Weng et al. [260] fabricated lightweight AgNW/MXene hybrid sponges via a method of dip-coating and unidirectional freeze-drying, as shown in Fig. 32(a). The light sponges $\left(43.0 \mathrm{mg} \cdot \mathrm{cm}^{-3}\right)$ with a novel buckling design exhibited a conductivity of up to $15.3 \mathrm{~S} \cdot \mathrm{cm}^{-1}$ and superior EMI SE of above $40.0 \mathrm{~dB}$ in the X-band (Fig. 32(b)). The introduction of an irregular honeycomb-like MXene architecture enabled an EMI SE of $52.6 \mathrm{~dB}$ associated an enhanced conductivity $\left(24.5 \mathrm{~S} \cdot \mathrm{cm}^{-1}\right)$ at $49.5 \mathrm{mg} \cdot \mathrm{cm}^{-3}$. These impressive performances of the sponges manifested the advantages of buckled structures and the synergistic effect of AgNW and MXene (Fig. 32(c)).

To reconcile the lightness and the mechanical robustness, Wang et al. [261] fabricated a waterborne polyurethane/ $\mathrm{Ti}_{3} \mathrm{C}_{2} \mathrm{~T}_{x}$ MXene/nickel ferrite (WPU/ 

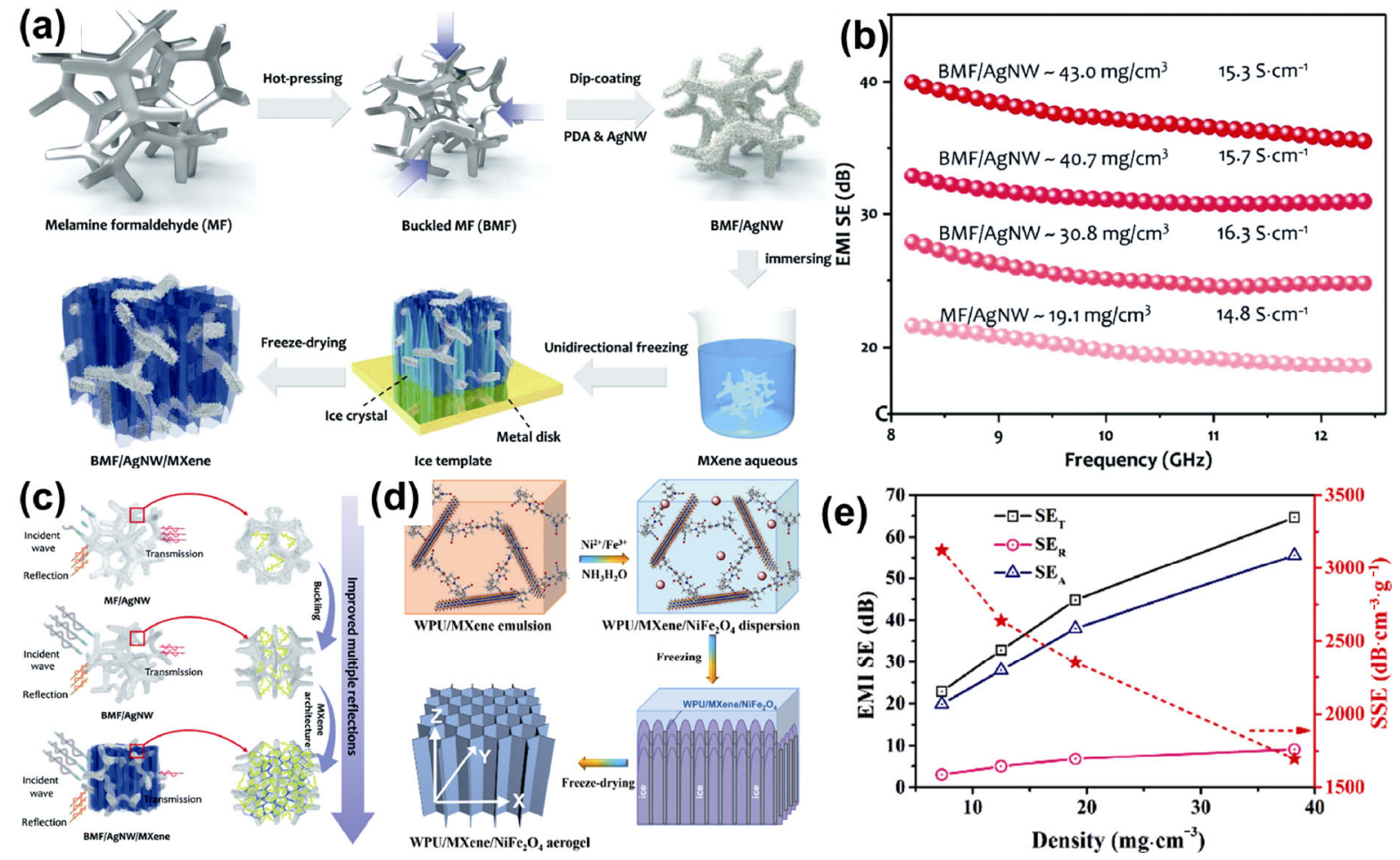

Fig. 32 (a) Fabrication process of the BMF/AgNW/MXene hybrid sponge. (b) EMI SE (X band) of MF/AgNW and BMF/AgNW sponges compressed with different volume ratios. (c) Schematic illustration of EMI shielding mechanisms for $\mathrm{MF} / \mathrm{AgNW}, \mathrm{BMF} / \mathrm{AgNW}$, and BMF/AgNW/MXene sponges. Reproduced with permission from Ref. [260], (C) Royal Society of Chemistry 2019. (d) Fabrication process of WPU/MXene/ $\mathrm{NiFe}_{2} \mathrm{O}_{4}$ hybrid aerogels. (e) Average EMI SE values and SSE values of the WM20-N3 sample at various densities. Reproduced with permission from Ref. [261], (C) American Chemical Society 2021.

MXene/ $\mathrm{NiFe}_{2} \mathrm{O}_{4}$ ) hybrid aerogel. In this aerogel, there was a strong chemical bonding interaction between an NCO-terminated WPU prepolymer and hydroxyl functionalized MXene nanosheets, as shown in Fig. 32(d). As expected, the resultant aerogels were remarkably light and mechanically strong, and in particular, their high compressive stress far exceeded that of other MXene-based porous materials. Furthermore, synergistic effects of the oriented porous architecture and the multiphase skeleton endowed the hybrid aerogels with a high X-band EMI SE of $64.7 \mathrm{~dB}$ at $38.2 \mathrm{mg} \cdot \mathrm{cm}^{-3}$ (Fig. 32(e)), surpassing most of the reported EMI shielding materials.

CNT was also employed to enhance the mechanical robustness of MXene aerogels by Sambyal et al. [262], and via the bidirectional freezing method, the authors fabricated a 3D porous $\mathrm{Ti}_{3} \mathrm{C}_{2} \mathrm{~T}_{x} / \mathrm{CNT}$ hybrid aerogel. The as-prepared CNT-reinforced MXene/CNT hybrid aerogels exhibited satisfactory mechanical robustness and increased the compressional modulus (nearly 100 times that of the pristine MXene aerogel). Furthermore, the synergism of the lamellar and porous structure of the MXene/CNT hybrid aerogels contributed to both their excellent electrical conductivity $\left(9.43 \mathrm{~S} \cdot \mathrm{cm}^{-1}\right)$ and superior EMI SE $(103.9 \mathrm{~dB}$ at $3 \mathrm{~mm}$ thickness at the X-band frequency). Graphene oxide (GO) was used to form a 3D porous architecture of MXenes via directional-freezing and subsequent freeze-drying route in a successful demonstration by Zhao et al. [263]. The resultant hybrid aerogels exhibited an aligned cellular microstructure, where the GO sheets served as the inner skeleton, while the compactly attached $\mathrm{Ti}_{3} \mathrm{C}_{2} \mathrm{~T}_{x}$ sheets presented as shells of each cell. The highly conductive aerogels $\left(1085 \mathrm{~S} \cdot \mathrm{m}^{-1}\right)$ were highly efficient to endow epoxy nanocomposite with a high electrical conductivity $\left(695.9 \mathrm{~S} \cdot \mathrm{m}^{-1}\right)$ and an outstanding EMI SE $\left(>50 \mathrm{~dB}\right.$ in the X-band at a low $\mathrm{Ti}_{3} \mathrm{C}_{2} \mathrm{~T}_{x}$ content of $0.74 \mathrm{vol} \%$ ).

In conclusion, the novel 2D MXenes have presented great potential in EMI shielding applications with excellent metal conductivity, layered structure, abundant surface defects and functional groups, and easy processability in solution. The ultrathin solo MXene film exhibits high EMI SE, but their poor mechanical 
properties, relatively high densities, and large EM secondary pollution caused by high reflection loss hinder their applications in the field of flexible electronics and intelligent garments. Therefore, the MXene composite films have been developed by compounding with functional materials such as polymers and metals, which can significantly improve the mechanical properties, and enhanced EM absorption. The development of MXene coatings and electronic inks has further promoted the application of MXene as flexible electronic devices. Besides, by constructing 3D porous structures (foams and aerogels) of MXenes, it can make the materials improve impedance matching and absorption loss of EM. MXenes have provided a new opportunity for the development of high-performance EMI shielding materials, and they are promising to see commercial applications as the related researches are being exploded.

\section{Summary and outlook}

In this review, the developments of MAX phases and MXenes are reviewed. The synthesis, structures, properties, and applications of the two families of materials are summarized. Especially, this review focuses on the conversion process from MAX phases to MXenes. We try to introduce the $2 \mathrm{D}$ materials (MXenes) to the scientists on ceramics, and clarify the difference and the connection between the 3D MAX phases and their 2D counterpart MXenes.

MAX phases are generally processed and applied as structure ceramics. The typical method to process ceramics, such as PLS sintering, hot-pressing, SPS, and SHS, can be used to process MAX phase. Compared with typical structure ceramics $\left(\mathrm{Al}_{2} \mathrm{O}_{3}, \mathrm{Si}_{3} \mathrm{~N}_{4}\right.$, $\mathrm{SiC}$, etc.), MAX phases are relatively soft, damage tolerant, readily machinable, and electrically conductive. Although many applications, such as structure components, heat elements, and electrical contacts, have been explored, there are still have difficulties for the commoditization of MAX phases as structure ceramics. This is because those structural materials always cost sensitively. MAX phases, like many other new materials, are costly.

MXenes are 2D materials made from MAX phases by removing A elements. MXene can be considered as conductive clay. They can be dispersed in water for forming colloidal solution and processed as slurry or pellet. MXenes have large layer space to store metal ions or air molecules, and they are electrically conductive. Their chemical composition, surface terminations, and microstructure can be regulated to control their properties. Thus, MXene can be applied in the areas of energy storage, catalysis, EMI shielding, sensors, etc.

Different with MAX phases, MXenes are mainly applied as functional materials. Thus, the applications of MXenes are not super sensitive to cost. Then MXenes are easier to be commercialized than MAX phases. Then, the precursor of MXenes is a very possible way to commercialize MAX phases. It has been found that there are some MAX phases in sale in markets as precursors of MXenes.

For the applications of MXenes, the improvement of performance is prior to the reduce of cost. The chemical composition is a key factor to determine the performance of MXene. The chemical composition of precursor MAX phase determines the chemical composition of MXene, in turn, the performance of MXene. For example, Mo-contained MXenes and V-contained MXenes have different properties with the common Ti-contained MXenes $\left(\mathrm{Ti}_{3} \mathrm{C}_{2}\right.$ and $\left.\mathrm{Ti}_{2} \mathrm{C}\right)$. To obtain those two kinds of MXenes, the related MAX phases, $\mathrm{Mo}_{2} \mathrm{Ga}_{2} \mathrm{C}$ and $\mathrm{V}_{2} \mathrm{AlC}$, should be synthesized first. By the way to design MAX phases, MXenes with different chemical composition and properties can be designed and prepared. Therefore, for the purpose to obtian MXenes with desired compositions/performance, it is significant to fully understand the synthesis process of MAX phases and conversion process from MAX phases to MXenes.

\section{Acknowledgements}

This work was supported by the National Natural Science Foundation of China (51772077, 51602184, and 11872171), Program for Innovative Research Team (in Science and Technology) in the University of Henan Province (19IRTSTHN027), China Postdoctoral Science Foundation (2019M652537), Henan Postdoctoral Foundation (19030065), Henan Province Key Science and Technology Research Projects (202102310628), and the Foundation of Henan Educational Committee (20B430006). We thank the graduate students in our groups (Yitong GUO and Ru YANG from Henan Polytechnic University, and Meng WU and Lu LIU from Hohai University) for helping collect data and organize the manuscript. We also acknowledge the contribution of Dr. Renfei CHENG to this review. 


\section{Author contributions}

All authors contributed equally to this work. Aiguo ZHOU from Henan Polytechnic University: 1 Introduction and 4 Preparation of MXenes from MAX phases; Yi LIU from Shaanxi University of Science \& Technology: 2 Structure and preparation of MAX phases; Shibo LI from Beijing Jiaotong University: 3 Crack healing properties and potential applications of MAX phases; Xiaohui WANG from the Institute of Metals Research, Chinese Academy of Sciences: 5 Microstructure of MXenes; Guobing YING from Hohai University: 6 Preparation and characterization of MXene composites; Qixun XIA from Henan Polytechnic University: 7 Application of MXenes in energy storage; Peigen ZHANG from Southeast University: 8 Application of MXenes as electromagnetic interference shielding materials.

\section{References}

[1] Jeitschko W, Nowotny H. Die Kristallstruktur von $\mathrm{Ti}_{3} \mathrm{SiC}_{2}$ - ein neuer Komplexcarbid-Typ. Monatshefte Für Chemie Chem Mon 1967, 98: 329-337.

[2] Jeitschko W, Nowotny H, Benesovsky F. Kohlenstoffhaltige ternäre verbindungen (H-phase). Monatshefte Für Chemie Und Verwandte Teile Anderer Wissenschaften 1963, 94 : 672-676.

[3] Jeitschko W, Nowotny H, Benesovsky F. Carbides of formula $\mathrm{T}_{2}$ MC. J Less Common Met 1964, 7: 133-138.

[4] Barsoum MW, El-Raghy T. Synthesis and characterization of a remarkable ceramic: $\mathrm{Ti}_{3} \mathrm{SiC}_{2}$. J Am Ceram Soc 1996, 79: 1953-1956.

[5] Novoselov KS, Geim AK, Morozov SV, et al. Electric field effect in atomically thin carbon films. Science 2004, 306: 666-669.

[6] Naguib M, Kurtoglu M, Presser V, et al. Two-dimensional nanocrystals produced by exfoliation of $\mathrm{Ti}_{3} \mathrm{AlC}_{2} . A d v$ Mater 2011, 23: 4248-4253.

[7] Naguib M, Come J, Dyatkin B, et al. MXene: A promising transition metal carbide anode for lithium-ion batteries. Electrochem Commun 2012, 16: 61-64.

[8] Naguib M, Mashtalir O, Carle J, et al. Two-dimensional transition metal carbides. ACS Nano 2012, 6: 1322-1331.

[9] Mashtalir O, Naguib M, Mochalin VN, et al. Intercalation and delamination of layered carbides and carbonitrides. Nat Commun 2013, 4: 1716.

[10] Naguib M, Mochalin VN, Barsoum MW, et al. 25th anniversary article: MXenes: A new family of twodimensional materials. Adv Mater 2014, 26: 992-1005.

[11] Kamysbayev V, Filatov AS, Hu H, et al. Covalent surface modifications and superconductivity of two-dimensional metal carbide MXenes. Science 2020, 369: 979-983.

[12] Li YB, Shao H, Lin ZF, et al. A general Lewis acidic etching route for preparing MXenes with enhanced electrochemical performance in non-aqueous electrolyte. Nat Mater 2020, 19: 894-899.

[13] Schuster JC, Nowotny H. Investigations of the ternary systems (Zr,Hf,Nb,Ta)-Al-C and studies on complex carbides. Int J Mater Res 1980, 71: 341-346.

[14] Barsoum MW, El-Raghy T. A progress report on $\mathrm{Ti}_{3} \mathrm{SiC}_{2}$, $\mathrm{Ti}_{3} \mathrm{GeC}_{2}$, and the H-phases, $\mathrm{M}_{2} \mathrm{BX}$. J Mater Synth Process 1997, 5: 197-216.

[15] Barsoum MW, Farber L, Levin I, et al. High-resolution transmission electron microscopy of $\mathrm{Ti}_{4} \mathrm{AlN}_{3}$, or $\mathrm{Ti}_{3} \mathrm{Al}_{2} \mathrm{~N}_{2}$ revisited. J Am Ceram Soc 1999, 82: 2545-2547.

[16] Hu CF, Li FZ, Zhang J, et al. $\mathrm{Nb}_{4} \mathrm{AlC}_{3}$ : A new compound belonging to the MAX phases. Scripta Mater 2007, 57 : 893-896.

[17] Lin ZJ, Zhuo MJ, Zhou YC, et al. Microstructures and theoretical bulk modulus of layered ternary tantalum aluminum carbides. J Am Ceram Soc 2006, 89: 3765-3769.

[18] Fashandi H, Dahlqvist M, Lu J, et al. Synthesis of $\mathrm{Ti}_{3} \mathrm{AuC}_{2}, \mathrm{Ti}_{3} \mathrm{Au}_{2} \mathrm{C}_{2}$ and $\mathrm{Ti}_{3} \mathrm{IrC}_{2}$ by noble metal substitution reaction in $\mathrm{Ti}_{3} \mathrm{SiC}_{2}$ for high-temperature-stable ohmic contacts to SiC. Nat Mater 2017, 16: 814-818.

[19] Li M, Lu J, Luo K, et al. Element replacement approach by reaction with lewis acidic molten salts to synthesize nanolaminated MAX phases and MXenes. $J$ Am Chem Soc 2019, 141: 4730-4737.

[20] Xu Q, Zhou YC, Zhang HM, et al. Theoretical prediction, synthesis, and crystal structure determination of new MAX phase compound $\mathrm{V}_{2}$ SnC. $J$ Adv Ceram 2020, 9: 481-492.

[21] Chen LL, Deng ZX, Li M, et al. Phase diagrams of novel MAX phases. J Inorg Mater 2020, 35: 35-40.

[22] Högberg H, Eklund P, Emmerlich J, et al. Epitaxial $\mathrm{Ti}_{2} \mathrm{GeC}, \mathrm{Ti}_{3} \mathrm{GeC}_{2}$, and $\mathrm{Ti}_{4} \mathrm{GeC}_{3}$ MAX-phase thin films grown by magnetron sputtering. J Mater Res 2005, 20: 779-782.

[23] Scabarozi TH, Hettinger JD, Lofland SE, et al. Epitaxial growth and electrical-transport properties of $\mathrm{Ti}_{7} \mathrm{Si}_{2} \mathrm{C}_{5}$ thin films synthesized by reactive sputter-deposition. Scripta Mater 2011, 65: 811-814.

[24] Etzkorn J, Ade M, Hillebrecht H. $\mathrm{V}_{2} \mathrm{AlC}, \mathrm{V}_{4} \mathrm{AlC}_{3-x}(x \approx$ 0.31 ), and $\mathrm{V}_{12} \mathrm{Al}_{3} \mathrm{C}_{8}$ : Synthesis, crystal growth, structure, and superstructure. Inorg Chem 2007, 46: 7646-7653.

[25] $\mathrm{Hu} \mathrm{C}$, Lai CC, Tao Q, et al. $\mathrm{Mo}_{2} \mathrm{Ga}_{2} \mathrm{C}$ : A new ternary nanolaminated carbide. Chem Commun (Camb) 2015, 51: 6560-6563.

[26] Wang JJ, Ye TN, Gong YT, et al. Discovery of hexagonal ternary phase $\mathrm{Ti}_{2} \mathrm{InB}_{2}$ and its evolution to layered boride TiB. Nat Commun 2019, 10: 2284.

[27] Qi XX, Song GP, Yin WL, et al. Analysis on phase stability and mechanical property of newly-discovered ternary layered boride $\mathrm{Cr}_{4} \mathrm{AlB}_{4}$. J Inorg Mater 2020, 35: $53-60$.

[28] Liu ZM, Wu ED, Wang JM, et al. Crystal structure and formation mechanism of $\left(\mathrm{Cr}_{2 / 3} \mathrm{Ti}_{1 / 3}\right)_{3} \mathrm{AlC}_{2} \mathrm{MAX}$ phase. 
Acta Mater 2014, 73: 186-193.

[29] Tao QZ, Dahlqvist M, Lu J, et al. Two-dimensional $\mathrm{Mo}_{1.33} \mathrm{C}$ MXene with divacancy ordering prepared from parent 3D laminate with in-plane chemical ordering. Nat Commun 2017, 8: 14949.

[30] Li YB, Lu J, Li M, et al. Multielemental single-atom-thick $A$ layers in nanolaminated $\mathrm{V}_{2}(\mathrm{Sn}, A) \mathrm{C}(A=\mathrm{Fe}, \mathrm{Co}, \mathrm{Ni}, \mathrm{Mn})$ for tailoring magnetic properties. Proc Natl Acad Sci USA 2020, 117: 820-825.

[31] Sokol M, Natu V, Kota S, et al. On the chemical diversity of the MAX phases. Trends Chem 2019, 1: 210-223.

[32] Mian L, Qing H. Recent progress and prospects of ternary layered carbides/nitrides MAX phases and their derived two-dimensional nanolaminates MXenes. J Inorg Mater 2019, 35: 1-7. (in Chinese)

[33] Zhang H, Hu T, Wang XH, et al. Structural defects in MAX phases and their derivative MXenes: A look forward. J Mater Sci Technol 2020, 38: 205-220.

[34] Zhang $\mathrm{H}, \mathrm{Hu} \mathrm{T}$, Wang $\mathrm{XH}$, et al. Discovery of carbon-vacancy ordering in $\mathrm{Nb}_{4} \mathrm{AlC}_{3-x}$ under the guidance of first-principles calculations. Sci Rep 2015, 5: 14192.

[35] Bao WC, Wang XG, Ding HJ, et al. High-entropy $\mathrm{M}_{2} \mathrm{AlC}-\mathrm{MC}(\mathrm{M}=\mathrm{Ti}, \mathrm{Zr}, \mathrm{Hf}, \mathrm{Nb}, \mathrm{Ta})$ composite: Synthesis and microstructures. Scripta Mater 2020, 183: 33-38.

[36] Anasori B, Dahlqvist M, Halim J, et al. Experimental and theoretical characterization of ordered MAX phases $\mathrm{Mo}_{2} \mathrm{TiAlC}_{2}$ and $\mathrm{Mo}_{2} \mathrm{Ti}_{2} \mathrm{AlC}_{3}$. J Appl Phys 2015, 118: 094304.

[37] Tao QZ, Lu J, Dahlqvist M, et al. Atomically layered and ordered rare-earth i-MAX phases: A new class of magnetic quaternary compounds. Chem Mater 2019, 31: 2476-2485.

[38] Barsoum MW. The $\mathrm{M}_{N+1} \mathrm{AX}_{N}$ phases: A new class of solids: Thermodynamically stable nanolaminates. Prog Solid State Chem 2000, 28: 201-281.

[39] Fang Y, Liu XH, Feng YX, et al. Microstructure and mechanical properties of $\mathrm{Ti}_{3}(\mathrm{Al}, \mathrm{Ga}) \mathrm{C}_{2} / \mathrm{Al}_{2} \mathrm{O}_{3}$ composites prepared by in situ reactive hot pressing. J Adv Ceram 2020, 9: 782-790.

[40] Gong YM, Tian WB, Zhang PG, et al. Slip casting and pressureless sintering of $\mathrm{Ti}_{3} \mathrm{AlC}_{2} . J$ Adv Ceram 2019, 8: 367-376.

[41] Lorenz M, Travitzky N, Rambo CR. Effect of processing parameters on in situ screen printing-assisted synthesis and electrical properties of $\mathrm{Ti}_{3} \mathrm{SiC}_{2}$-based structures. $J$ Adv Ceram 2021, 10: 129-138.

[42] Liu G, Li J, Chen Y, et al. Self-propagating high-temperature synthesis (SHS) of Ti-containing ceramic composites under ultra-high gravity. Rare Met Mater Eng 2011, 40: 262-264. (in Chinese)

[43] Yeh CL, Chen JH. Combustion synthesis of $\left(\mathrm{Ti}_{1-x} \mathrm{Nb}_{x}\right)_{2} \mathrm{AlC}$ solid solutions from elemental and $\mathrm{Nb}_{2} \mathrm{O}_{5} / \mathrm{Al}_{4} \mathrm{C}_{3}$-containing powder compacts. Ceram Int 2011, 37: 3089-3094.

[44] Zhou AG, Wang CG, Ge ZB, et al. Preparation of $\mathrm{Ti}_{3} \mathrm{AlC}_{2}$ and $\mathrm{Ti}_{2} \mathrm{AlC}$ by self-propagating high-temperature synthesis. J Mater Sci Lett 2001, 20: 1971-1973.

[45] Yan M, Mei BC, Zhu JQ, et al. Synthesis of high-purity bulk $\mathrm{Ti}_{2} \mathrm{AlN}$ by spark plasma sintering (SPS). Ceram Int 2008, 34: 1439-1442.

[46] Shi SL, Pan W. Machinable $\mathrm{Ti}_{3} \mathrm{SiC}_{2}$ /hydroxyapatite bioceramic composites by spark plasma sintering. $\mathrm{J} \mathrm{Am}$ Ceram Soc 2007, 90: 3331-3333.

[47] Zhou AG, Wang CG, Hunag Y. Synthesis and mechanical properties of $\mathrm{Ti}_{3} \mathrm{AlC}_{2}$ by spark plasma sintering. J Mater Sci 2003, 38: 3111-3115.

[48] Niu YH, Fu S, Zhang KB, et al. Synthesis, microstructure, and properties of high purity $\mathrm{Mo}_{2} \mathrm{TiAlC}_{2}$ ceramics fabricated by spark plasma sintering. $J$ Adv Ceram 2020, 9: 759-768.

[49] Li FZ, Zhang HB, Wang Q, et al. Microwave sintering of $\mathrm{Ti}_{3} \mathrm{Si}(\mathrm{Al}) \mathrm{C}_{2}$ ceramic. $J$ Am Ceram Soc 2014, 97: 2731-2735.

[50] Liu WL, Qiu CJ, Zhou J, et al. Fabrication of $\mathrm{Ti}_{2} \mathrm{AlN}$ ceramics with orientation growth behavior by the microwave sintering method. J Eur Ceram Soc 2015, 35: 1385-1391.

[51] Bai YL, He XD, Li YB, et al. Rapid synthesis of bulk $\mathrm{Ti}_{2} \mathrm{AlC}$ by self-propagating high temperature combustion synthesis with a pseudo-hot isostatic pressing process. $J$ Mater Res 2009, 24: 2528-2535.

[52] Bai YL, Zhang HX, He XD, et al. Growth morphology and microstructural characterization of nonstoichiometric $\mathrm{Ti}_{2} \mathrm{AlC}$ bulk synthesized by self-propagating high temperature combustion synthesis with pseudo hot isostatic pressing. Int J Refract Met Hard Mater 2014, 45: 58-63.

[53] Bai YL, He XD, Zhu CC, et al. Preparation of ternary layered $\mathrm{Ti}_{3} \mathrm{SiC}_{2}$ ceramic by SHS/PHIP. Key Eng Mater 2008, 368-372: 1851-1854.

[54] Palmquist JP, Jansson U, Seppänen T, et al. Magnetron sputtered epitaxial single-phase $\mathrm{Ti}_{3} \mathrm{SiC}_{2}$ thin films. Appl Phys Lett 2002, 81: 835-837.

[55] Joelsson T, Hörling A, Birch J, et al. Single-crystal $\mathrm{Ti}_{2} \mathrm{AlN}$ thin films. Appl Phys Lett 2005, 86: 111913.

[56] Rosén J, Ryves L, Persson POÅ, et al. Deposition of epitaxial $\mathrm{Ti}_{2} \mathrm{AlC}$ thin films by pulsed cathodic arc. $J$ Appl Phys 2007, 101: 056101.

[57] Phani AR, Krzanowski JE, Nainaparampil JJ. Structural and mechanical properties of $\mathrm{TiC}$ and $\mathrm{Ti}-\mathrm{Si}-\mathrm{C}$ films deposited by pulsed laser deposition. J Vac Sci Technol A: Vac Surf Films 2001, 19: 2252-2258.

[58] Goto T, Hirai T. Chemically vapor deposited $\mathrm{Ti}_{3} \mathrm{SiC}_{2}$. Mater Res Bull 1987, 22: 1195-1201.

[59] Pickering E, Lackey WJ, Crain S. CVD of $\mathrm{Ti}_{3} \mathrm{SiC}_{2}$. Chem Vap Deposition 2000, 6: 289-295.

[60] Eklund P, Beckers M, Jansson U, et al. The $\mathrm{M}_{n+1} \mathrm{AX}_{n}$ phases: Materials science and thin-film processing. Thin Solid Films 2010, 518: 1851-1878.

[61] Xiao D, Zhu JF, Wang F, et al. Synthesis of nano sized 
$\mathrm{Cr}_{2} \mathrm{AlC}$ powders by molten salt method. J Nanosci Nanotechnol 2015, 15: 7341-7345.

[62] Wang BX, Zhou AG, Hu QK, et al. Synthesis and oxidation resistance of $\mathrm{V}_{2} \mathrm{AlC}$ powders by molten salt method. Int J Appl Ceram Technol 2017, 14: 873-879.

[63] Liu HJ, Wang Y, Yang LX, et al. Synthesis and characterization of nanosized $\mathrm{Ti}_{3} \mathrm{AlC}_{2}$ ceramic powder by elemental powders of $\mathrm{Ti}, \mathrm{Al}$ and $\mathrm{C}$ in molten salt. J Mater Sci Technol 2020, 37: 77-84.

[64] Dash A, Vaßen R, Guillon O, et al. Molten salt shielded synthesis of oxidation prone materials in air. Nat Mater 2019, 18: 465-470.

[65] Heuer AH, Roberts JP. The influence of annealing on the strength of corundum Crystals Proc Brit Ceram Soc 1966, 6: $17-27$.

[66] Lange FF, Gupta TK. Crack healing by heat treatment. $J$ Am Ceram Soc 1970, 53: 54-55.

[67] Roberts JTA, Wrona BJ. Crack healing in $\mathrm{UO}_{2}$. J Am Ceram Soc 1973, 56: 297-299.

[68] Gupta TK. Crack healing and strengthening of thermally shocked alumina. J Am Ceram Soc 1976, 59: 259-262.

[69] Lange FF. Healing of surface cracks in SiC by oxidation. $J$ Am Ceram Soc 1970, 53: 290.

[70] Easler TE, Bradt RC, Tressler RE. Effects of oxidation and oxidation under load on strength distributions of $\mathrm{Si}_{3} \mathrm{~N}_{4}$. J Am Ceram Soc 1982, 65: 317-320.

[71] Zhang YH, Edwards L, Plumbridge WJ. Crack healing in a silicon nitride ceramic. J Am Ceram Soc 1998, 81: 1861-1868.

[72] Korouš J, Chu MC, Nakatani M, et al. Crack healing behavior of silicon carbide ceramics. J Am Ceram Soc 2000, 83: 2788-2792.

[73] Takahashi K, Kim BS, Chu MC, et al. Crack-healing behavior and static fatigue strength of $\mathrm{Si}_{3} \mathrm{~N}_{4} / \mathrm{SiC}$ ceramics held under stress at temperature $\left(800,900,1000{ }^{\circ} \mathrm{C}\right) . J$ Eur Ceram Soc 2003, 23: 1971-1978.

[74] Takahashi K, Yokouchi M, Lee SK, et al. Crack-healing behavior of $\mathrm{Al}_{2} \mathrm{O}_{3}$ toughened by $\mathrm{SiC}$ whiskers. $\mathrm{J} \mathrm{Am}$ Ceram Soc 2003, 86: 2143-2147.

[75] Osada T, Kamoda K, Mitome M, et al. A novel design approach for self-crack-healing structural ceramics with 3D networks of healing activator. Sci Rep 2017, 7: 17853.

[76] Greil P. Generic principles of crack-healing ceramics. $J$ Adv Ceram 2012, 1: 249-267.

[77] Lee JK, Kim H. Monoclinic-to-tetragonal transformation and crack healing by annealing in aged 2 Y-TZP ceramics. J Mater Sci Lett 1993, 12: 1765-1767.

[78] Jun L, Zheng ZX, Ding HF, et al. Preliminary study of the crack healing and strength recovery of $\mathrm{Al}_{2} \mathrm{O}_{3}$-matrix composites. Fatigue Fract Eng Mater Struct 2004, 27: 89-97.

[79] Geng X, Yang F, Chen YQ, et al. Silver assisted crack healing in SiC. Acta Mater 2016, 105: 121-129.

[80] Li SB, Bei GP, Chen XD, et al. Crack healing induced electrical and mechanical properties recovery in a $\mathrm{Ti}_{2} \mathrm{SnC}$ ceramic. J Eur Ceram Soc 2016, 36: 25-32.

[81] Song GM, Pei YT, Sloof WG, et al. Oxidation-induced crack healing in $\mathrm{Ti}_{3} \mathrm{AlC}_{2}$ ceramics. Scripta Mater 2008, 58: 13-16.

[82] Yang HJ, Pei YT, Rao JC, et al. High temperature healing of $\mathrm{Ti}_{2} \mathrm{AlC}$ : On the origin of inhomogeneous oxide scale. Scripta Mater 2011, 65: 135-138.

[83] Li SB, Song GM, Kwakernaak K, et al. Multiple crack healing of a $\mathrm{Ti}_{2} \mathrm{AlC}$ ceramic. J Eur Ceram Soc 2012, 32: 1813-1820.

[84] Yang HJ, Pei YT, Rao JC, et al. Self-healing performance of $\mathrm{Ti}_{2} \mathrm{AlC}$ ceramic. J Mater Chem 2012, 22: 8304.

[85] Li SB, Xiao LO, Song GM, et al. Oxidation and crack healing behavior of a fine-grained $\mathrm{Cr}_{2} \mathrm{AlC}$ ceramic. $J \mathrm{Am}$ Ceram Soc 2013, 96: 892-899.

[86] Bei GP, Pedimonte BJ, Fey T, et al. Oxidation behavior of MAX phase $\mathrm{Ti}_{2} \mathrm{Al}_{(1-x)} \mathrm{Sn}_{x} \mathrm{C}$ solid solution. J Am Ceram Soc 2013, 96: 1359-1362.

[87] Bei GP, Pedimonte BJ, Pezoldt M, et al. Crack healing in $\mathrm{Ti}_{2} \mathrm{Al}_{0 .}{ }_{5} \mathrm{Sn}_{0 .} \mathrm{C}-\mathrm{Al}_{2} \mathrm{O}_{3}$ composites. J Am Ceram Soc 2015, 98: 1604-1610.

[88] Li SB, Li HL, Zhou Y, et al. Mechanism for abnormal thermal shock behavior of $\mathrm{Cr}_{2} \mathrm{AlC}$. J Eur Ceram Soc 2014, 34: 1083-1088.

[89] Li SB, Zhang LQ, Yu WB, et al. Precipitation induced crack healing in a $\mathrm{Ti}_{2} \mathrm{SnC}$ ceramic in vacuum. Ceram Int 2017, 43: 6963-6966.

[90] Zhang HB, Zhou YC, Bao YW, et al. Abnormal thermal shock behavior of $\mathrm{Ti}_{3} \mathrm{SiC}_{2}$ and $\mathrm{Ti}_{3} \mathrm{AlC}_{2}$. J Mater Res 2006, 21: 2401-2407.

[91] Li HL, Li SB, Zhou Y. Cyclic thermal shock behaviour of a $\mathrm{Cr}_{2} \mathrm{AlC}$ ceramic. Mater Sci Eng: A 2014, 607: 525-529.

[92] Wang XH, Zhou YC. High-temperature oxidation behavior of $\mathrm{Ti}_{2} \mathrm{AlC}$ in air. Oxid Met 2003, 59: 303-320.

[93] Wang XH, Zhou YC. Oxidation behavior of $\mathrm{Ti}_{3} \mathrm{AlC}_{2}$ at 1000-1400 ${ }^{\circ} \mathrm{C}$ in air. Corros Sci 2003, 45: 891-907.

[94] Pei R, McDonald SA, Shen L, et al. Crack healing behaviour of $\mathrm{Cr}_{2} \mathrm{AlC}$ MAX phase studied by X-ray tomography. J Eur Ceram Soc 2017, 37: 441-450.

[95] Song GM, Li SB, Zhao CX, et al. Ultra-high temperature ablation behavior of $\mathrm{Ti}_{2} \mathrm{AlC}$ ceramics under an oxyacetylene flame. J Eur Ceram Soc 2011, 31: 855-862.

[96] Hu SJ, Li SB, Li HL, et al. Oxyacetylene torch testing and microstructural characterization of a $\mathrm{Cr}_{2} \mathrm{AlC}$ ceramic. $J$ Alloys Compd 2018, 740: 77-81.

[97] Yang HJ, Pei YT, Song GM, et al. Healing performance of $\mathrm{Ti}_{2} \mathrm{AlC}$ ceramic studied with in situ microcantilever bending. J Eur Ceram Soc 2013, 33: 383-391.

[98] Sloof WG, Pei RZ, McDonald SA, et al. Repeated crack healing in MAX-phase ceramics revealed by 4D in situ synchrotron X-ray tomographic microscopy. Sci Rep 2016, 6: 23040 .

[99] Toohey KS, Sottos NR, Lewis JA, et al. Self-healing materials with microvascular networks. Nat Mater 2007, 6: $581-585$. 
[100] Boatemaa L, Bosch M, Farle AS, et al. Autonomous high-temperature healing of surface cracks in $\mathrm{Al}_{2} \mathrm{O}_{3}$ containing $\mathrm{Ti}_{2} \mathrm{AlC}$ particles. $J$ Am Ceram Soc 2018, 101: 5684-5693.

[101] Wang ZY, Sun J, Xu BB, et al. Reducing the self-healing temperature of $\mathrm{Ti}_{2} \mathrm{AlC}$ MAX phase coating by substituting Al with Sn. J Eur Ceram Soc 2020, 40: 197-201.

[102] Sarkar D, Padhiary A, Cho SJ, et al. Oxidation-induced strength behavior of $\mathrm{Ti}_{3} \mathrm{SiC}_{2}$. J Mater Process Technol 2009, 209: 641-646.

[103] Berger O, Boucher R. Crack healing in Y-doped $\mathrm{Cr}_{2} \mathrm{AlC}-\mathrm{MAX}$ phase coatings. Surf Eng 2017, 33: 192-203.

[104] Liu B, Wang JY, Zhang J, et al. Theoretical investigation of A-element atom diffusion in $\mathrm{Ti}_{2} \mathrm{AC}(\mathrm{A}=\mathrm{Sn}, \mathrm{Ga}, \mathrm{Cd}$, In, and $\mathrm{Pb}$ ). Appl Phys Lett 2009, 94: 181906.

[105] Ding JX, Tian WB, Zhang PG, et al. Preparation and arc erosion properties of $\mathrm{Ag} / \mathrm{Ti}_{2} \mathrm{SnC}$ composites under electric arc discharging. $J A d v$ Ceram 2019, 8: 90-101.

[106] Gonzalez-Julian J, Mauer G, Sebold D, et al. $\mathrm{Cr}_{2} \mathrm{AlC}$ MAX phase as bond coat for thermal barrier coatings: Processing, testing under thermal gradient loading, and future challenges. $J \mathrm{Am}$ Ceram Soc 2020, 103: 2362-2375.

[107] Wang ZY. Study on preparation and properties of novel $\mathrm{Ti}_{3} \mathrm{SiC}_{2}-\mathrm{Cu}$ vacuum contact materials. M.S. Thesis. Beijing, China: Beijng Jiaotong University, 2008. (in Chinese)

[108] Hu WQ, Huang ZY, Wang YB, et al. Layered ternary MAX phases and their MX particulate derivative reinforced metal matrix composite: A review. $J$ Alloys Compd 2021, 856: 157313.

[109] Mashtalir O, Naguib M, Dyatkin B, et al. Kinetics of aluminum extraction from $\mathrm{Ti}_{3} \mathrm{AlC}_{2}$ in hydrofluoric acid. Mater Chem Phys 2013, 139: 147-152.

[110] Li ZY, Wang LB, Sun DD, et al. Synthesis and thermal stability of two-dimensional carbide MXene $\mathrm{Ti}_{3} \mathrm{C}_{2}$. Mater Sci Eng: B 2015, 191: 33-40.

[111] Sun DD, Wang MS, Li ZY, et al. Two-dimensional $\mathrm{Ti}_{3} \mathrm{C}_{2}$ as anode material for $\mathrm{Li}$-ion batteries. Electrochem Commun 2014, 47: 80-83.

[112] Hu SJ, Li SB, Xu WM, et al. Rapid preparation, thermal stability and electromagnetic interference shielding properties of two-dimensional $\mathrm{Ti}_{3} \mathrm{C}_{2}$ MXene. Ceram Int 2019, 45: 19902-19909.

[113] Hu J, Li SB, Zhang J, et al. Mechanical properties and frictional resistance of $\mathrm{Al}$ composites reinforced with $\mathrm{Ti}_{3} \mathrm{C}_{2} \mathrm{~T}_{x}$ MXene. Chin Chem Lett 2020, 31: 996-999.

[114] $\mathrm{Xu} \mathrm{WM}, \mathrm{Li} \mathrm{SB}, \mathrm{Hu} \mathrm{SJ}$, et al. Effect of $\mathrm{Ti}_{3} \mathrm{AlC}_{2}$ precursor and processing conditions on microwave absorption performance of resultant $\mathrm{Ti}_{3} \mathrm{C}_{2} \mathrm{~T}_{x}$ MXene. $J$ Mater Sci 2021, 56: 9287-9301.

[115] Ghidiu M, Lukatskaya MR, Zhao MQ, et al. Conductive two-dimensional titanium carbide 'clay' with high volumetric capacitance. Nature 2014, 516: 78-81.

[116] Liu FF, Zhou AG, Chen JF, et al. Preparation of $\mathrm{Ti}_{3} \mathrm{C}_{2}$ and
$\mathrm{Ti}_{2} \mathrm{C}$ MXenes by fluoride salts etching and methane adsorptive properties. Appl Surf Sci 2017, 416: 781-789.

[117] Wu M, Wang BX, Hu QK, et al. The synthesis process and thermal stability of $\mathrm{V}_{2} \mathrm{C}$ MXene. Materials 2018, 11: 2112.

[118] Liu FF, Zhou J, Wang SW, et al. Preparation of high-purity $\mathrm{V}_{2} \mathrm{C}$ MXene and electrochemical properties as Li-ion batteries. $J$ Electrochem Soc 2017, 164: A709-A713.

[119] Tian ZB, Chen KX, Sun SY, et al. Crystalline boron nitride nanosheets by sonication-assisted hydrothermal exfoliation. $J$ Adv Ceram 2019, 8: 72-78.

[120] Wang LB, Zhang H, Wang B, et al. Synthesis and electrochemical performance of $\mathrm{Ti}_{3} \mathrm{C}_{2} \mathrm{~T}_{x}$ with hydrothermal process. Electron Mater Lett 2016, 12: 702-710.

[121] Wang LB, Liu DR, Lian WW, et al. The preparation of $\mathrm{V}_{2} \mathrm{CT}_{x}$ by facile hydrothermal-assisted etching processing and its performance in lithium-ion battery. J Mater Res Technol 2020, 9: 984-993.

[122] Wu M, He Y, Wang LB, et al. Synthesis and electrochemical properties of $\mathrm{V}_{2} \mathrm{C}$ MXene by etching in opened/closed environments. J Adv Ceram 2020, 9: 749-758.

[123] Guo YT, Jin S, Wang LB, et al. Synthesis of two-dimensional carbide $\mathrm{Mo}_{2} \mathrm{CT}_{x}$ MXene by hydrothermal etching with fluorides and its thermal stability. Ceram Int 2020, 46: 19550-19556.

[124] Sun DD, Zhou AG, Li ZY, et al. Corrosion behavior of $\mathrm{Ti}_{3} \mathrm{AlC}_{2}$ in molten $\mathrm{KOH}$ at $700{ }^{\circ} \mathrm{C} . J$ Adv Ceram 2013, 2: 313-317.

[125] Urbankowski P, Anasori B, Makaryan T, et al. Synthesis of two-dimensional titanium nitride $\mathrm{Ti}_{4} \mathrm{~N}_{3}$ (MXene). Nanoscale 2016, 8: 11385-11391.

[126] Li M, Li YB, Luo K, et al. Synthesis of novel max phase $\mathrm{Ti}_{3} \mathrm{ZnC}_{2}$ via A-site-element-substitution approach. J Inorg Mater 2019, 34: 60.

[127] Sun W, Shah SA, Chen Y, et al. Electrochemical etching of $\mathrm{Ti}_{2} \mathrm{AlC}$ to $\mathrm{Ti}_{2} \mathrm{CT}_{x}$ (MXene) in low-concentration hydrochloric acid solution. J Mater Chem A 2017, 5: 21663-21668.

[128] Yang S, Zhang PP, Wang FX, et al. Fluoride-free synthesis of two-dimensional titanium carbide (MXene) using A binary aqueous system. Angew Chem Int Ed 2018, 57: 15491-15495.

[129] Li TF, Yao LL, Liu QL, et al. Fluorine-free synthesis of high-purity $\mathrm{Ti}_{3} \mathrm{C}_{2} \mathrm{~T}_{x}(\mathrm{~T}=\mathrm{OH}, \mathrm{O})$ via alkali treatment. Angew Chem Int Ed 2018, 130: 6223-6227.

[130] Natu V, Pai R, Sokol M, et al. 2D $\mathrm{Ti}_{3} \mathrm{C}_{2} \mathrm{~T}_{z}$ MXene synthesized by water-free etching of $\mathrm{Ti}_{3} \mathrm{AlC}_{2}$ in polar organic solvents. Chem 2020, 6: 616-630.

[131] Meshkian R, Näslund LA, Halim J, et al. Synthesis of two-dimensional molybdenum carbide, $\mathrm{Mo}_{2} \mathrm{C}$, from the gallium based atomic laminate $\mathrm{Mo}_{2} \mathrm{Ga}_{2}$ C. Scripta Mater 2015, 108: 147-150.

[132] Halim J, Kota S, Lukatskaya MR, et al. Synthesis and characterization of 2D molybdenum carbide (MXene). 
Adv Funct Mater 2016, 26: 3118-3127.

[133] Naguib M, Halim J, Lu J, et al. New two-dimensional niobium and vanadium carbides as promising materials for Li-ion batteries. $J$ Am Chem Soc 2013, 135: 15966-15969.

[134] Wang H, Wu Y, Yuan XZ, et al. Clay-inspired MXenebased electrochemical devices and photo-electrocatalyst: State-of-the-art progresses and challenges. Adv Mater 2018, 30: 1704561.

[135] Chang FY, Li CS, Yang J, et al. Synthesis of a new graphene-like transition metal carbide by de-intercalating $\mathrm{Ti}_{3} \mathrm{AlC}_{2}$. Mater Lett 2013, 109: 295-298.

[136] Cheng RF, $\mathrm{Hu} \mathrm{T}$, Zhang $\mathrm{H}$, et al. Understanding the lithium storage mechanism of $\mathrm{Ti}_{3} \mathrm{C}_{2} \mathrm{~T}_{x}$ MXene. $J$ Phys Chem C 2019, 123: 1099-1109.

[137] Cui C, Hu MM, Zhang C, et al. High-capacitance $\mathrm{Ti}_{3} \mathrm{C}_{2} \mathrm{~T}_{x}$ MXene obtained by etching submicron $\mathrm{Ti}_{3} \mathrm{AlC}_{2}$ grains grown in molten salt. Chem Commun (Camb) 2018, 54: 8132-8135.

[138] Guo LC, Zhang ZY, Li MH, et al. Extremely high thermal conductivity of carbon fiber/epoxy with synergistic effect of MXenes by freeze-drying. Compos Commun 2020, 19: 134-141.

[139] Alhabeb M, Maleski K, Anasori B, et al. Guidelines for synthesis and processing of two-dimensional titanium carbide $\left(\mathrm{Ti}_{3} \mathrm{C}_{2} \mathrm{~T}_{x}\right.$ MXene). Chem Mater 2017, 29: 7633-7644.

[140] Yang LX, Wang Y, Zhang HL, et al. A simple method for the synthesis of nanosized $\mathrm{Ti}_{3} \mathrm{AlC}_{2}$ powder in $\mathrm{NaCl}-\mathrm{KCl}$ molten salt. Mater Res Lett 2019, 7: 361-367.

[141] Baldino L, Concilio S, Cardea S, et al. Interpenetration of natural polymer aerogels by supercritical drying. Polymers 2016, 8: 106.

[142] Rakhi RB, Ahmed B, Hedhili MN, et al. Effect of postetch annealing gas composition on the structural and electrochemical properties of $\mathrm{Ti}_{2} \mathrm{CT}_{x}$ MXene electrodes for supercapacitor applications. Chem Mater 2015, 27: 5314-5323.

[143] Hu MM, Cheng RF, Li ZJ, et al. Interlayer engineering of $\mathrm{Ti}_{3} \mathrm{C}_{2} \mathrm{~T}_{x}$ MXenes towards high capacitance supercapacitors. Nanoscale 2020, 12: 763-771.

[144] Zhao D, Clites M, Ying G, et al. Alkali-induced crumpling of $\mathrm{Ti}_{3} \mathrm{C}_{2} \mathrm{~T}_{x}$ (MXene) to form 3D porous networks for sodium ion storage. Chem Commun (Camb) 2018, 54: 4533-4536.

[145] Tan C, Cao X, Wu XJ, et al. Recent advances in ultrathin two-dimensional nanomaterials. Chem Rev 2017, 117: 6225-6331.

[146] Wang C, Cheng R, Hou PX, et al. MXene-carbon nanotube hybrid membrane for robust recovery of $\mathrm{Au}$ from trace-level solution. ACS Appl Mater Interfaces 2020, 12: 43032-43041.

[147] Cheng RF, Hu T, Hu MM, et al. MXenes induce epitaxial growth of size-controlled noble nanometals: A case study for surface enhanced Raman scattering (SERS). J Mater
Sci Technol 2020, 40: 119-127.

[148] Cui C, Cheng RF, Zhang $\mathrm{H}$, et al. Ultrastable MXene@Pt/SWCNTs' nanocatalysts for hydrogen evolution reaction. Adv Funct Mater 2020, 30: 2000693.

[149] Crewe AV. Scanning transmission electron microscopy. $J$ Microsc 1974, 100: 247-259.

[150] Murray CB, Kagan CR, Bawendi MG. Synthesis and characterization of monodisperse nanocrystals and close-packed nanocrystal assemblies. Annu Rev Mater Sci 2000, 30: 545-610.

[151] Halim J, Palisaitis J, Lu J, et al. Synthesis of two-dimensional $\mathrm{Nb}_{1.33} \mathrm{C}$ (MXene) with randomly distributed vacancies by etching of the quaternary solid solution $\left(\mathrm{Nb}_{2 / 3} \mathrm{Sc}_{1 / 3}\right)_{2} \mathrm{AlC}$ MAX phase. ACS Appl Nano Mater 2018, 1: 2455-2460.

[152] Zhang H, Hu T, Sun WW, et al. Atomic repartition in MXenes by electron probes. Chem Mater 2019, 31: 4385-4391.

[153] Zhang JQ, Zhao YF, Guo X, et al. Single platinum atoms immobilized on an MXene as an efficient catalyst for the hydrogen evolution reaction. Nat Catal 2018, 1: 985-992.

[154] Sang XH, Xie Y, Lin MW, et al. Atomic defects in monolayer titanium carbide $\left(\mathrm{Ti}_{3} \mathrm{C}_{2} \mathrm{~T}_{x}\right)$ MXene. ACS Nano 2016, 10: 9193-9200.

[155] Dahlqvist M, Lu J, Meshkian R, et al. Prediction and synthesis of a family of atomic laminate phases with Kagomé-like and in-plane chemical ordering. Sci $A d v$ 2017, 3: e1700642.

[156] Meshkian R, Dahlqvist M, Lu J, et al. W-based atomic laminates and their 2D derivative $\mathrm{W}_{1.33} \mathrm{C}$ MXene with vacancy ordering. Adv Mater 2018, 30: 1706409.

[157] Xia F, Lao J, Yu R, et al. Ambient oxidation of $\mathrm{Ti}_{3} \mathrm{C}_{2}$ MXene initialized by atomic defects. Nanoscale 2019, 11: 23330-23337.

[158] Palisaitis J, Persson I, Halim J, et al. On the structural stability of MXene and the role of transition metal adatoms. Nanoscale 2018, 10: 10850-10855.

[159] Zhang X, Zhang ZH, Zhou Z. MXene-based materials for electrochemical energy storage. $J$ Energy Chem 2018, 27: 73-85.

[160] Cheng RF, Wang ZH, Cui C, et al. One-step incorporation of nitrogen and vanadium between $\mathrm{Ti}_{3} \mathrm{C}_{2} \mathrm{~T}_{x}$ MXene interlayers enhances lithium ion storage capability. $J$ Phys Chem C 2020, 124: 6012-6021.

[161] Liu L, Ying GB, Wen D, et al. Aqueous solution-processed MXene $\left(\mathrm{Ti}_{3} \mathrm{C}_{2} \mathrm{~T}_{x}\right)$ for non-hydrophilic epoxy resin-based composites with enhanced mechanical and physical properties. Mater Des 2021, 197: 109276.

[162] Zhang H, Wang LB, Chen Q, et al. Preparation, mechanical and anti-friction performance of MXene/polymer composites. Mater Des 2016, 92: 682-689.

[163] Fei MM, Lin RZ, Lu YW, et al. MXene-reinforced alumina ceramic composites. Ceram Int 2017, 43: 17206-17210.

[164] Wozniak J, Petrus M, Cygan T, et al. Silicon carbide 
matrix composites reinforced with two-dimensional titanium carbide-Manufacturing and properties. Ceram Int 2019, 45: 6624-6631.

[165] Liu FF, Liu YC, Zhao XD, et al. Pursuit of a high-capacity and long-life Mg-storage cathode by tailoring sandwichstructured MXene@carbon nanosphere composites. J Mater Chem A 2019, 7: 16712-16719.

[166] Shen CJ, Wang LB, Zhou AG, et al. $\mathrm{MoS}_{2}$-decorated $\mathrm{Ti}_{3} \mathrm{C}_{2}$ MXene nanosheet as anode material in lithium-ion batteries. J Electrochem Soc 2017, 164: A2654-A2659.

[167] Yan J, Ren CE, Maleski K, et al. Flexible MXene/graphene films for ultrafast supercapacitors with outstanding volumetric capacitance. Adv Funct Mater 2017, 27: 1701264.

[168] Liu R, Li J, Li M, et al. MXene-coated air-permeable pressure-sensing fabric for smart wear. ACS Appl Mater Interfaces 2020, 12: 46446-46454.

[169] Wang YH, Zhou Y, Wang YJ. Humidity activated ionic-conduction formaldehyde sensing of reduced graphene oxide decorated nitrogen-doped MXene/titanium dioxide composite film. Sens Actuat B: Chem 2020, 323: 128695.

[170] Shao BB, Wang JJ, Liu ZF, et al. $\mathrm{Ti}_{3} \mathrm{C}_{2} \mathrm{~T}_{x}$ MXene decorated black phosphorus nanosheets with improved visible-light photocatalytic activity: Experimental and theoretical studies. J Mater Chem A 2020, 8: 5171-5185.

[171] Cai C, Wang R, Liu SF, et al. Synthesis of self-assembled phytic acid-MXene nanocomposites via a facile hydrothermal approach with elevated dye adsorption capacities. Colloid Surface A 2020, 589: 124468.

[172] Deng RX, Chen BB, Li HG, et al. MXene $/ \mathrm{Co}_{3} \mathrm{O}_{4}$ composite material: Stable synthesis and its enhanced broadband microwave absorption. Appl Surf Sci 2019, 488: 921-930.

[173] Kshetri T, Tran DT, Le HT, et al. Recent advances in MXene-based nanocomposites for electrochemical energy storage applications. Prog Mater Sci 2021, 117: 100733.

[174] Wang L, Zhang MY, Yang B, et al. Recent advances in multidimensional (1D, 2D, and 3D) composite sensors derived from MXene: Synthesis, structure, application, and perspective. Small Methods 2021, 5: 2100409.

[175] Liu FF, Jin S, Xia QX, et al. Research progress on construction and energy storage performance of MXene heterostructures. J Energy Chem 2021, 62: 220-242.

[176] Ling Z, Ren CG, Zhao MQ, et al. Flexible and conductive MXene films and nanocomposites with high capacitance. PNAS 2014, 111: 16676-16681.

[177] Liu R, Li W. High-thermal-stability and high-thermalconductivity $\mathrm{Ti}_{3} \mathrm{C}_{2} \mathrm{~T}_{x}$ MXene/poly(vinyl alcohol) (PVA) composites. ACS Omega 2018, 3: 2609-2617.

[178] Mirkhani SA, Shayesteh Zeraati A, Aliabadian E, et al. High dielectric constant and low dielectric loss via poly(vinyl alcohol) $/ \mathrm{Ti}_{3} \mathrm{C}_{2} \mathrm{~T}_{x}$ MXene nanocomposites. ACS Appl Mater Interfaces 2019, 11: 18599-18608.

[179] Yu B, Tawiah B, Wang LQ, et al. Interface decoration of exfoliated MXene ultra-thin nanosheets for fire and smoke suppressions of thermoplastic polyurethane elastomer. $J$ Hazard Mater 2019, 374: 110-119.

[180] Wu XL, Hao L, Zhang JK, et al. Polymer- $\mathrm{Ti}_{3} \mathrm{C}_{2} \mathrm{~T}_{x}$ composite membranes to overcome the trade-off in solvent resistant nanofiltration for alcohol-based system. $J$ Membr Sci 2016, 515: 175-188.

[181] Naguib M, Saito $\mathrm{T}$, Lai $\mathrm{S}$, et al. $\mathrm{Ti}_{3} \mathrm{C}_{2} \mathrm{~T}_{x}$ (MXene)-polyacrylamide nanocomposite films. RSC $A d v$ 2016, 6: 72069-72073.

[182] Liu Y, Zhang J, Zhang X, et al. $\mathrm{Ti}_{3} \mathrm{C}_{2} \mathrm{~T}_{x}$ filler effect on the proton conduction property of polymer electrolyte membrane. ACS Appl Mater Interfaces 2016, 8: 20352-20363.

[183] Cao Y, Deng QH, Liu ZD, et al. Enhanced thermal properties of poly(vinylidene fluoride) composites with ultrathin nanosheets of MXene. RSC $A d v$ 2017, 7: 20494-20501.

[184] Han RL, Ma XF, Xie YL, et al. Preparation of a new 2D MXene/PES composite membrane with excellent hydrophilicity and high flux. $R S C A d v$ 2017, 7: 56204-56210.

[185] Si JY, Tawiah B, Sun WL, et al. Functionalization of MXene nanosheets for polystyrene towards high thermal stability and flame retardant properties. Polymers 2019, 11: 976.

[186] Wang BX, Zhou AG, Liu FF, et al. Carbon dioxide adsorption of two-dimensional carbide MXenes. $J A d v$ Ceram 2018, 7: 237-245.

[187] Wu M, He Y, Wang LB, et al. Synthesis and electrochemical properties of $\mathrm{V}_{2} \mathrm{C}$ MXene by etching in opened/closed environments. $J$ Adv Ceram 2020, 9: 749-758.

[188] Zhang H, Wang LB, Zhou AG, et al. Effects of 2-D transition metal carbide $\mathrm{Ti}_{2} \mathrm{CT}_{x}$ on properties of epoxy composites. RSC Adv 2016, 6: 87341-87352.

[189] Wang L, Chen LX, Song P, et al. Fabrication on the annealed $\mathrm{Ti}_{3} \mathrm{C}_{2} \mathrm{~T}_{x}$ MXene/epoxy nanocomposites for electromagnetic interference shielding application. Compos B: Eng 2019, 171: 111-118.

[190] Carey MS, Sokol M, Palmese GR, et al. Water transport and thermomechanical properties of $\mathrm{Ti}_{3} \mathrm{C}_{2} \mathrm{~T}_{z}$ MXene epoxy nanocomposites. ACS Appl Mater Interfaces 2019, 11: 39143-39149.

[191] Wei HW, Dong JD, Fang XJ, et al. $\mathrm{Ti}_{3} \mathrm{C}_{2} \mathrm{~T}_{x}$ MXene/polyaniline (PANI) sandwich intercalation structure composites constructed for microwave absorption. Compos Sci Technol 2019, 169: 52-59.

[192] Qin LQ, Tao QZ, Liu XJ, et al. Polymer-MXene composite films formed by MXene-facilitated electrochemical polymerization for flexible solid-state microsupercapacitors. Nano Energy 2019, 60: 734-742.

[193] Wang HR, Li L, Zhu CC, et al. In situ polymerized $\mathrm{Ti}_{3} \mathrm{C}_{2} \mathrm{~T}_{x} / \mathrm{PDA}$ electrode with superior areal capacitance for supercapacitors. J Alloys Compd 2019, 778: 858-865.

[194] Boota M, Anasori B, Voigt C, et al. Pseudocapacitive 
electrodes produced by oxidant-free polymerization of pyrrole between the layers of 2D titanium carbide (MXene). Adv Mater 2016, 28: 1517-1522.

[195] Tong Y, He M, Zhou YM, et al. Hybridizing polypyrrole chains with laminated and two-dimensional $\mathrm{Ti}_{3} \mathrm{C}_{2} \mathrm{~T}_{x}$ toward high-performance electromagnetic wave absorption. Appl Surf Sci 2018, 434: 283-293.

[196] Sheng XX, Zhao YF, Zhang L, et al. Properties of two-dimensional $\mathrm{Ti}_{3} \mathrm{C}_{2} \mathrm{MXene} /$ thermoplastic polyurethane nanocomposites with effective reinforcement via melt blending. Compos Sci Technol 2019, 181: 107710.

[197] Mai YJ, Li YG, Li SL, et al. Self-lubricating $\mathrm{Ti}_{3} \mathrm{C}_{2}$ nanosheets/copper composite coatings. J Alloys Compd 2019, 770: $1-5$.

[198] Kamysbayev V, James NM, Filatov AS, et al. Colloidal gelation in liquid metals enables functional nanocomposites of 2D metal carbides (MXenes) and lightweight metals. ACS Nano 2019, 13: 12415-12424.

[199] Xue YW, Wu CH, Shi XL, et al. High temperature tribological behavior of textured CSS-42L bearing steel filled with $\mathrm{Sn}-\mathrm{Ag}-\mathrm{Cu}-\mathrm{Ti}_{3} \mathrm{C}_{2}$. Tribol Int 2021, 164: 107205.

[200] Guo J, Legum B, Anasori B, et al. Cold sintered ceramic nanocomposites of 2D MXene and zinc oxide. Adv Mater 2018, 30: 1801846.

[201] Lu XF, Zhang QH, Liao JC, et al. High-efficiency thermoelectric power generation enabled by homogeneous incorporation of MXene in $(\mathrm{Bi}, \mathrm{Sb})_{2} \mathrm{Te}_{3}$ matrix. $A d v$ Energy Mater 2020, 10: 1902986.

[202] Xu SK, Wei GD, Li JZ, et al. Flexible MXene-graphene electrodes with high volumetric capacitance for integrated co-cathode energy conversion/storage devices. J Mater Chem A 2017, 5: 17442-17451.

[203] Yue Y, Liu N, Ma Y, et al. Highly self-healable 3D microsupercapacitor with MXene-graphene composite aerogel. ACS Nano 2018, 12: 4224-4232.

[204] Xu M, Bai N, Li HX, et al. Synthesis of MXene-supported layered $\mathrm{MoS}_{2}$ with enhanced electrochemical performance for Mg batteries. Chin Chem Lett 2018, 29: 1313-1316.

[205] Cao W, Ma C, Tan S, et al. Ultrathin and flexible CNTs/MXene/cellulose nanofibrils composite paper for electromagnetic interference shielding. Nano-Micro Lett 2019, 11: 72.

[206] Shen J, Liu GZ, Ji YF, et al. 2D MXene nanofilms with tunable gas transport channels. Adv Funct Mater 2018, 28: 1801511

[207] Tian W, VahidMohammadi A, Wang Z, et al. Layer-by-layer self-assembly of pillared two-dimensional multilayers. Nat Commun 2019, 10: 2558.

[208] Yang QY, Xu Z, Fang B, et al. MXene/graphene hybrid fibers for high performance flexible supercapacitors. $J$ Mater Chem A 2017, 5: 22113-22119.

[209] Rastin H, Zhang BY, Mazinani A, et al. 3D bioprinting of cell-laden electroconductive MXene nanocomposite bioinks. Nanoscale 2020, 12: 16069-16080.
[210] Wang XL, Wang LB, He Y, et al. The effect of two-dimensional $d-\mathrm{Ti}_{3} \mathrm{C}_{2}$ on the mechanical and thermal conductivity properties of thermoplastic polyurethane composites. Polym Compos 2020, 41: 350-359.

[211] Tarascon JM, Armand M. Issues and challenges facing rechargeable lithium batteries. Nature 2001, 414: 359-367.

[212] Chu S, Cui Y, Liu N. The path towards sustainable energy. Nat Mater 2016, 16: 16-22.

[213] Eftekhari A. On the theoretical capacity/energy of lithium batteries and their counterparts. ACS Sustainable Chem Eng 2019, 7: 3684-3687.

[214] Ge H, Li N, Li DY, et al. Study on the theoretical capacity of spinel lithium titanate induced by low-potential intercalation. J Phys Chem C 2009, 113: 6324-6326.

[215] Dahn JR, Zheng T, Liu Y, et al. Mechanisms for lithium insertion in carbonaceous materials. Science 1995, 270: 590-593.

[216] Tang Q, Zhou Z, Shen P. Are Mxenes promising anode materials for Li ion batteries? Computational studies on electronic properties and li storage capability of $\mathrm{Ti}_{3} \mathrm{C}_{2}$ and $\mathrm{Ti}_{3} \mathrm{C}_{2} \mathrm{X}_{2}(\mathrm{X}=\mathrm{F}, \mathrm{OH})$ monolayer. J Am Chem Soc 2012, 134: 16909-16916.

[217] Sun DD, Hu QK, Chen JF, et al. Structural transformation of MXene $\left(\mathrm{V}_{2} \mathrm{C}, \mathrm{Cr}_{2} \mathrm{C}\right.$, and $\left.\mathrm{Ta}_{2} \mathrm{C}\right)$ with $\mathrm{O}$ groups during lithiation: A first-principles investigation. ACS Appl Mater Interfaces 2016, 8: 74-81.

[218] Zhang YJ, Li JL, Gong ZW, et al. Nitrogen and sulfur co-doped vanadium carbide MXene for highly reversible lithium-ion storage. J Colloid Interface Sci 2021, 587: 489-498.

[219] Jin S, Su TC, Hu QK, et al. Thermal conductivity and electrical transport properties of double-A-layer MAX phase $\mathrm{Mo}_{2} \mathrm{Ga}_{2} \mathrm{C}$. Mater Res Lett 2020, 8: 158-164.

[220] Mei J, Ayoko GA, Hu CF, et al. Two-dimensional fluorine-free mesoporous $\mathrm{Mo}_{2} \mathrm{C}$ MXene via UV-induced selective etching of $\mathrm{Mo}_{2} \mathrm{Ga}_{2} \mathrm{C}$ for energy storage. Sustain Mater Technol 2020, 25: e00156.

[221] Bonso JS, Kalaw GD, Ferraris JP. High surface area carbon nanofibers derived from electrospun PIM-1 for energy storage applications. J Mater Chem A 2014, 2: 418-424.

[222] Zhu GY, He Z, Chen J, et al. Highly conductive three-dimensional $\mathrm{MnO}_{2}$-carbon nanotube-graphene-Ni hybrid foam as a binder-free supercapacitor electrode. Nanoscale 2014, 6: 1079-1085.

[223] Lukatskaya MR, Mashtalir O, Ren CE, et al. Cation intercalation and high volumetric capacitance of two-dimensional titanium carbide. Science 2013, 341: 1502-1505.

[224] $\mathrm{Hu} \mathrm{M}$, Li Z, Zhang $\mathrm{H}$, et al. Self-assembled $\mathrm{Ti}_{3} \mathrm{C}_{2} \mathrm{~T}_{x}$ MXene film with high gravimetric capacitance. Chem Commun: Camb 2015, 51: 13531-13533.

[225] Xia QX, Shinde NM, Zhang T, et al. Seawater electrolyte-mediated high volumetric MXene-based electrochemical symmetric supercapacitors. Dalton Trans 
2018, 47: 8676-8682.

[226] He HT, Xia QX, Wang BX, et al. Two-dimensional vanadium carbide $\left(\mathrm{V}_{2} \mathrm{CT}_{x}\right)$ MXene as supercapacitor electrode in seawater electrolyte. Chin Chem Lett 2020, 31: 984-987.

[227] Wen YY, Rufford TE, Chen XZ, et al. Nitrogen-doped $\mathrm{Ti}_{3} \mathrm{C}_{2} \mathrm{~T}_{x}$ MXene electrodes for high-performance supercapacitors. Nano Energy 2017, 38: 368-376.

[228] Yu LY, Hu LF, Anasori B, et al. MXene-bonded activated carbon as a flexible electrode for high-performance supercapacitors. ACS Energy Lett 2018, 3: 1597-1603.

[229] $\mathrm{Hu} \mathrm{MM}, \mathrm{Hu} \mathrm{T}$, Cheng RF, et al. MXene-coated silk-derived carbon cloth toward flexible electrode for supercapacitor application. J Energy Chem 2018, 27: 161-166

[230] Liu L, Wang LB, Liu XQ, et al. High-performance wearable strain sensor based on MXene@Cotton fabric with network structure. Nanomaterials 2021, 11: 889.

[231] Li HY, Cheng Z, Natan A, et al. Dual-function, tunable, nitrogen-doped carbon for high-performance Li metal-sulfur full cell. Small 2019, 15: 1804609.

[232] Naguib M, Adams RA, Zhao YP, et al. Electrochemical performance of MXenes as K-ion battery anodes. Chem Commun 2017, 53: 6883-6886.

[233] Wu YJ, Sun YJ, Zheng JF, et al. MXenes: Advanced materials in potassium ion batteries. Chem Eng $J$ 2021, 404: 126565.

[234] Er DQ, Li JW, Naguib M, et al. $\mathrm{Ti}_{3} \mathrm{C}_{2}$ MXene as a high capacity electrode material for metal $(\mathrm{Li}, \mathrm{Na}, \mathrm{K}, \mathrm{Ca})$ ion batteries. ACS Appl Mater Interfaces 2014, 6: 11173-11179.

[235] Wild M, O'Neill L, Zhang T, et al. Lithium sulfur batteries, a mechanistic review. Energy Environ Sci 2015, 8: 3477-3494.

[236] Dong Y, Zheng S, Qin J, et al. All-MXene-based integrated electrode constructed by $\mathrm{Ti}_{3} \mathrm{C}_{2}$ nanoribbon framework host and nanosheet interlayer for high-energydensity Li-S batteries. ACS Nano 2018, 12: 2381-2388.

[237] Pang JB, Mendes RG, Bachmatiuk A, et al. Applications of 2D MXenes in energy conversion and storage systems. Chem Soc Rev 2019, 48: 72-133.

[238] Sun SJ, Liao C, Hafez AM, et al. Two-dimensional MXenes for energy storage. Chem Eng J 2018, 338: 27-45.

[239] Verger L, Natu V, Carey M, et al. MXenes: An introduction of their synthesis, select properties, and applications. Trends Chem 2019, 1: 656-669.

[240] Shahzad F, Alhabeb M, Hatter CB, et al. Electromagnetic interference shielding with 2D transition metal carbides (MXenes). Science 2016, 353: 1137-1140.

[241] Geetha S, Satheesh Kumar KK, Rao CRK, et al. EMI shielding: Methods and materials-A review. J Appl Polym Sci 2009, 112: 2073-2086.

[242] Cao WT, Chen FF, Zhu YJ, et al. Binary strengthening and toughening of MXene/cellulose nanofiber composite paper with nacre-inspired structure and superior electromagnetic interference shielding properties. ACS Nano 2018, 12: 4583-4593.

[243] Iqbal A, Shahzad F, Hantanasirisakul K, et al. Anomalous absorption of electromagnetic waves by $2 \mathrm{D}$ transition metal carbonitride $\mathrm{Ti}_{3} \mathrm{CNT}_{x}$ (MXene). Science 2020, 369: 446-450.

[244] Iqbal A, Sambyal P, Koo CM. 2D MXenes for electromagnetic shielding: A review. Adv Funct Mater 2020, 30: 2000883.

[245] Wan YJ, Li XM, Zhu PL, et al. Lightweight, flexible MXene/polymer film with simultaneously excellent mechanical property and high-performance electromagnetic interference shielding. Compos A: Appl Sci Manuf 2020, 130: 105764.

[246] Wan Y, Xiong P, Liu J, et al. Ultrathin, strong, and highly flexible $\mathrm{Ti}_{3} \mathrm{C}_{2} \mathrm{~T}_{x}$ MXene/bacterial cellulose composite films for high-performance electromagnetic interference shielding. ACS Nano 2021, 15: 8439-8449.

[247] Weng GM, Li JY, Alhabeb M, et al. Layer-by-layer assembly of cross-functional semi-transparent MXenecarbon nanotubes composite films for next-generation electromagnetic interference shielding. Adv Funct Mater 2018, 28: 1803360 .

[248] Yang RL, Gui XC, Yao L, et al. Ultrathin, lightweight, and flexible CNT buckypaper enhanced using MXenes for electromagnetic interference shielding. Nano-Micro Lett 2021, 13: 66 .

[249] Ma ZL, Kang SL, Ma JZ, et al. Ultraflexible and mechanically strong double-layered aramid nanofiber$\mathrm{Ti}_{3} \mathrm{C}_{2} \mathrm{~T}_{x}$ MXene/silver nanowire nanocomposite papers for high-performance electromagnetic interference shielding. ACS Nano 2020, 14: 8368-8382.

[250] Liang L, Han G, Li Y, et al. Promising $\mathrm{Ti}_{3} \mathrm{C}_{2} \mathrm{~T}_{x}$ MXene/Ni chain hybrid with excellent electromagnetic wave absorption and shielding capacity. ACS Appl Mater Interfaces 2019, 11: 25399-25409.

[251] Wang QW, Zhang HB, Liu J, et al. Multifunctional and water-resistant MXene-decorated polyester textiles with outstanding electromagnetic interference shielding and joule heating performances. Adv Funct Mater 2019, 29: 1806819.

[252] Li Y, Tian X, Gao SP, et al. Reversible crumpling of 2D titanium carbide (MXene) nanocoatings for stretchable electromagnetic shielding and wearable wireless communication. Adv Funct Mater 2020, 30: 1907451.

[253] Vural M, Pena-Francesch A, Bars-Pomes J, et al. Inkjet printing of self-assembled 2D titanium carbide and protein electrodes for stimuli-responsive electromagnetic shielding. Adv Funct Mater 2018, 28: 1801972.

[254] Lin Y, Liu F, Casano G, et al. Pristine graphene aerogels by room-temperature freeze gelation. Adv Mater 2016, 28 : 7993-8000.

[255] Bian RJ, He GL, Zhi WQ, et al. Ultralight MXene-based aerogels with high electromagnetic interference shielding performance. J Mater Chem C 2019, 7: 474-478. 
[256] Liu J, Zhang HB, Sun RH, et al. Hydrophobic, flexible, and lightweight MXene foams for high-performance electromagnetic-interference shielding. Adv Mater 2017 , 29: 1702367.

[257] Wu XY, Han BY, Zhang HB, et al. Compressible, durable and conductive polydimethylsiloxane-coated MXene foams for high-performance electromagnetic interference shielding. Chem Eng J 2020, 381: 122622.

[258] Sun RH, Zhang HB, Liu J, et al. Highly conductive transition metal carbide/carbonitride(MXene)@polystyrene nanocomposites fabricated by electrostatic assembly for highly efficient electromagnetic interference shielding. Adv Funct Mater 2017, 27: 1702807.

[259] Han MK, Yin XW, Hantanasirisakul K, et al. Anisotropic MXene aerogels with a mechanically tunable ratio of electromagnetic wave reflection to absorption. $A d v O p t$ Mater 2019, 7: 1900267.

[260] Weng C, Wang G, Dai Z, et al. Buckled AgNW/MXene hybrid hierarchical sponges for high-performance electromagnetic interference shielding. Nanoscale 2019, 11: 22804-22812.

[261] Wang Y, Qi Q, Yin G, et al. Flexible, ultralight, and mechanically robust waterborne polyurethane $/ \mathrm{Ti}_{3} \mathrm{C}_{2} \mathrm{~T}_{x}$ mxene/nickel ferrite hybrid aerogels for high-performance electromagnetic interference shielding. ACS Appl Mater
Interfaces 2021, 13: 21831-21843.

[262] Sambyal P, Iqbal A, Hong J, et al. Ultralight and mechanically robust $\mathrm{Ti}_{3} \mathrm{C}_{2} \mathrm{~T}_{x}$ hybrid aerogel reinforced by carbon nanotubes for electromagnetic interference shielding. ACS Appl Mater Interfaces 2019, 11: 38046-38054.

[263] Zhao S, Zhang HB, Luo JQ, et al. Highly electrically conductive three-dimensional $\mathrm{Ti}_{3} \mathrm{C}_{2} \mathrm{~T}_{x}$ MXene/reduced graphene oxide hybrid aerogels with excellent electromagnetic interference shielding performances. ACS Nano 2018, 12: 11193-11202.

Open Access This article is licensed under a Creative Commons Attribution 4.0 International License, which permits use, sharing, adaptation, distribution and reproduction in any medium or format, as long as you give appropriate credit to the original author(s) and the source, provide a link to the Creative Commons licence, and indicate if changes were made.

The images or other third party material in this article are included in the article's Creative Commons licence, unless indicated otherwise in a credit line to the material. If material is not included in the article's Creative Commons licence and your intended use is not permitted by statutory regulation or exceeds the permitted use, you will need to obtain permission directly from the copyright holder.

To view a copy of this licence, visit http://creativecommons. org/licenses/by/4.0/. 